Article

\title{
Incorporating Temporal and Spatial Variations of Groundwater into the Construction of a Water-Based Ecological Network: A Case Study in Denko County
}

\author{
Qiang Yu ${ }^{1} \mathbb{B}^{(0)}$, Qun'ou Jiang ${ }^{2, *}$, Di Yang ${ }^{3} \mathbb{C}^{(\mathbb{D}}$, Depeng Yue ${ }^{1}$, Huan Ma ${ }^{1}$, Yuan Huang ${ }^{1}$, \\ Qibin Zhang ${ }^{1}$ and Minzhe Fang ${ }^{1}$ \\ 1 College of Forestry, Beijing Forestry University, Beijing 100083, China; yuqiang@bjfu.edu.cn (Q.Y.); \\ yuedepeng@126.com (D.Y.); xiaohuan27@163.com (H.M.); uchiyamakouki@126.com (Y.H.) \\ bin0538@foxmail.com (Q.Z.); fangminzhegis@foxmail.com (M.F.) \\ 2 School of Soil and Water Conservation, Beijing Forestry University, Beijing 100083, China \\ 3 Department of Geography, University of Florida, Gainesville, FL 32611, USA; Yangdi1031@ufl.edu \\ * Correspondence: jiangqo.dls@163.com; Tel.: +86-010-6233-6588
}

Received: 29 June 2017; Accepted: 1 November 2017; Published: 6 November 2017

\begin{abstract}
It is of great practical significance to construct a water-based ecological network in arid and semi-arid areas. The spatial distribution of water resources is one of the most important factors in determining the ecological stability of such areas. In this study, groundwater level trends were analyzed with a model called Empirical Mode Decomposition (EMD). The temporal and spatial evolution of groundwater depth data from 1990 to 2016 were analyzed. The surface water bodies were analyzed using a point pattern analysis method. Based on this, a water-based ecological network was constructed with a minimum cumulative resistance surface model. The study indicated that the trend lines for the groundwater tables of 17 wells could be divided into five types in Denko County. The landscape types that changed from a desert landscape to an oasis landscape had a positive impact on groundwater. Precipitation trend was related to the spatial distribution of the groundwater depth, and the spatial pattern of the water nodes was characterized by a small-scale highly aggregated distribution and a large-scale uniform distribution in Denko County. These results suggest that for the stability of arid and semi-arid ecological environments, the appropriate human intervention (such as construction of an artificial oasis) is of great significance. Based on the analysis of groundwater and surface water bodies, a water-based ecological network in Denko County, which consisted of 391 ecological sources and 7360 ecological corridors, was constructed in 2016. The water-based ecological network constructed in this study was more sustainable and stable, and also suitable for arid and semi-arid areas, which is of great practical significance and application value.
\end{abstract}

Keywords: water table depth; groundwater distribution; water-based ecological network; Denko County

\section{Introduction}

Desertification has become one of the most serious environmental and socio-economic problems worldwide because of its widespread distribution and harmful intensities [1], and is particularly serious in the arid and semi-arid areas of Northwest China [2]. In addition, urbanization has also led to the acceleration of desertification; humans play a vital role in this process [3]. For example, well drilling represents an increasing trend in Northwest China where this human environmental interference not only changes the landscape pattern, but also affects the regional eco-hydrological processes. Furthermore, the interaction between eco-hydrological processes and landscape pattern is the most concerning scientific problem at present [4]. The change in ecological hydrological processes has led to the evolution of landscape patterns, and vice versa [5]. In arid and semi-arid areas, groundwater is 
the most important constituent element in the ecological hydrological process [6], especially in Denko County, which is in the northeastern margin of the Ulan Buh Desert. In this area, the source of water for vegetation is mainly dependent on groundwater recharge. Therefore, it is significant to carry out ecological environment restoration based on groundwater. This approach can make the ecological environment more stable and ensure sustainable development.

In ecological restoration, the construction of an ecological network is indispensable. At present, the theory of landscape ecology and land planning are combined to construct ecological networks in the study of ecological network structures [7,8], which include the Natura 2000 network, the emerald network, the Dutch national ecological network, and the European ecological network [9]. In addition, for different objects, research on ecological network construction has mostly focused on the construction of forest ecological networks [10], wetland ecological networks [11], the ecological network of urban green spaces [12], and the ecological network of desert protection [13]. Among them, the ecological network constructed for arid and semi-arid ecological fragile areas in Northwest China is a typical desert ecological network [14]. The ecologically fragile areas in Northwest China are characterized by severe desertification, the fragmentation of landscape patches, and an extremely fragile ecological environment [15]. A protective ecological network can connect broken habitats by ecological corridors and ecological sources to form a complete landscape network, thus ensuring regional ecological security [16]. Ecological sources can promote the development of ecological processes in the pattern and research process. Ecological source is a land type that could have a positive impact on the surroundings and exist in a relatively stable state. The ecological source acts as an engine in the regional ecological network, continuously providing energy [17].

Desertification and urbanization have caused large-scale habitat patches within the region to be invaded and eroded, and the degree of landscape fragmentation is exacerbated [18,19]. Landscape fragmentation has a great impact on ecological plaques, for example, the ecological plaque area will become smaller, ecological corridors will be cut off, ecological patches will become increasingly island-like, and landscape connectivity will be reduced [20]. This will interfere with normal landscape ecological processes and ecological regulation, cause reduced biodiversity, and the health integrity of the ecosystem will be compromised. Eventually, the ecosystem service function changes [21]. The construction of an ecological network could connect the broken ecological patches through a habitat corridor to form a complete landscape and habitat network [22]. This could restore a connection between the broken ecological patches and improve the connectivity of the landscape, to promote the exchange of information between ecological patches, and better maintain the process of ecological energy flow [23]. Thus, the construction of an ecological network realizes the connection between structure and function [24].

Since 1990, plenty of research on the construction of an eco-network has been carried out by many scholars [25]. Furthermore, the minimum path method based on Geographic Information Systems (GIS) has been widely used in recent years. The reason is that this method, rooted in some related theories such as landscape ecology and conservation ecology, takes the behavioral characteristics of the geographic information of the landscape and flow of ecological energy into consideration, and can also reflect landscape patterns and horizontal ecological processes [26]. We can build a resistance surface considering the influence of different kinds of land-use, the distribution of hydrology and landforms on the ecological source, and simulate underlying ecological corridors using GIS [27]. In this way, the location and pattern of ecological corridors can be confirmed scientifically. However, this method cannot identify the relative importance of ecological corridors in a scientific way [28]. To solve this dilemma, the method requires a quantitative analysis on the relative importance of ecological corridors to confirm its protection priority scientifically [29]. Ecological corridors are the backbone of the ecological network and ecological energy flow channel [30]. The extraction method of the ecological corridor mainly includes landscape resistance analysis, network analysis, the minimum cumulative resistance surface model, and the morphological spatial pattern model [31,32]. Among them, the minimum cumulative resistance surface model is widely used in the extraction of ecological 
corridors and can be used to extract different types of ecological networks [33]. The environment in our study area, which is an arid and semi-arid region, is extremely vulnerable and presents ecological corridors; simulated potential ecological corridors deserve extra protection [34]. Thus, all simulated potential ecological corridors in this research are supposed to be placed at a level of vital importance. The key of ecological network construction lies in the selection of an ecological source [35]. Currently, most people would like to choose woodland and nature reserves-possessing better eco-environmental qualities-as the source region [36]. The selection of an ecological source based on land use also considers an ecological indicator system such as an ecological service value. However, research on ecological source selection based on ecological hydrology is scarce [37]. An oasis comes into being with water and a desert without water in an arid region [38]. In accordance with this, the research would use the experience of ecological source selection based on land use, and choose surface water bodies which have existed steadily for many years as an ecological source to construct an ecological network. The change in shallow groundwater has been drastic and unstable in different years in Denko County. Consequently, Denko County is not supposed to be an ecological source even if the shallow groundwater has a great effect on the distribution of vegetation.

After the identification of the ecological sources and the extraction of ecological corridors, a water-based ecological network (an ecological network built on the spatial distribution of groundwater and surface water) was constructed in this study. The spatial distribution of ground and surface water was analyzed and considered for building a water-based ecological network. From a temporal perspective, the Empirical Modal Decomposition (EMD) method was used to analyze the data of the wells [39]. EMD is a method used for decomposing complex, multi-component signals into several elementary oscillations, called intrinsic mode functions (IMFs) [40]. This method performs well when dealing with complex nonlinear signals. From a spatial perspective, the co-Kriging interpolation algorithm was used to obtain the spatial distribution of groundwater depth, and the GIS spatial analysis method was used to analyze the evolution of the groundwater. The surface water body (ecological source) was analyzed using the spatial point pattern analysis method [41]. This method is widely used in the study of vegetation community structure, which can quantitatively analyze the distribution characteristics of spatial points [42]. Currently, the spatial analysis of ecological sources mainly focuses on the importance of the source patches, the connectivity between the sources, and the intensity of the action between the patches. There have been few studies on the spatial distribution of ecological sources; however, the spatial distribution of the ecological source is also important. Therefore, the point pattern analysis method was applied to the study of the spatial distribution characteristics of the source.

In this study, a water-based ecological network was constructed based on groundwater and surface water body networks. This mapping strategy provided us with new ideas for the construction of an ecological network in arid and semi-arid areas, and may assist in creating a potential ecological network. This ecological network is more suitable for arid and semi-arid areas, and in practical applications is the most stable ecological network. Potential ecological networks may not realize actual situations, but are the best way to carry out the repair construction in accordance with the simulated potential ecological network in the future as it has affluent moisture in the potential ecological corridors, and the desert vegetation could survive easily. The results of this study can provide theoretical support and practical significance for ecological environment protection and water resources management in arid and semi-arid areas.

\section{Materials}

\subsection{Site Description and Data Sources}

Denko County is located in the terrain surrounded by the Inner Mongolia He Tao Plain, backed by the Lang Shan Mountain, and is northeast of the Ulan Buh Desert (Figure 1). The study area is characterized by two distinct landscape types: desert and oasis. Geographically, this region is located 
between $106^{\circ} 09^{\prime}-107^{\circ} 10^{\prime} \mathrm{E}$ and $40^{\circ} 09^{\prime}-40^{\circ} 57^{\prime} \mathrm{N}$ and is characterized by the Yellow River, where the urbanization process is a major factor in changing landscape patterns, and has large potential for further development. The climate of the study area is described as temperate continental monsoon. The average wind speed is $3.0 \mathrm{~m} / \mathrm{s}$, instantaneous maximum wind speed is $28 \mathrm{~m} / \mathrm{s}$, average annual rainfall is $143.9 \mathrm{~mm}$, average annual potential evaporation is $2327 \mathrm{~mm}$, average temperature is $7.6^{\circ} \mathrm{C}$, and the frost-free period is 136 days.
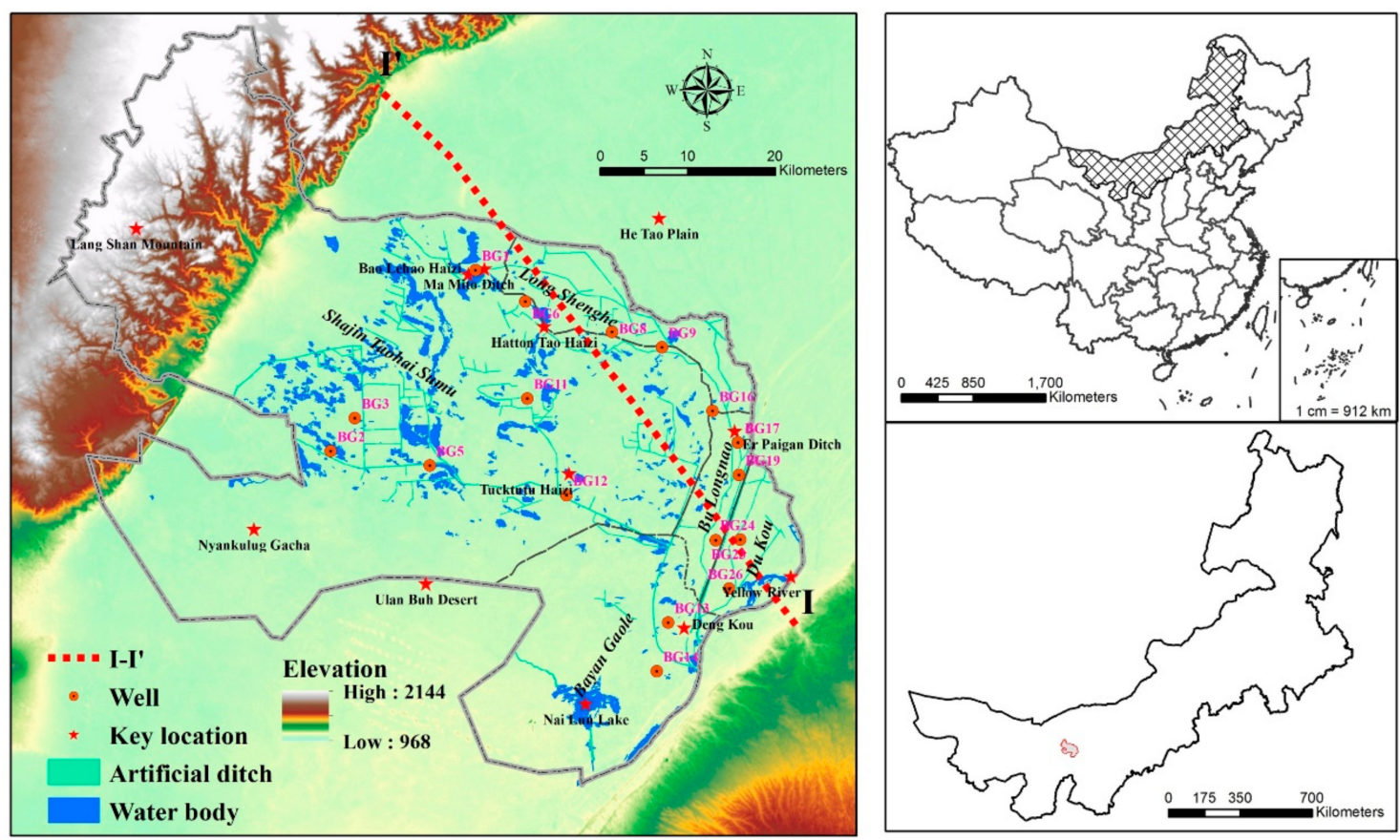

Figure 1. Study area and lithological cross section line.

In 2015, the Denko County farmland forest network construction was completed. The degree of farmland networking is more than $90 \%$. Furthermore, 12.36 million hectares of nature reserves have been built around the Lang Shan Mountain. On the edge of the Ulan Buh Desert, based on the original $154 \mathrm{~km}$ of sand prevention forest belt, a 30-50 m wide tree shelterbelt was built. Dust outbreaks also occur frequently and result in serious damage to the surrounding ecological environment. The main reasons include (1) The decline in the groundwater level and a decrease of wetland area; (2) Climate drought and precipitation are scarce; (3) Transition grazing, which is the most important human disturbance; (4) Serious aging of wind breaks and sand fixation forests; and (5) The low development rate of the ecological industry. Among them, the construction of an ecological network based on the first reason is the focus of this research.

The long-term (27 years) monthly Water Table (WT) depth data from 1990 to 2016, were collected from the Yellow River Administration Bureau of Denko County (YRAB). Seventeen observation wells (Figure 1) have been used for monitoring the groundwater levels. The number of observation wells, with the elevation and coordinates under each sub-administrative district, is provided in Table 1. 
Table 1. Well numbers under different sub-administrative districts of Denko County used for the study.

\begin{tabular}{|c|c|c|c|c|c|}
\hline No. & $\begin{array}{c}\text { Sub-Administrative } \\
\text { District }\end{array}$ & Well No. & Elevation (m) & Longitude $\left(^{\circ}\right)$ & Latitude $\left(^{\circ}\right)$ \\
\hline \multirow{2}{*}{1} & \multirow{2}{*}{ Bayan Gaole } & BG13 & 1040 & 106.98 & 40.33 \\
\hline & & BG14 & 1047 & 106.96 & 40.28 \\
\hline \multirow{4}{*}{2} & \multirow{4}{*}{ Bu Longnao } & BG16 & 1030 & 107.05 & 40.55 \\
\hline & & BG17 & 1041 & 107.08 & 40.52 \\
\hline & & BG19 & 1045 & 107.08 & 40.48 \\
\hline & & BG23 & 1040 & 107.05 & 40.42 \\
\hline \multirow{2}{*}{3} & \multirow{2}{*}{ Du Kou } & BG24 & 1042 & 107.08 & 40.42 \\
\hline & & BG26 & 1038 & 107.07 & 40.37 \\
\hline 4 & Long Shenghe & BG8 & 1027 & 106.92 & 40.63 \\
\hline \multirow{8}{*}{5} & \multirow{8}{*}{ Shajin Taohai Sumu } & BG1 & 1029 & 106.73 & 40.70 \\
\hline & & BG2 & 1019 & 106.53 & 40.52 \\
\hline & & BG3 & 1029 & 106.57 & 40.55 \\
\hline & & BG5 & 1036 & 106.67 & 40.50 \\
\hline & & BG6 & 1028 & 106.80 & 40.67 \\
\hline & & BG9 & 1034 & 106.98 & 40.62 \\
\hline & & BG11 & 1039 & 106.80 & 40.57 \\
\hline & & BG12 & 1032 & 106.85 & 40.47 \\
\hline
\end{tabular}

Note: Bayanur Groundwater (BG). Bayanur, an agricultural city in Inner Mongolia, is also an important base for agricultural products in China. Denko County, part of Bayanur.

The hydrogeological survey data were extracted from the hydrogeological map of the Hetao Basin, which was drawn by the Inner Mongolia Autonomous Region Geological Survey. Landsat Thematic Mapper (TM) images (1990, 1995, and 2000), Landsat Enhanced Thematic Mapper Plus (ETM+) images (2005 and 2010), and Landsat Operational Land Imager (OLI) images (2016) with little cloud cover were selected as the major data source in this study (http:/ /www.gscloud.cn). The resolution of the Landsat images was $30 \mathrm{~m}$, and all images were captured during summer. The precipitation data of Denko County from 1990 to 2016 were provided by the Climate Hazards Group InfraRed Precipitation with Station data (CHIRPS, version 2.0 final) [43]. The introduction of CHIRPS and the code are given in Appendix A.

\subsection{Physiography and Hydrogeological Conditions}

Most areas in the study area are composed of tertiary and neogene sediments; bedrock exposure only occurs in the north. The main geomorphic types can be divided into the mountainous region, desert, plain, and river. Altitude is 1030-2046 m in Denko County, and the altitude in the southeast is higher than that in the northwest except for the mountainous areas. The northwest area of Denko County, which belongs to the Lang Shan Mountain Chain, is the extension to the southwest of the Yin Mountain. Additionally, there are proluvial fans and the Gobi Desert is in front of the mountain. The central and southern parts of Denko County belong to the Ulan Buh Desert, which extensively covers distributed ground sand ribbons as well as some sand dunes and flat desert. The hypsography in the east and northeast of Denko County is flat. This area belongs to the Yellow River irrigated plain, which is the main agricultural land of Denko County.

The abundant surface water and groundwater is a powerful guarantee for the development of Denko County and its ecological security. The water table (WT) depth of the He Tao area is $0.5-3 \mathrm{~m}$, the WT depth of the sandy area is $3-10 \mathrm{~m}$, and the WT depth in front of the mountain is 3-30 m. The exploitable area of groundwater is $3452.11 \mathrm{~km}^{2}$ and the groundwater resource reserves are 0.5258 billion $\mathrm{m}^{3}$. From the southeast to the northwest $\left(\mathrm{I}-\mathrm{I}^{\prime}\right)$, as shown in Figure 2, the water yield property of the aquifer first transitions from 1000-3000 to 3000-5000 $\mathrm{m}^{3} /$ day; with the gradual close of the Piedmont alluvial fan, the water yields are significantly reduced. In the Lang Mountain area, 
the water yield property of the aquifer was less than $100 \mathrm{~m}^{3} /$ day. From the surface to the depth of $200 \mathrm{~m}$ underground, most of the soil types are fine sand, which is intermittently intertwined with clay, loam layers, and muddy soil layers. The silty clay layer is mainly distributed in the Yellow River region. Two distinct faults appear in the alluvial area in front of the Lang Mountain.

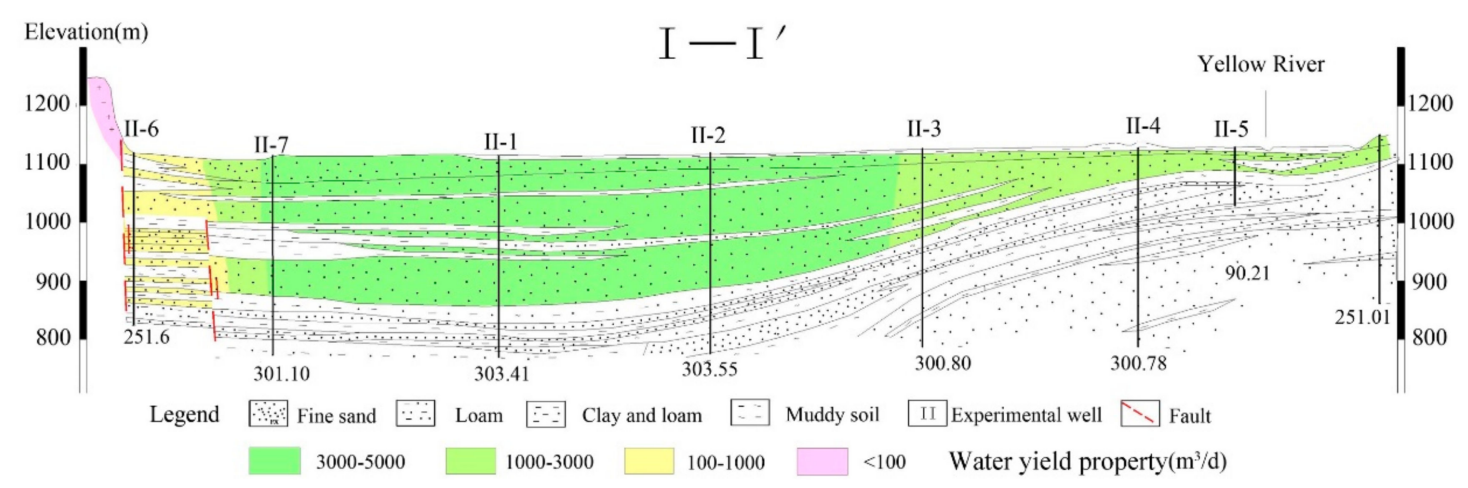

Figure 2. Lithological cross section of the study area.

\section{Methodology}

\subsection{Empirical Modal Decomposition Model}

The long-term WT depth dynamics are presented graphically to explain the dynamic behavior of the groundwater level. Parametric (linear regression) and non-parametric approaches were applied to analyze the hydrological data trends. EMD is an adaptive time series data analysis model, which has been a breakthrough in the analysis of linear and steady state spectra based on Fourier analysis [39]. Fourier spectrum analysis takes the sine function or exponential function as the basis function, and the EMD algorithm can decompose a set of finite long-time series signals into finite IMFs. Compared with traditional Fourier spectrum analysis, the internal mode function is extracted from the signal to be analyzed. This reflects the variation of the data itself and has strong adaptability. Nonlinear and non-stationary process data were also linearized and stabilized, and the properties of the data itself were well preserved during the decomposition process.

EMD decomposes a given signal $x(t)$ into a finite set of mono-component-like components (IMFs), plus a nonzero mean residual $r(t)$.

$$
x(t)=\sum_{i=1}^{N} i m f_{i}(t)+r(t)
$$

where $i m f_{i}(t)$ is the $i$-th intrinsic mode function (IMF).

To obtain each IMF, an iterative procedure called the sifting process was used. Given an input time series signal $x(t)$ to be decomposed, the sifting process of EMD can be summarized as follows (Figure 3).

(1) Find the local maxima in the original sequence $x(t)$. To better preserve the characteristics of the original sequence, the local maximum was defined as the value of a point in the time series, which is not larger than the previous or subsequent moment.

(2) Next, the cubic spline function was used to interpolate, and the upper envelope sequence $e_{\max }(t)$ of the original sequence $x(t)$ was obtained.

(3) Similarly, the lower envelope $e_{\min }(t)$ was obtained.

(4) The maximum envelope $e_{\max }(t)$ and the minimum envelope $e_{\min }(t)$ were averaged, and the instantaneous average value $m(t)$ obtained:

$$
m(t)=\left[e_{\max }(t)+e_{\min }(t)\right] / 2
$$


(5) The class normal value sequence $h(t)$ was obtained by subtracting the instantaneous mean sequence $m(t)$ from the original sequence $x(t)$ :

$$
h(t)=x(t)-m(t)
$$

For different data sequences, $h(t)$ may or may not be an internal model function as it is dependent on whether it satisfies two necessary conditions of the internal model function, i.e., that the number of extremes is equal to the number of points exceeding 0 or within 1 of the difference in the function $h(t)$. Otherwise, the function $h(t)$ is treated as an original sequence, repeating the above (1)-(5) steps until the $h(t)$ satisfies the definition of the internal model function. Finally, the internal model function IMF was obtained.

EMD decomposes the data into IMF components and a residual component. This residual signal curve represents the trend of the original time series. In this paper, Matlab software (Math Works, Natick, USA) was used to implement the EMD algorithm, and the procedure is referenced in Rilling et al. [44].

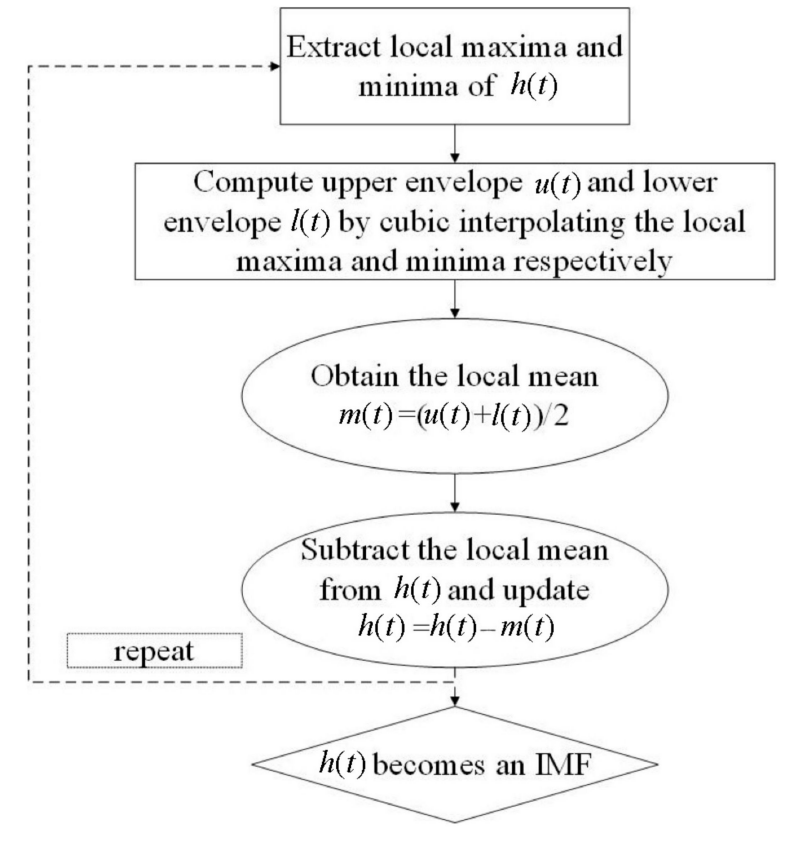

Figure 3. The sifting process of Empirical Modal Decomposition.

\subsection{Co-Kriging Interpolation Algorithm}

To virtualize the process, groundwater location datasets were constructed using spatial interpolation algorithms to estimate the surface water networks (or to estimate the missing data). The co-Kriging method was used for the spatial interpolation of measured groundwater data. Additionally, the cross-covariance function and cross-variogram function model were established as per the correlation among the regionalized variables [45]. Variables that were easily observed and controlled were used for the local estimation of variables that were not easily observable.

Based on the conclusions of Ma et al. [46] in Denko County, two synergistic variables that are closely related to the spatial distribution of groundwater are regional evapotranspiration (ET), and the normalized difference vegetation index (NDVI). Therefore, the WT depth data at the point scale was taken as the major variable; ET and NDVI were used as secondary variables.

NDVI is the most commonly used indicator of the status of vegetation health [47] and was retrieved by satellite remote sensing images in this study. The selected satellite datasets were also different due to different times. Landsat 5 TM images were used to calculate the NDVI in 1990, 1995, and 2001; Landsat 7 ETM+ images were used to calculate NDVI in 2005 and 2010, and Landsat 8 OLI 
images were used to calculate the NDVI in 2016 (Equation (4)) (http:/ / www.gscloud.cn). Six dates of $30 \mathrm{~m}$ NDVI were calculated based on red and near-infrared reflectance.

$$
N D V I=\frac{\rho_{\text {nir }}-\rho_{\text {red }}}{\rho_{\text {nir }}+\rho_{\text {red }}}
$$

where $\rho_{\text {red }}$ and $\rho_{\text {nir }}$ are surface reflectance at the red and near-infrared band, respectively.

ET was retrieved by using the Surface Energy Balance Algorithm (SEBAL) for land model and satellite remote sensing images. This model was developed from the regional energy budget equation and requires visible, near-infrared, thermal infrared data, and meteorological data combined together [48].

In the SABAL model, we computed the sub-models including net radiation $\left(R_{n}\right)$, soil heat flux $(\mathrm{G})$, and sensible heat flux $(\mathrm{H})$ for each pixel. The latent heat flux $(\mathrm{ET})$ was acquired as a residual in the energy balance equation. ET is the flux of heat from the earth's surface to the atmosphere that is associated with evaporation or transpiration of water. NDVI, atmospheric emissivity $(\varepsilon)$, albedo $(\alpha)$, and surface radiation temperature $\left(T_{S}\right)$ were initially computed to obtain the regional surface radiation balance, $R_{n}$, followed by the regional surface energy balance. Soil heat flux $G$ was computed by an empirical relation function with $R_{n}, \alpha, T_{s}$, and NDVI. Sensible heat flux $\mathrm{H}$ was obtained by the surface temperature gradient $d T$. The key variables and formulas of the SEBAL model are shown in Table 2 and the flow chart of the computation of the sub-models using the SEBAL model is shown in Figure 4. The detailed operation process of the SEBAL model was described in the study of Lihong et al. [49].

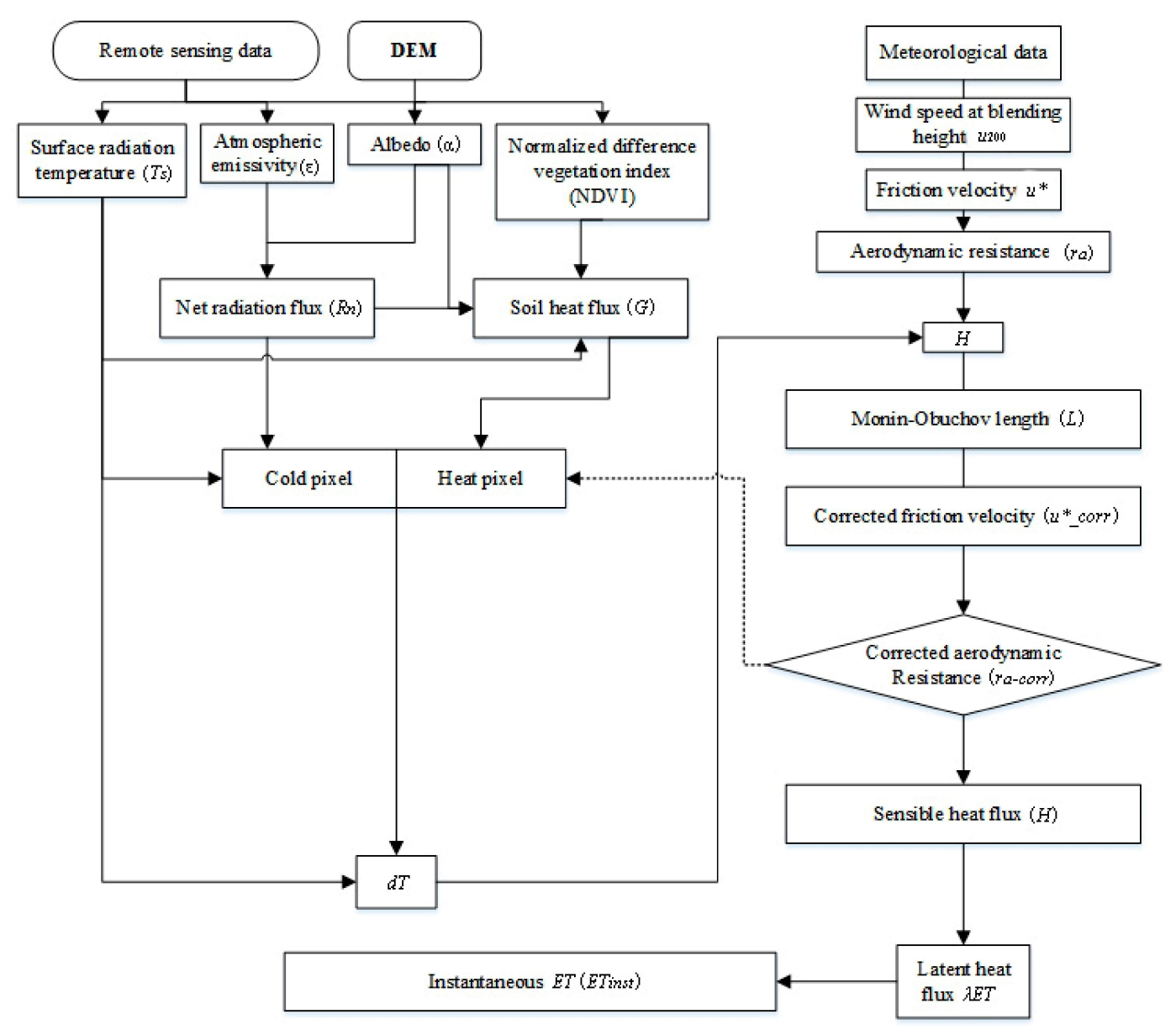

Figure 4. The algorithm flow of the Surface Energy Balance Algorithm model. 
Table 2. The key variables and formulas of the Surface Energy Balance Algorithm model.

\begin{tabular}{|c|c|c|}
\hline Key Variables & Formulas & Basic Variables \\
\hline Normalized difference vegetation index & $N D V I=\left(\rho_{3}-\rho_{4}\right) /\left(\rho_{3}+\rho_{4}\right)$ & $\rho_{3}$ and $\rho_{4}$ : reflectivities for bands 4 and band 3 \\
\hline Atmospheric emissivity $(\varepsilon)$ & $\varepsilon=1.009+0.047 \ln (N D V I)$ & - \\
\hline \multirow[t]{3}{*}{ The surface radiation temperature $(\mathrm{K})$} & $T_{s}=K_{2} / \ln \left(K_{1} \cdot \varepsilon / L_{6}+1\right)$ & $\begin{array}{c}K_{1}: \text { constant for Landsat images, } 607.76 \\
\mathrm{~mW} / \mathrm{cm}^{2} / \mathrm{sr} / \mu \mathrm{m}\end{array}$ \\
\hline & & $\begin{array}{l}K_{2}: \text { constant for Landsat images, } 1260.56 \\
\mathrm{~mW} / \mathrm{cm}^{2} / \mathrm{sr} / \mu \mathrm{m}\end{array}$ \\
\hline & & $L_{6}:$ the spectral radiance of band 6 \\
\hline \multirow[t]{2}{*}{ Albedo } & $\alpha=R_{s-r e f l e c t e d} / R_{s}$ & $R_{s-\text { reflected }}$ : the reflected radiation $\left(\mathrm{W} / \mathrm{m}^{2}\right)$ \\
\hline & & $\begin{array}{l}R_{S}: \text { the total incident shortwave } \\
\text { radiation }\left(\mathrm{W} / \mathrm{m}^{2}\right)\end{array}$ \\
\hline \multirow[t]{4}{*}{ Net radiation flux $\left(\mathrm{W} / \mathrm{m}^{2}\right)$} & $R_{n}=K_{\text {in }}-\alpha \cdot K_{\text {in }}+L_{\text {in }}-L_{\text {out }}$ & $K_{i n}$ : incoming shortwave radiation $\left(\mathrm{W} / \mathrm{m}^{2}\right)$ \\
\hline & & $\alpha K_{\text {in }}:$ reflected shortwave radiation $\left(\mathrm{W} / \mathrm{m}^{2}\right)$ \\
\hline & & $L_{\text {in }}$ : incoming longwave radiation $\left(\mathrm{W} / \mathrm{m}^{2}\right)$ \\
\hline & & $L_{\text {out }}$ : outgoing longwave radiation $\left(\mathrm{W} / \mathrm{m}^{2}\right)$ \\
\hline Soil heat flux $\left(\mathrm{W} / \mathrm{m}^{2}\right)$ & $\begin{aligned} G=T_{S} \cdot R_{n} /\left[\alpha \cdot\left(0.0038 \alpha+0.0074 \alpha^{2}\right)\right. \\
\\
\left.\left(1-0.98 N D V I^{4}\right)\right]\end{aligned}$ & - \\
\hline \multirow[t]{4}{*}{ Sensible heat fluxes $\left(\mathrm{W} / \mathrm{m}^{2}\right)$} & $H=d T \cdot \rho \cdot C_{p} / r_{a}$ & $\begin{array}{l}d T: \text { temperature difference between the two } \\
\text { certain heights }(\mathrm{K})\end{array}$ \\
\hline & & $\rho:$ air density, $1.293 \times 10^{3} \mathrm{~kg} / \mathrm{m}^{3}$ \\
\hline & & $C_{p}:$ air specific heat, $1004 \mathrm{~J} / \mathrm{kg} / \mathrm{K}$ \\
\hline & & $\begin{array}{l}r_{a}: \text { aerodynamic resistance to heat } \\
\text { transport }(\mathrm{s} / \mathrm{m})\end{array}$ \\
\hline Latent heat fluxes $\left(\mathrm{W} / \mathrm{m}^{2}\right)$ & $\lambda E T=R_{n}-G-H$ & - \\
\hline Instantaneous ET (mm/h) & $E T_{\text {inst }}=3600\left(R_{n}-G-H\right) / \lambda$ & $\lambda$ : latent heat of vaporization $(\mathrm{J} / \mathrm{kg})$ \\
\hline \multirow[t]{4}{*}{ Wind speed at the blending height $(\mathrm{m} / \mathrm{s})$} & $u_{200}=u^{*} \cdot \ln \left(z_{200} / z_{0}\right) / k$ & $\begin{array}{l}u^{*}: \text { the friction velocity at the weather } \\
\text { station }(\mathrm{m} / \mathrm{s})\end{array}$ \\
\hline & & $z_{200}$ : the blending height, $200 \mathrm{~m}$ \\
\hline & & $\begin{array}{l}z_{0} \text { : the measure of the land surface friction, } 0.36 \\
\text { m in this case study }\end{array}$ \\
\hline & & $k$ : the von Karman's constant, 0.41 \\
\hline Friction velocity at each pixel (m/s) & $u^{*}=k \cdot u_{200} / \ln \left(z_{200} / z_{0}\right)$ & - \\
\hline $\begin{array}{l}\text { Aerodynamic resistance to heat } \\
\text { transport }(\mathrm{s} / \mathrm{m})\end{array}$ & $r_{a}=\ln \left(z_{2} / z_{1}\right) /\left(u^{*} \cdot k\right)$ & $\begin{array}{c}z_{1} \text { and } z_{2}: \text { the heights in meters above zero } \\
\text { displacement of the vegetation }\end{array}$ \\
\hline
\end{tabular}

\subsection{Point Pattern Analysis Algorithm}

Surface water body is the area where the WT depth is 0 , which has great ecological influence on the surrounding environment. The spatial distribution pattern of the surface water body determines the spatial distribution pattern of the ecological network. In this study, the surface water bodies were extracted from remote sensing images, and converted into point data in accordance with the centroid. The O-ring function was used to describe the spatial pattern of the surface water nodes, and the pairing correlation function (PCF) was used to compute the O-ring function. PCF was derived from the $\mathrm{K}$-function, and the annulus was used instead of the circle in the K-function [50]. This improvement allowed the PCF algorithm to have no cumulative effect. The K-function was formulated as follows:

$$
K(t)=\left(\frac{A}{n^{2}}\right) \sum_{i=1}^{n} \sum_{j=1}^{n} \frac{1}{W_{i j}} I_{i}\left(u_{i j}\right)(i \neq j)
$$

where $n$ is the total number of water body nodes in the study area $A\left(\mathrm{~m}^{2}\right) ; u_{i j}$ is the distance between the $i$ th (focal) node and the $j$ th (neighboring) node, where the focal node is located within area $A ; I_{i}\left(u_{i j}\right)$ is an indicator function, equaling 1 if $u_{i j} \leq r$ and 0 otherwise; and $W_{i j}$ is a circular edge-correction, defined as the inverse of the proportion of a circle of radius $r$, placed over each point within the total 
study area $A$. If the entire circumference of the circle lies within $A$, then $w=1$. If $g(r)>1$, there were more pairs of points at distance $r$ from each other than expected under a random pattern, which indicated aggregation at scale $r$. If $g(r)<1$, there were fewer points at distance $r$ than expected under a random pattern, showing segregation at scale $r$, and $g(r)=1$ expresses a homogeneous Poisson process (complete spatial randomness, CSR). Node distribution function $g(r)$ is calculated as:

$$
g(r)=\frac{1}{2 \pi r} \cdot \frac{d K(r)}{d r}
$$

The O-ring function is derived from the PCF function, and O-ring statistics include univariate statistics and bivariate statistics. Univariate O-ring statistics can analyze spatial patterns of single objectives. The formula is as follows:

$$
O_{11}(r)=\frac{\sum_{i=1}^{n} \operatorname{Point}\left[R_{i}^{w}(r)\right]}{\sum_{i=1}^{n} \operatorname{Area}\left[R_{i}^{w}(r)\right]}
$$

where $w$ is the width of the annulus; $O_{11}(r)$ is the horizontal distribution pattern function; $R_{i}^{w}(r)$ is the annulus whose center of circle is $i$, radius is $r$ and the width of the annulus is $w$. Point $\left[R_{i}^{w}(r)\right]$ is the number of water body nodes in this annulus; and $\operatorname{Area}\left[R_{i}^{w}(r)\right]$ is the area of this annulus.

Programita software (version 2010) (Helmholtz Centre for Environmental Research, Leipzig, Germany) (http:/ / programita.org) was used to complete the spatial pattern analysis of the water body nodes. Single factor analysis of variance and the Duncan method were used for Analysis of Variance (ANOVA) and multiple comparisons. The space scale was set from 0 to $60 \mathrm{~km}$, and the step length was set to $1 \mathrm{~km}$. After 19 Monte Carlo simulations, 95\% confidence intervals were obtained, i.e., the upper and lower limit. If the $O_{11}(r)$ value was greater than the upper limit, the water body nodes showed a clustered distribution pattern. If the $O_{11}(r)$ value was between the upper and lower limit, the water body nodes showed a random distribution pattern. If the $O_{11}(r)$ value was less than the lower limit, the water body nodes showed a uniform distribution pattern.

\subsection{Minimum Cumulative Resistance Surface Model}

Ecological networks can guarantee the stability of regional ecological environments in arid and semi-arid areas. Particularly for Denko County, groundwater is the most important factor for the stability of a terrestrial ecological network. Therefore, based on the spatial distribution and the temporal-spatial evolution characteristics of groundwater, the minimum cumulative resistance surface model (MCR) was used to build a potential ecological network based on groundwater in Denko County [51]. The MCR model was proposed by ecologist Knappen of Holland [52] and first used in the study of the species diffusion process and has been widely used in ecological fields such as species conservation and landscape pattern analysis.

The basic formula of the basic ecological resistance model, MCR, is as follows:

$$
V_{\mathrm{MCR}}=f_{\min } \sum_{j=n}^{i=m}\left(D_{i j} R_{i}\right)
$$

where $V_{\mathrm{MCR}}$ is the value of the minimum cumulative resistance surface; $f$ is a function of the positive correlation that reflects the relation of the least resistance for any point in space to the distance from any point to any source and the characteristics of the landscape base surface; min denotes the minimum value of cumulative resistance produced in different processes of landscape unit $i$ transforming into a different source unit $j ; D_{i j}$ is the spatial distance between landscape unit $i$ and source unit $j$; and $R_{i}$ denotes the resistance coefficient that exists in transition from landscape unit $i$. to source unit $j$.

In Denko County, the spatial distribution of green ecological land (natural forest land, shrub land, natural grassland, etc.) is closely related to the spatial distribution of surface water. Surface water body 
is the area where the WT depth is 0 . The abundance of natural vegetation is distributed around the water body, and the farther away from the surface water, the fewer species and quantities of natural vegetation. Based on this and previous studies, the surface water body was regarded as an ecological source in this study [51].

Different ecological sources have different ecological energy, thus influencing the diversity of the ecological sources. Therefore, this study used the relative energy factor of different levels in the modified MCR model. The ecological sources were graded according to their area, and each level given an energy value. The modified model originates from four factors for the ecological land expansion, including the sources, the source level, the distance, and the base resistance characteristics [51]. The modified formula is expressed as:

$$
V_{\text {MCR-E }}=f_{\min } \sum_{j=n}^{i=m}\left(D_{i j} R_{i} E_{j}\right)
$$

where $E$. indicates the energy factor of the ecological source $j$; the higher the value of $E$, the greater the energy of the ecological source.

The ecological network constructed in this study was based on the groundwater and surface water body. Therefore, the spatial distribution data of groundwater and the distance to the water body were selected to construct the ecological resistance surface. The overall flow chart of this study is shown in Figure 5.

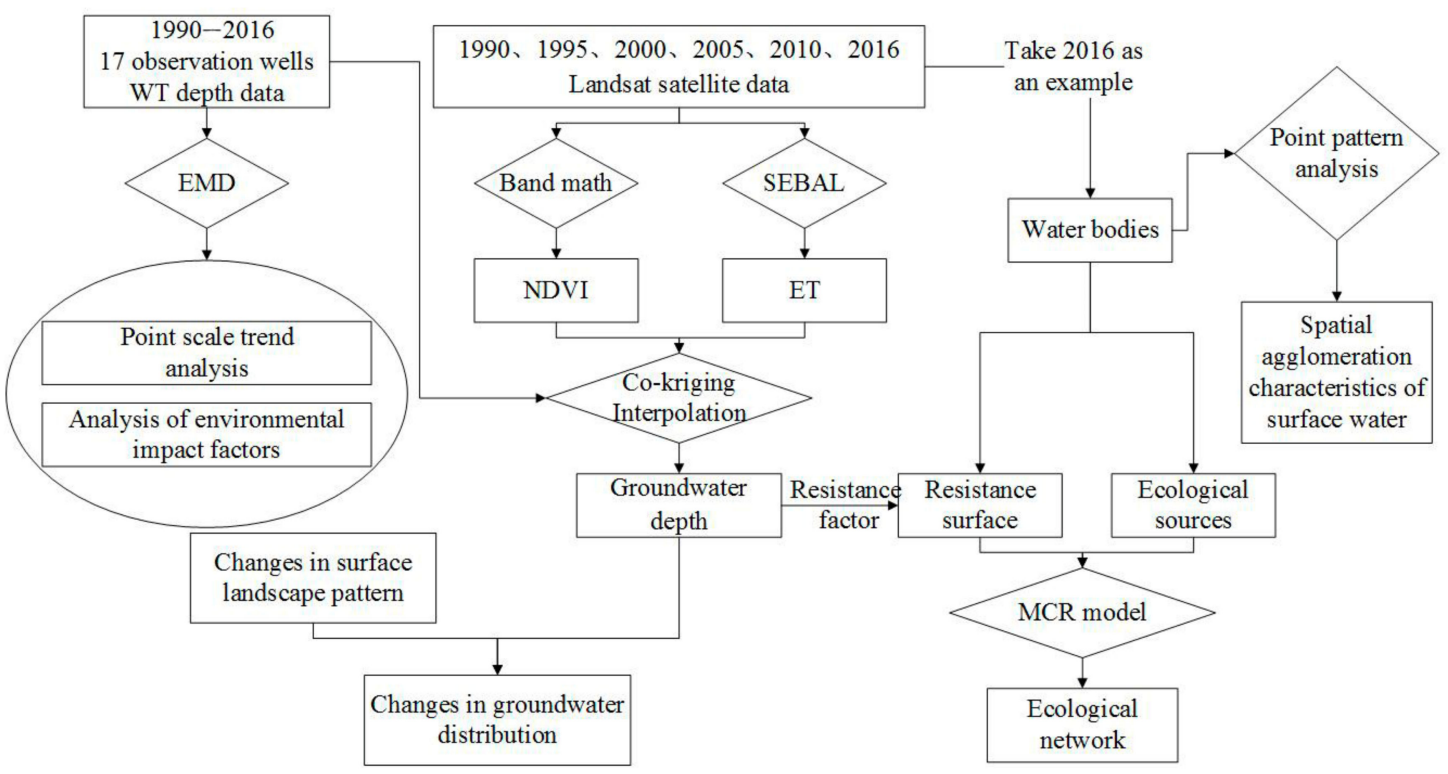

Figure 5. The overall flow chart of this study.

\section{Results and Discussions}

\subsection{Water Table Dynamics}

For water table depth temporal changes, the EMD method was used to analyze the trend of monthly WT depth data over the last 27 years. Taking BG1 as an example, the first panel in the BG1 caption is the initial groundwater depth time series. This time series was decomposed into seven components that contained six IMF components and a residual trend component. IMF1 had the highest frequency and the maximum amplitude, while IMF6 had the lowest frequency and the minimum amplitude. Due to the second panel in the BG1 caption, the IMF1 component showed high frequency and short cyclicality. During the period from 1990 to 2000, the IMF1 component had a larger amplitude, especially in 1995, when its magnitude reached its maximum. After 2000, the amplitude gradually 
became smaller and tended to be stable. The IMF2 component showed a fluctuation period of $2-4$ years. IMF3 showed a fluctuation period of 4-6 years. As shown in the BG1 caption, the fluctuation cycles of IMF4, IMF5, and IMF6 gradually increased. The last panel shows the residual trend component of the initial groundwater depth time series of BG1. During the last 27 years, the groundwater depth of this well showed a downward trend, with a decline of $5.7 \%$. The decomposition of the groundwater time series data of well BG1 based on the EMD model is shown in Figure 6 and the EMD decomposition data for the other 16 wells are provided in Appendix B.
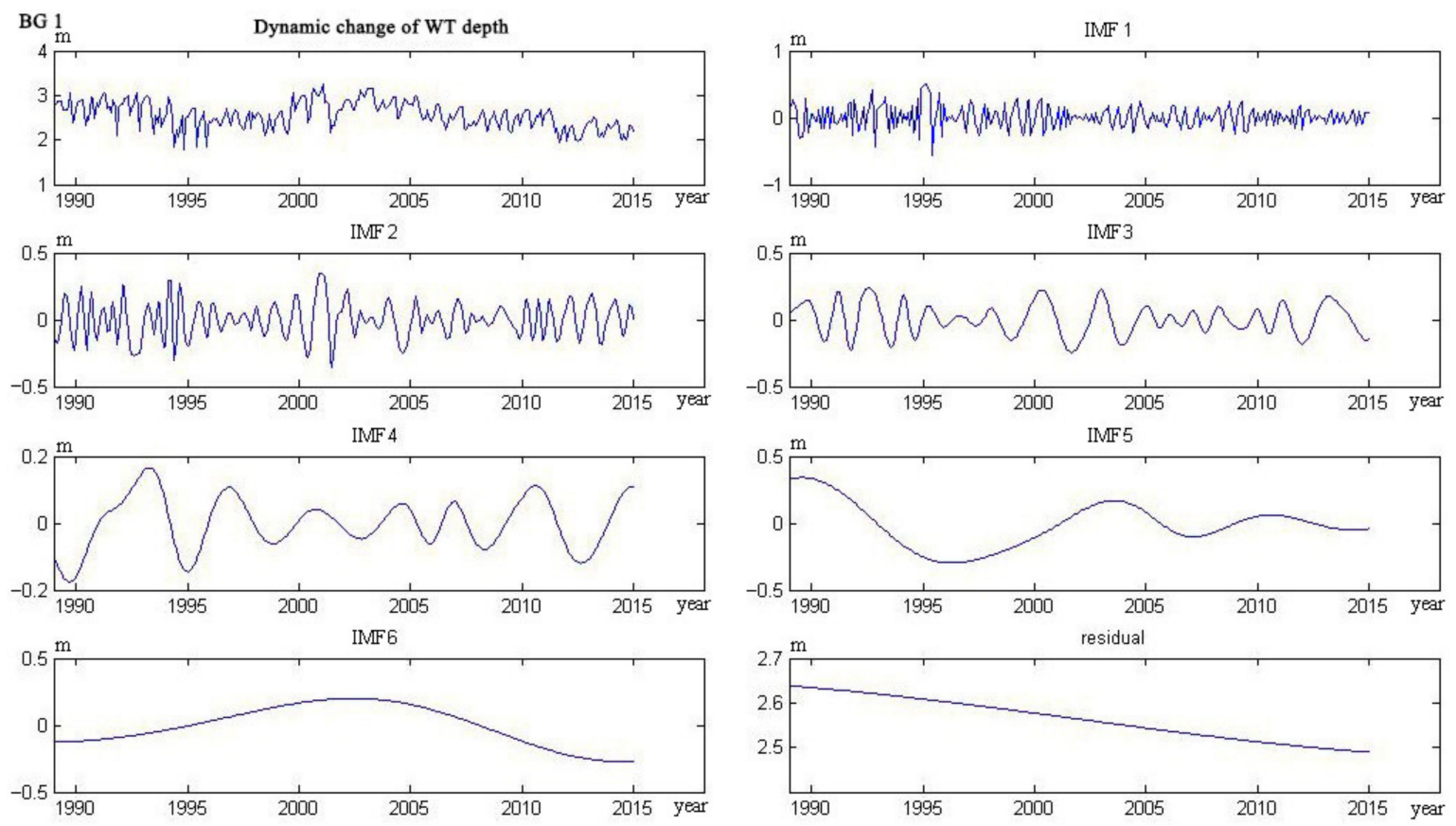

Figure 6. Decomposition of groundwater time series data of well BG1 based on the Empirical Modal Decomposition model.

The WT depth data of each observation well were processed using the EMD method, respectively. All time series observations were broken down into IMFs and a trend item component. As shown in Figures 7-10, all the trend curves were nonlinear. For the residual trend curves, the trend lines of the 17 wells can be divided into five types based on the temporal time series patterns.

The first type has a monotonically decreasing curve, including four wells: BG1, BG6, BG12, and BG17. BG1 is in the northeast of Bao Lehao Haizi (Haizi is the name of an inland lake in arid and semi-arid areas) and the south of Ma Mito ditch. BG6 is to the west of Hatton Tao Haizi. BG12 is near the Tucktutu Haizi and BG17 is near the Er Paigan ditch. The four wells are close to the surrounding water body. Furthermore, their WT depths are shallow, mainly concentrated at about $2 \mathrm{~m}$. Their WT depths are affected by nearby water bodies, which also indicates that the water levels around the four wells have declined in the past 27 years. Among the four wells, the degree of declining WT depth in BG12 was the largest, reaching $67.8 \%$.

The second type was where the curve monotonically rose, and included six wells: BG2, BG3, BG9, BG11, BG19, and BG26. BG2 and BG9 are near water bodies, and BG3 is in the woodlands. The average value of WT depth in BG2 $=1.55 \mathrm{~m}, \mathrm{BG} 3=1.18 \mathrm{~m}$, and BG9 $=2.22 \mathrm{~m}$, which indicates a shallow WT depth. BG11, BG19, and BG26 were situated in cultivated land and their WT depths were greater than two meters. 

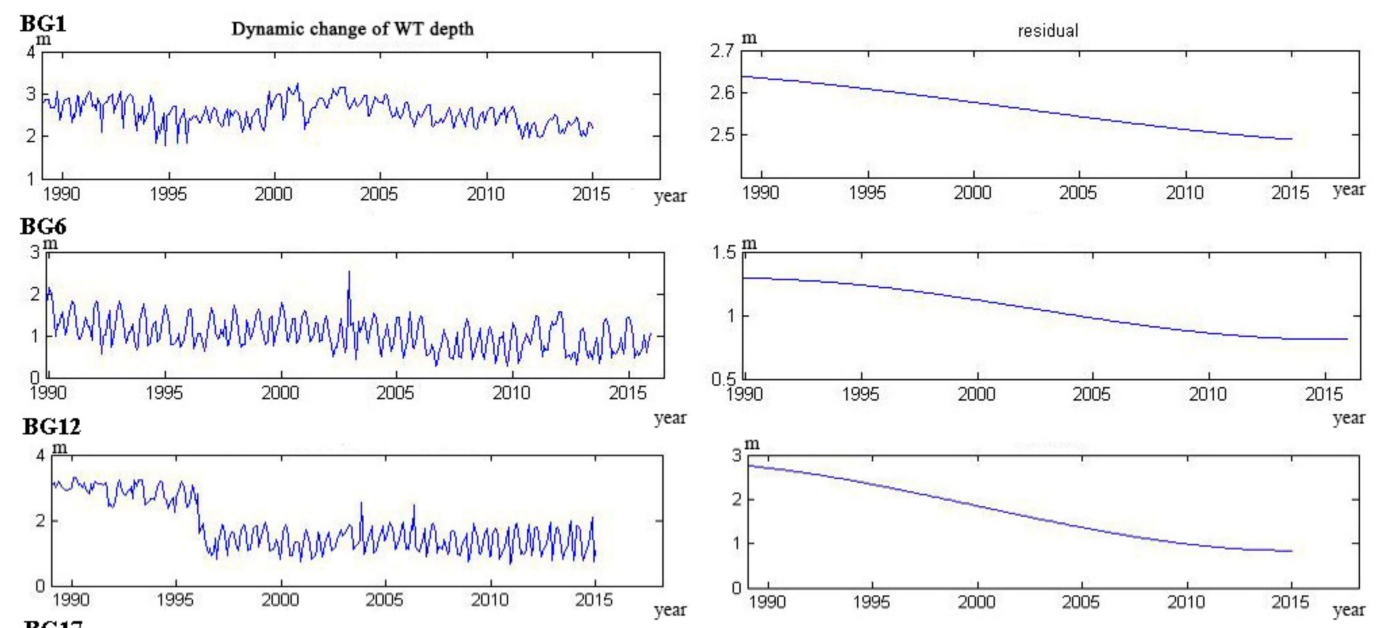

BG17
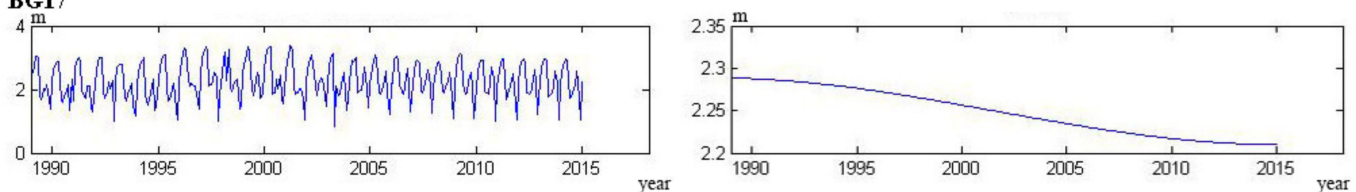

Figure 7. Empirical Modal Decomposition of the first type of curve.
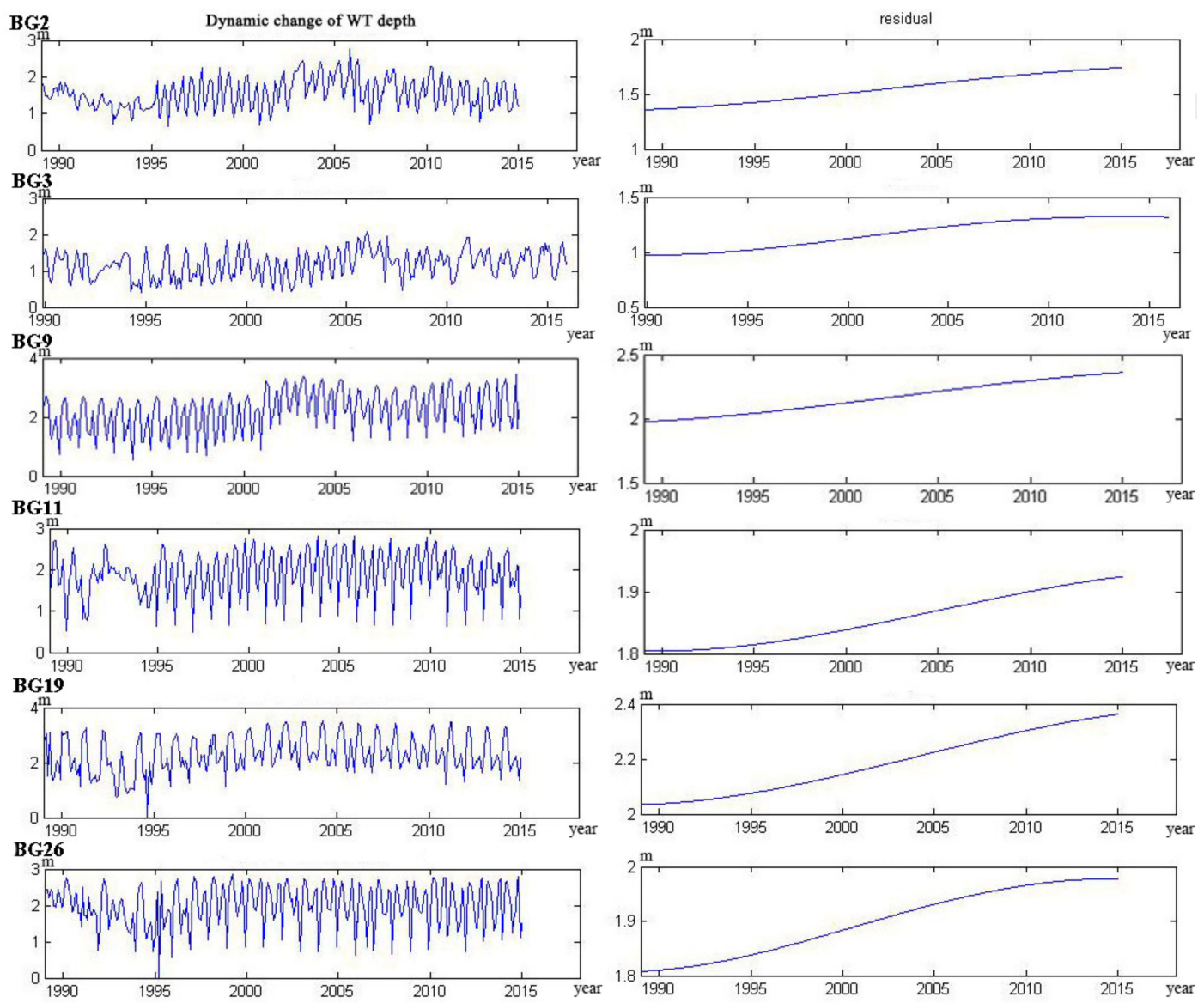

Figure 8. Empirical Modal Decomposition of the second type of curve. 

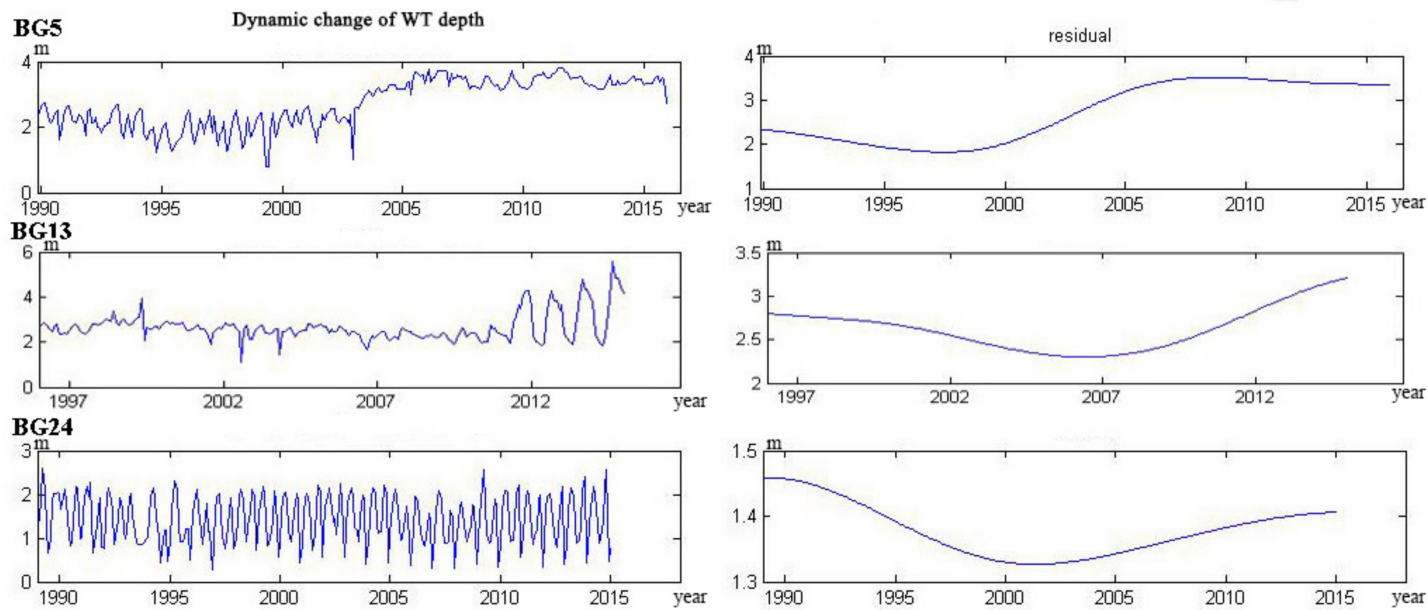

Figure 9. Empirical Modal Decomposition of the third type of curve.
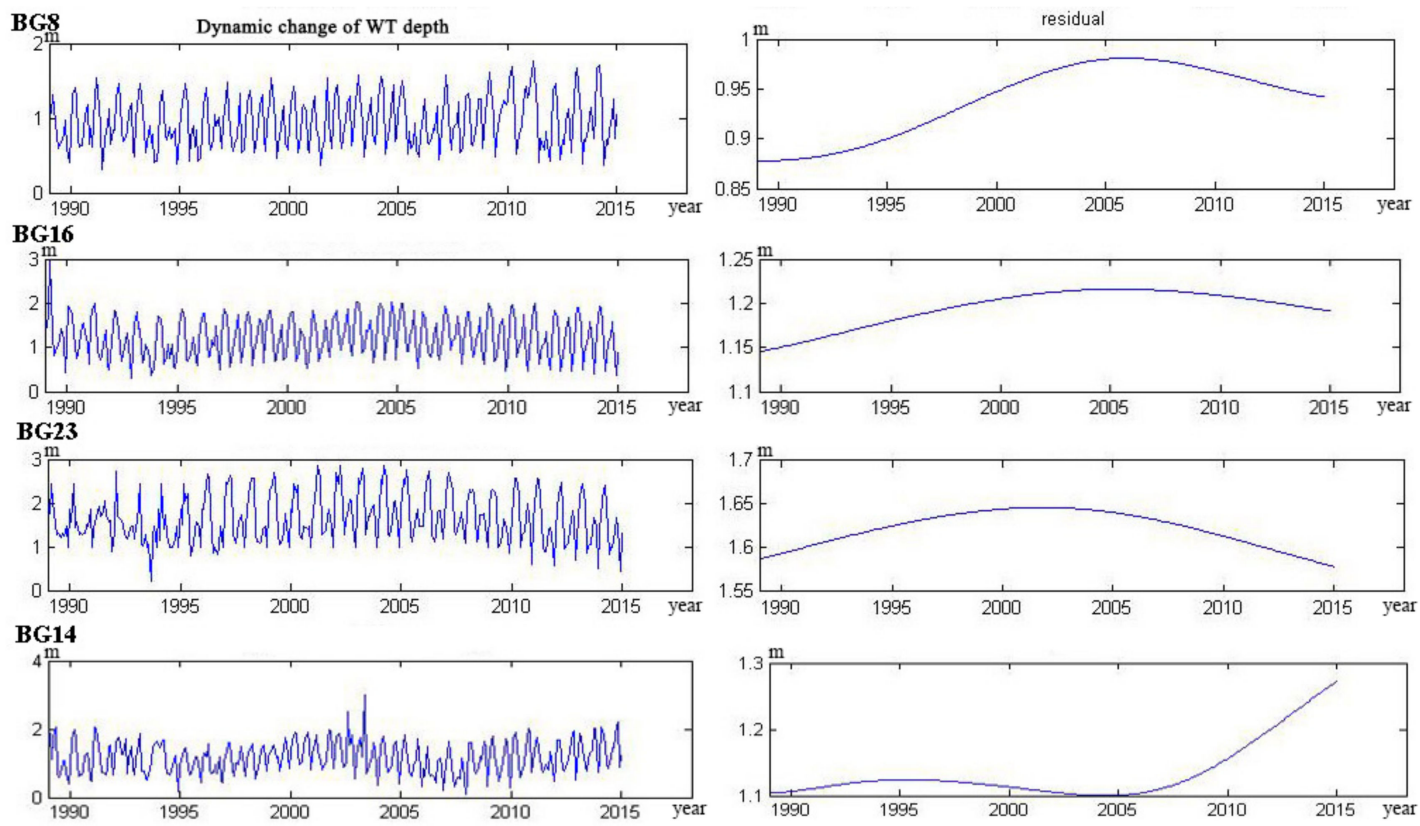

Figure 10. Empirical Modal Decomposition of the fourth and fifth types of curve.

The third type was a curve that showed a trend of decline to rise and included three wells: BG5, BG13, and BG24. BG5 is near the water bodies, BG13 is in the construction land, and BG24 is in cultivated land. The average value of WT depth in $\mathrm{BG} 5=2.73 \mathrm{~m}$, and $\mathrm{BG} 24=1.44 \mathrm{~m}$. The average value of WT depth in BG13 was greater than BG3 and BG24, and reached $3.37 \mathrm{~m}$. This well is in the downtown area of Denko County. This region is densely populated and a large amount of groundwater is exploited, resulting in the formation of a groundwater funnel in this area.

The fourth type is a curve that showed a trend from rise to decline, which included three wells: BG8, BG16, and BG23. BG8 and BG16 are near natural pastures, and BG23 is in cultivated land. The mean value of these three wells is less than $2 \mathrm{~m}$, and the average value of WT depth in BG8 $=0.95 \mathrm{~m}$. The fifth type is a curve with a trend from rise to decline and rise again, and included only one well: BG14. BG14 is in the nearby woodlands surrounded by cultivated land. The value of WT depth in BG14 $=5.70 \mathrm{~m}$. In addition, the WT depth of this well fluctuated considerably. This phenomenon was caused by the complex geographical environment around this well, i.e., disturbed by human activities, the impact of the Yellow River lateral seepage, and desert expansion. 


\subsection{Spatial Distribution of Groundwater}

The average value of the measured data of the WT depth in each year was taken as the main variable. ET and NDVI data retrieved by remote sensing images were used as auxiliary variables. The co-Kriging interpolation algorithm was used to calculate the spatial distribution data of the WT depth. In addition, the spatial distribution data were divided into eight levels. Respectively, Level 1 was less than 2 m; Level 2 was 2-4 m; Level 3 was 4-6 m, Level 4 was 6-8 m; Level 5 was 8-10 m; Level 6 was 10-12 m; Level 7 was 12-14 m; and Level 8 was greater than $14 \mathrm{~m}$. The spatial classification data of WT depth in 1990, 1995, 2000, 2005, 2010, and 2016 are shown in Figure 11. The maximum and minimum values of groundwater depth for each year are shown in Table 3.
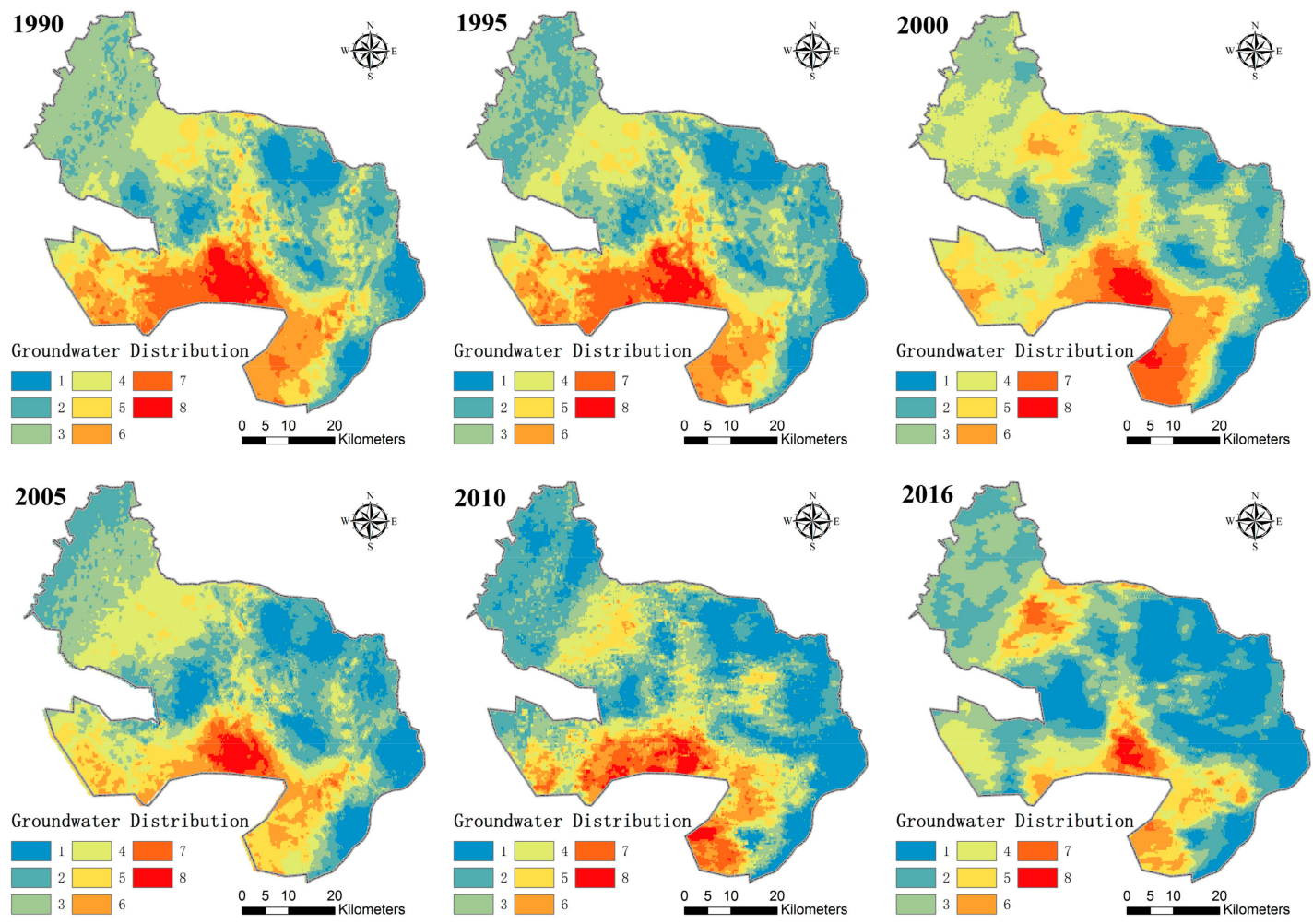

Figure 11. The spatial classification data of Water Table (WT) depth.

Table 3. The maximum and minimum values of groundwater depth (m).

\begin{tabular}{ccccccc}
\hline Groundwater Depth & $\mathbf{1 9 9 0}$ & $\mathbf{1 9 9 5}$ & $\mathbf{2 0 0 0}$ & $\mathbf{2 0 0 5}$ & $\mathbf{2 0 1 0}$ & $\mathbf{2 0 1 6}$ \\
\hline Max & 20.54 & 19.43 & 19.91 & 22.36 & 20.71 & 20.83 \\
Min & 0.21 & 0.23 & 0.50 & 0.18 & 0.20 & 0.57 \\
\hline
\end{tabular}

The minimum depth of groundwater in the study area was about $0.5 \mathrm{~m}$, and the maximum about $20 \mathrm{~m}$. As shown in Figure 7, Levels 1 and 2 were mainly distributed in farmland irrigation areas, located in the eastern part of the study area. Levels 3 and 4 were in the intertwined area between the desert and the oasis, which was the transitional area. Levels 5 and 6 were mainly distributed in the natural pasture area, which is distributed with natural Acanthus, Artemisia ordosica, Sacsaoul, and Tamarix. Levels 7 and 8 were distributed in the northeastern margin of the Ulan Buh Desert. The surface was mainly distributed with fixed dunes, semi-fixed dunes, and mobile dunes.

From 1990 to 2016, the depth of groundwater in the Piedmont alluvial fan area increased, and the depth of groundwater in the eastern agricultural irrigation area decreased. With years of desertification control, the water level in the northeastern margin of the Ulan Buh Desert has risen gradually. 
The areas of Levels 7 and 8 have been significantly reduced. Overall, the annual groundwater level fluctuated considerably.

In addition, there were three representative areas where the groundwater level changed dramatically. The first was the Nai Lun Lake area, located in the south of the study area. In 2010, Nai Lun Lake was built and put into use, and compared to 2005, the groundwater level of this area has risen dramatically. In 2016, there were no Level 3 areas between Nai Lun Lake and the Yellow River.

The second is the Nyankulug Gacha area, located in the western part of the study area. With extensive development of arable land and the construction of the Yellow River irrigation channel, this area has been transformed from a desert landscape into an artificial oasis. From 1995 to 2016, the depth of the groundwater level varied greatly, and the expansion of the Ulan Buh Desert to the north was blocked by the artificial oasis. Thus, the construction of these two regions had a direct impact on the pattern of groundwater in the Ulan Buh Desert, which was of great significance to the improvement of the ecological environment. These results showed that two types of human disturbance (manmade lakes and oasis) can be considered as appropriate human disturbances.

The third is the town center of Bayan Gore. With the acceleration of urbanization, the area of the city has increased annually. This expansion process has had a great impact on the spatial distribution of groundwater. From 1990 to 2016, Level 5 gradually expanded eastward. In 2005, Level 6 began to appear sporadically in this region. Eventually in 2016, a larger area of Level 6 and a small area of Level 7 was distributed in this area. This phenomenon indicates that the groundwater in this area formed a groundwater funnel. Groundwater resources are heavily exploited in urban construction and development, which leads to an increase in groundwater depth. This type of human disturbance (urbanization) is inappropriate human disturbance. The results of this analysis indicated that groundwater should be avoided during the development of urban construction in arid and semi-arid areas. In addition, industrial structures and urban layout should be adjusted to avoid significant impacts on groundwater.

As shown in Figure 12a and Appendix C, precipitation increased from January 1990 to August 1997, and showed a decreasing trend from August 2000 to August 2007. During the period from 2008 to 2016, the precipitation greatly fluctuated and the maximum precipitation appeared in July 2008 (38.597 mm). In July 2008 and August 2014, precipitation appeared as two larger peaks. Overall, however, precipitation declined after August 1997. Precipitation has a pronounced yearly cycle, with peak precipitation in July and August each year, and is scarce in spring and winter. The sum of precipitation from July to August is shown every year in Figure 12b. Among them, the total precipitation in 1995 is the largest; its value is $112.543 \mathrm{~mm}$. The total precipitation in 2008 is the second largest, with a value of $112.543 \mathrm{~mm}$. Figure 11 shows that the groundwater depth in Denko County in 2000 was relatively large compared with the other five years, and the area of Level 1 was also smaller. This phenomenon is likely related to the trend of precipitation, i.e., the total amount of precipitation between 1998 and 2000 was relatively small. In addition, the impact of precipitation on groundwater also showed a hysteresis quality of 1-2 years. After 2015, precipitation was relatively low, which may have led to an increase in groundwater depth. This change will have a great impact on the future stability of the ecological environment of Denko County; therefore, it is particularly important to allocate water resources and ecological planning before the spatial distribution of water resources is affected. 

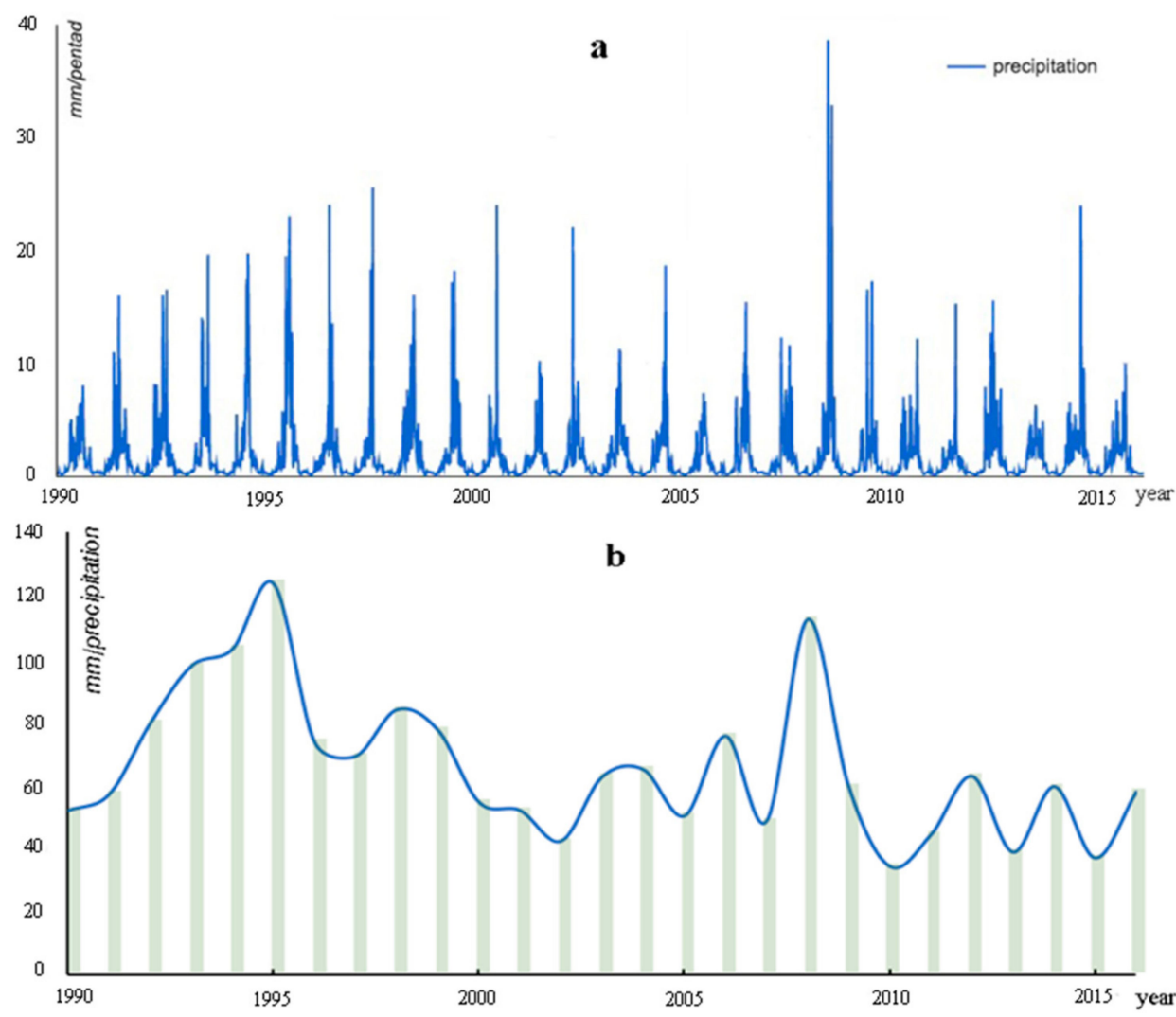

Figure 12. Precipitation of Denko County from 1990 to 2016 (a) and the sum of precipitation from July to August (b).

\subsection{Point Pattern Analysis of Surface Water}

Using the remote sensing image in 2016 as the research material, the spatial distribution pattern of the surface water body was analyzed. First, the surface water bodies were extracted, where the error was within four pixels. A detailed field investigation was carried out. Three types of water bodies, including lakes, ponds and rivers were identified in the study area (Figure 13). Classification and identification criteria included (1) the lake is natural surface water; (2) the pond is artificial surface water; and (3) the river is a band of surface water. Second, the lake and pond surface data were converted into point data. Finally, the O-ring function was used to analyze the spatial distribution of different types of water nodes at different spatial scales. Additionally, Programita software was used for calculation processing.

As shown in Figure 14, The lake nodes were randomly distributed on the scale of 31-34 km, and clustered at $0-31 \mathrm{~km}$. They showed a uniform distribution pattern after a scale of more than $34 \mathrm{~km}$. The pond nodes showed a clustering distribution at the scale of 0-34 km, distributed randomly at the scale of 34-45 m, and showed a uniform distribution pattern at a scale of more than $45 \mathrm{~km}$. The $O_{11}(r)$ curve of the pond nodes fluctuated strongly where it shows an increasing trend at $0-2 \mathrm{~km}$ scale, and descended at a $2-4 \mathrm{~km}$ scale, then continued to show a downward trend after the upward trend of 4-7 km. In addition, it showed a small upward trend at the $19 \mathrm{~km}$ scale. The two types of water nodes showed a clustering distribution at a small scale, and gradually appear randomly with the increase of the scale, and were evenly distributed on the large scale. The peak of the accumulation of pond nodes appeared at a $7 \mathrm{~km}$ scale. 

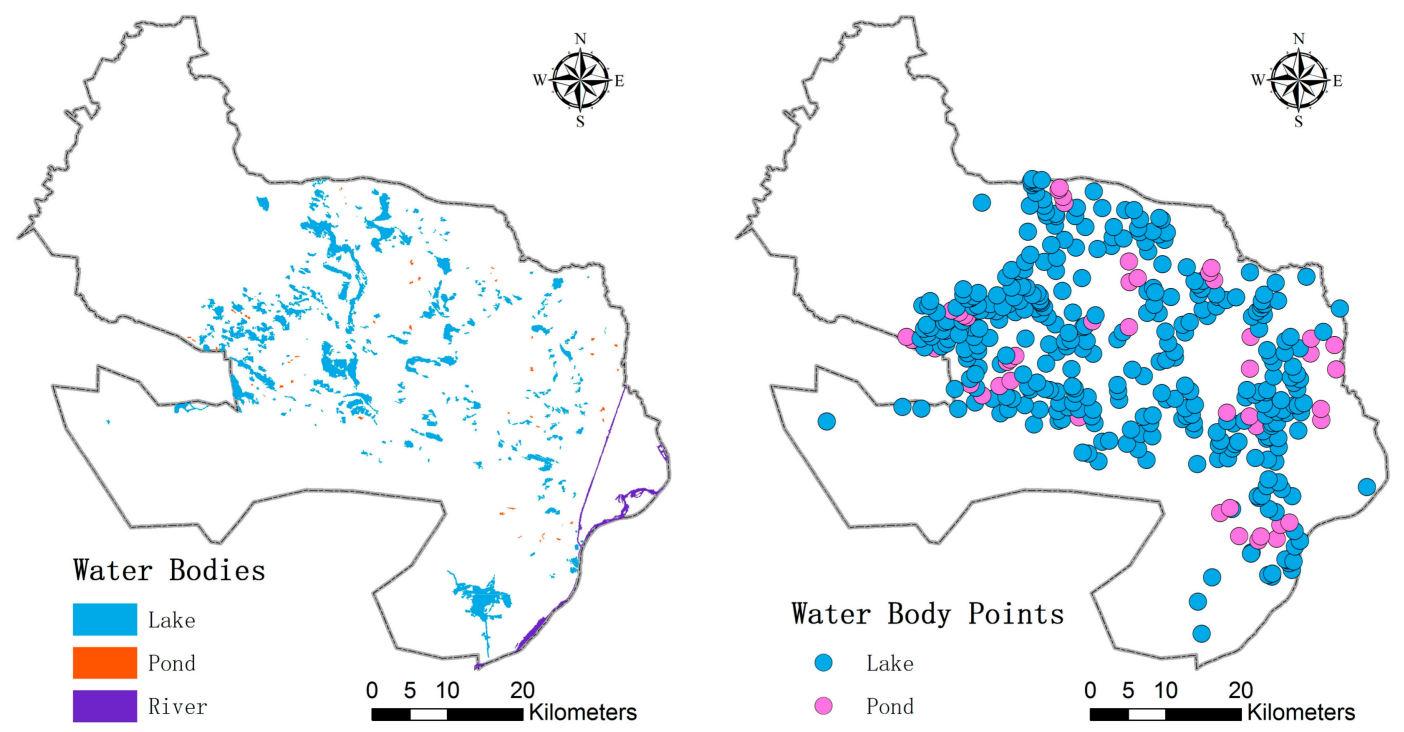

Figure 13. Spatial distribution of surface water bodies and nodes.
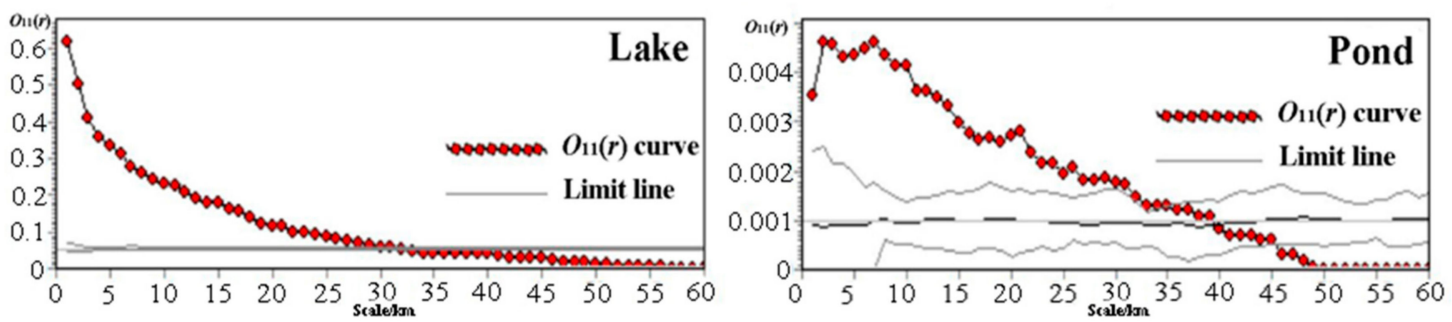

Figure 14. Horizontal distribution pattern function varies with spatial scale.

In Denko County, the expansion of the Ulan Buh Desert, groundwater instability, lack of rainfall, and other factors have directly affected the presence of surface water bodies. The results showed that the water nodes had high spatial clustering characteristics at a small scale. This high agglomeration feature ensured that the water bodies were interdependent. If the spatial distribution of water body aggregation was insufficient, it led to the reduced possibility of its survival. The water bodies are evenly distributed on a large scale. This uniform distribution phenomenon indicated that the water bodies can control and affect the entire study area. The surface water distribution was the result of human activities, vegetation successions, groundwater spatial distribution dynamics, climatic change, and desertification factors. In arid and semi-arid regions, this small-scale highly aggregated distribution and large-scale uniform distribution stabilizes the surface water and the regional environment. The results of this analysis also showed that a more stable ecological network could be constructed based on surface water bodies.

\subsection{Construction of a Water-Based Ecological Network}

Based on the above analysis, it is feasible to build an ecological network based on groundwater and surface water in Denko County. Therefore, based on the remote sensing image of 2016, the water-based ecological network of Denko County was extracted and constructed.

First, water-based ecological sources were extracted and graded. The ecological source was the type of land that had a positive impact on the surrounding environment, was relatively stable, and could output the ecological energy continuously, which is the engine of the ecological network. In arid and semi-arid areas, the distribution of vegetation landscape was directly affected by the distribution of water resources. Therefore, lakes, ponds, and major rivers were identified as ecological sources in this study. The ecological land type and plaque area were used as the discriminant index. 
After expert consultation with the actual situation of the study area, the ecological source was divided into four grades. Level 1 included the Yellow River, the main canal, and the lake with an area greater than $10 \mathrm{~km}^{2}$. Level 2 mainly included lakes with an area greater than $5 \mathrm{~km}^{2}$ and less than $10 \mathrm{~km}^{2}$. Level 3 mainly included lakes with an area greater than $1 \mathrm{~km}^{2}$ and less than $5 \mathrm{~km}^{2}$. Level 4 included lakes and ponds with an area of less than $1 \mathrm{~km}^{2}$.

Secondly, a minimum cumulative resistance surface was constructed. Spatial data of WT depth, multiple buffering data of surface water bodies, and spatial density data of surface water bodies were used to construct resistance surfaces. As shown in Table 4, the ecological resistance factors were divided into eight grades, and weights respectively given to 1-8. Among them, the multiple buffering data of surface water bodies were calculated by the multiple buffer analysis tool, and the buffer interval was set at $500 \mathrm{~m}$. Additionally, the spatial density data of surface water were also calculated by the kernel density analysis tool with a maximum density of 3.77 and a minimum value of 0 . The deletion calculator in the same software was used to calculate the resistance surface, and the result of the stack operation is shown in Figure 15. Based on this resistance, the modified MCR model was used to calculate the minimum cumulative resistance surface using the cost-distance module. As shown in Figure 15, the minimum cumulative resistance value was 23,478 , and the maximum value is $9,592,550$. A smaller cumulative resistance value indicated that the water resources were sufficient and ecological energy easily transmitted [33].

Table 4. The value system for ecological resistance factors.

\begin{tabular}{|c|c|c|}
\hline & Grade & Weight \\
\hline \multirow{8}{*}{ WT depth (m) } & $<2$ & 1 \\
\hline & $2-4$ & 2 \\
\hline & $4-6$ & 3 \\
\hline & $6-8$ & 4 \\
\hline & $8-10$ & 5 \\
\hline & $10-12$ & 6 \\
\hline & $12-14$ & 7 \\
\hline & $>14$ & 8 \\
\hline \multirow{8}{*}{ Distance from water bodies (m) } & $<500$ & 1 \\
\hline & $500-1000$ & 2 \\
\hline & $1000-1500$ & 3 \\
\hline & $1500-2000$ & 4 \\
\hline & $2000-2500$ & 5 \\
\hline & $2500-3000$ & 6 \\
\hline & $3500-4000$ & 7 \\
\hline & $>4000$ & 8 \\
\hline \multirow{8}{*}{ Density of surface water bodies } & $0.9-1$ & 1 \\
\hline & $0.75-0.9$ & 2 \\
\hline & $0.6-0.75$ & 3 \\
\hline & $0.45-0.6$ & 4 \\
\hline & $0.3-0.45$ & 5 \\
\hline & $0.15-0.3$ & 6 \\
\hline & $0-0.15$ & 7 \\
\hline & 0 & 8 \\
\hline
\end{tabular}

Note: we used 1-8 to represent the different levels of resistance, with 1 being lowest and 8 the highest, which is a subjective determination and not calculated by the MCRM (minimum cumulative resistance model) [31]. 

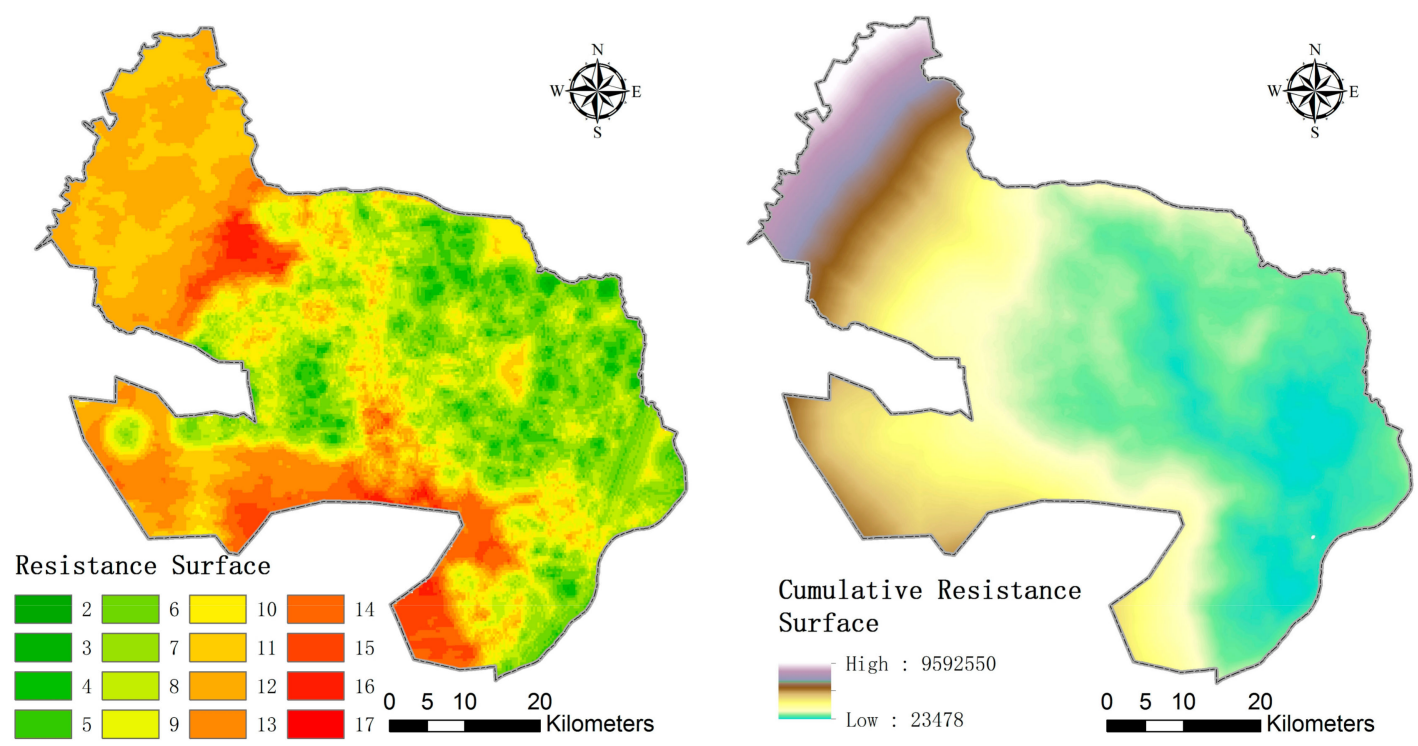

Figure 15. Ecological resistance and ecological cumulative resistance.

Eventually, the potential ecological corridor was extracted and the ecological network constructed. The cost-path module was used to calculate this minimum cumulative resistance surface and to extract the potential ecological corridors, and the results are shown in Figure 16. We extracted 7360 ecological corridors within the county, and the shortest ecological corridor was $601 \mathrm{~m}$, with the longest potential ecological corridor of $18,615 \mathrm{~m}$. After field verification, the extracted ecological corridor was constructed in practice. A corridor forms the basic element of an ecological network, not only to transfer the stream of landscape flow, but also to act as a zonal ecological source. The extracted ecological corridors were based on the distribution of water resources, therefore, the construction of the vegetation landscape on potential ecological corridors can ensure its ecological sustainable development. This ecological restoration model—based on the spatial distribution of groundwater and surface water-is the most reasonable for use in arid and semi-arid regions. The water-based ecological network in Denko County is shown in Figure 16 where the blue areas represent the ecological source; and green represents the ecological corridor.

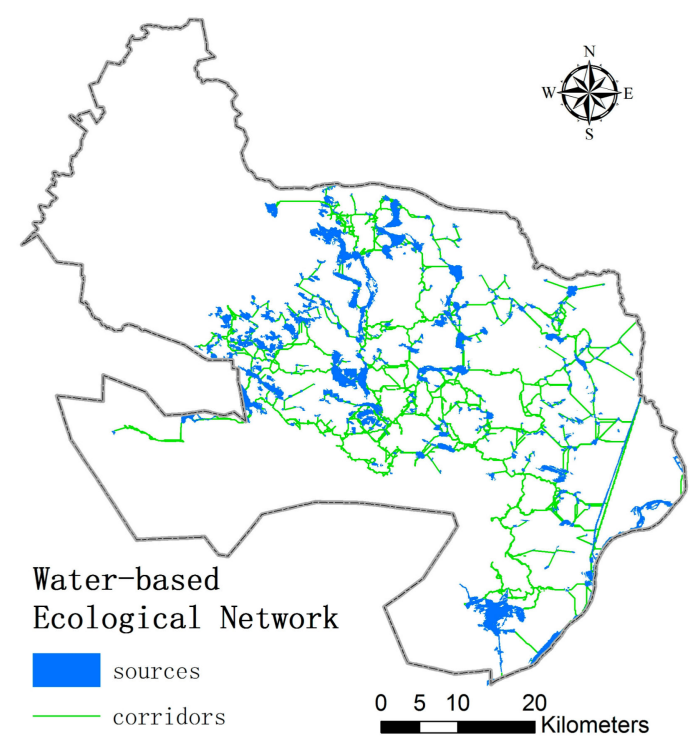

Figure 16. Water-based ecological network in Denko County. 


\subsection{Discussions on the Reliability of the Main Results}

The spatial distribution of groundwater is intertwined with the landscape patterns on the ground. The study area is a typical arid and semi-arid area, and its landscape pattern is greatly disturbed by human beings. The study area was divided into desert and oasis areas [53]. The oasis area has many artificial irrigation ditches. During the irrigation period, sufficient water in the ditch resulted in a significant rise of the groundwater level. The construction of an artificial oasis had a great impact on the spatial distribution of groundwater such as the first and second representative areas described in Section 3.2. The changes in the landscape pattern of these two regions had a positive effect on the spatial distribution of groundwater. However, the urbanization of the third representative area had a negative impact on the spatial distribution of groundwater. In summary, appropriate human disturbances (such as the construction of an artificial oasis) can be of great significance to the stability of arid and semi-arid ecological environments.

The current spatial distribution pattern of lakes has been formed by several diversions of the Yellow River watercourse over thousands of years. The lakes that are still present are the result of natural selection. Their spatial distribution represents the pattern that best fits the current environment. Based on the results of the point pattern analysis in this study, the spatial patterns of water nodes are characterized by a small-scale highly aggregated distribution and a large-scale uniform distribution. This pattern was the same as the findings of other research on plant communities [54], animal communities [55], and virus distribution [56], and is prevalent in natural and even human social networks. This small-scale clustering distribution and large-scale uniform distribution can ensure the sustainable and stable development of a community.

There have also been many studies on the construction of ecological network patterns, mostly focusing on the construction of the ecological network in cities or typical areas [12,57]. The minimum cumulative resistance surface model is widely used in the study of ecological network pattern construction [58]. For different types of ecological networks, the index system used to build the resistance surface varies. Based on the environmental characteristics of arid and semi-arid areas, spatial data of WT depth [59], multiple buffering data of surface water bodies, and spatial density data of surface water bodies were used to construct resistance surfaces in this study. In contrast to other studies, indicators such as vegetation coverage were not added to the index system [60] as all vegetation in arid and semi-arid areas must rely on water resources to survive. The real ecological source is the surface water body, and the real factor that hinders the flow of ecological energy is the spatial distribution of water resources. Therefore, the water-based ecological network constructed in this study is more sustainable and stable, and it is also suitable for arid and semi-arid areas, which is of great practical significance and application value.

The limitation of this method in this paper is the determination of the resistance factors, and the resistance surface is the simplification of the reality, which inevitably leads to deviation from the actual situation. The land use data, groundwater distribution data, soil type data, and ecological hydrological data should be considered when the feasibility of the potential ecological network is verified. However, the distribution of groundwater is changing over time. If the distribution of groundwater changes drastically, the structure of the potential water-based ecological network will also change dramatically. The simulation of this change is extremely complex, but it is important to determine the structure of a potential ecological network. A more detailed groundwater hydrology study will be warranted in future research for a better refined understanding of the local flow system. Therefore, how to integrate the eco-hydrological data with temporal and spatial dynamic information into the construction model of the potential ecological network represents a future research focus and challenge.

\section{Conclusions}

The WT depth of 17 observation wells from five sub-administrative districts in the Denko County for the period of 1990-2016 were analyzed to determine trends. The spatial distribution of WT depth in 1990, 1995, 2000, 2005, 2010, and 2016 was analyzed to determine its temporal and spatial evolution. 
A 2016 remote sensing image was used as the research material, and the spatial pattern of surface water bodies was studied to analyze the basic conditions for constructing an ecological network. Based on the above study, a water-based ecological network was constructed in 2016. The conclusions of this study are given as follows:

1. The trend lines of 17 wells could be categorized into five types. The curve of four wells monotonically decreased, and six wells monotonically rose. The curve of three wells showed a trend from decline to rise, and the other three wells showed a trend from rise to decline. Only one well showed a rise-decline-rise trend.

2. There were three representative areas where the groundwater level changed dramatically. Among them, the landscape type changed from a desert landscape to an oasis landscape in the first and second representative areas. The changes in the landscape pattern of these two regions had a positive effect on the spatial distribution of groundwater. However, the urbanization of the third representative area had a negative impact on the spatial distribution of groundwater. In summary, appropriate human interventions (such as the construction of an artificial oasis) are of great significance to the stability of arid and semi-arid ecological environments. Furthermore, the precipitation trends were related to the spatial distribution of groundwater depth.

3. The spatial pattern of water nodes was characterized by a small-scale highly aggregated distribution and a large-scale uniform distribution. This pattern stabilized the surface water bodies and the regional environment. A more stable ecological network was constructed based on surface water bodies.

4. Lakes, ponds, and major rivers were identified as ecological sources, and the ecological source was divided into four grades. Spatial data of WT depth, multiple buffering data of surface water bodies, and spatial density data of surface water bodies were used to construct resistance surfaces. The 2016 water-based ecological network in Denko County consisted of 391 ecological sites and 7360 ecological corridors.

Acknowledgments: This research was financially supported by the Fundamental Research Funds for the Central Universities (No. 2017JC15 and No. 2015ZCQSB03), the National Science Foundation of China (No. 20373014), the National Major Scientific Research Program: The Decision Support System for the Integrated Water Resource Management in Heihe River Basin (HRB) (Grant No. 91325302), and the National Science Foundation of China (No. 20373014): Study on Coupling and Regulating Rules between Landscape Patterns and Eco-hydrological processes in the Desert Oasis Eco tone. The authors thank the editors and anonymous reviewers for their helpful and constructive comments that greatly contributed to improving the quality of our paper.

Author Contributions: Qiang Yu conceived and designed the study and contributed to the writing of the paper; Huan Ma, Yuan Huang, Qibin Zhang, and Minzhe Fang participated in data processing; Di Yang, Qun'ou Jiang, and Depeng Yue reviewed the manuscript.

Conflicts of Interest: The authors declare no conflict of interest.

\section{Appendix A}

CHIRPS: Climate Hazards Group InfraRed Precipitation with Station data (version 2.0 final)

Climate Hazards Group InfraRed Precipitation with Station data (CHIRPS) is a $30+$ year quasi-global rainfall dataset. Spanning $50^{\circ} \mathrm{S}-50^{\circ} \mathrm{N}$ (and all longitudes), starting in 1981 to near-present, CHIRPS incorporates $0.05^{\circ}$ resolution satellite imagery with in-situ station data to create gridded rainfall time series for trend analysis and seasonal drought monitoring.

Each asset spans a pentad. Each of the first 5 pentads in a month have 5 days. The last pentad contains all the days from the 26th to the end of the month.

The dataset contains one band: 'precipitation' (mm/pentad)

To cite this dataset, please use:

Funk, C.C., Peterson, P.J., Landsfeld, M.F., Pedreros, D.H., Verdin, J.P., Rowland, J.D., Romero, B.E., Husak, G.J., Michaelsen, J.C., and Verdin, A.P., 2014, A quasi-global precipitation time series for drought monitoring: U.S. Geological Survey Data Series 832, 4 p., http:/ / dx.doi.org/10.3133/ds832 
Data availability (time)

1 January 1981-27 June 2017

ImageCollection ID

UCSB-CHG/CHIRPS/PENTAD

Code:

// Load the CHIRPS data

var CHIRPS = ee. ImageCollection ('UCSB-CHG/CHIRPS/PENTAD');

//Identify Denko County

var GLTP = ee.FeatureCollection('ft:14UUynJScUtra5vI9cZ-iPWWZgcZOmbnpgX7qLQL_');

Map. addLayer (GLTP) ;

//Identify region of interest

var ROI

// Select dates: the CHIRPS data is from 1981-01-01 to 2016-02-27

var precip = CHIRPS. filterDate('1990-01-01', '2016-02-27');

var TS5 = Chart.image. series (precip, GLTP, ee.Reducer.mean(), 1000,

'system:time_start'). setoptions( \{

title: 'Precipitation Full Time Series',

vAxis: \{title: 'mm/pentad'\},

\});

print (TS5);

// Charts One Year

var preciplyear $=$ CHIRPS. filterDate('2016-01-01', '2016-12-31');

var TS1 = Chart.image. series (preciplyear, GLTP, ee.Reducer.mean(), 1000,

'system: time_start'). set0ptions( \{

title: 'Precipitation 1-Year Time Series',

vAxis: \{title: 'mm/pentad'\},

\});

print (TS1);

var Precip1 $=$ preciplyear $\cdot \operatorname{mean}() \cdot \operatorname{clip}($ GLTP $)$;

var Precip=precip. mean ().clip (GLTP);

Map.addLayer(Precip1, \{'min': 0, 'max': 70, 'palette': "CCFFCC, 00CC66,006600" \}, 'Precip 2015');

Map.addLayer (Precip, \{'min': 0, 'max': 70, 'palette': "CCFFCC,00CC66,006600"\}, 'Precip 2000-2015');

var path $=$ Precip. getDownloadURL $(\{$

'scale': 250,

'crs': ‘EPSG:4326',

'region': ‘[ [21.4453125,-18.1249706393865], [33.310546875,-18.35452552912664], [34.27734375,-8.015715997869059], [21.59912109375,-7.776308503776192], [21.4453125,

$-18.1249706393865]]^{\prime}$

\});

print (path); 


\section{Appendix B}

Decomposition of groundwater time series data of 17 wells based on the EMD model.
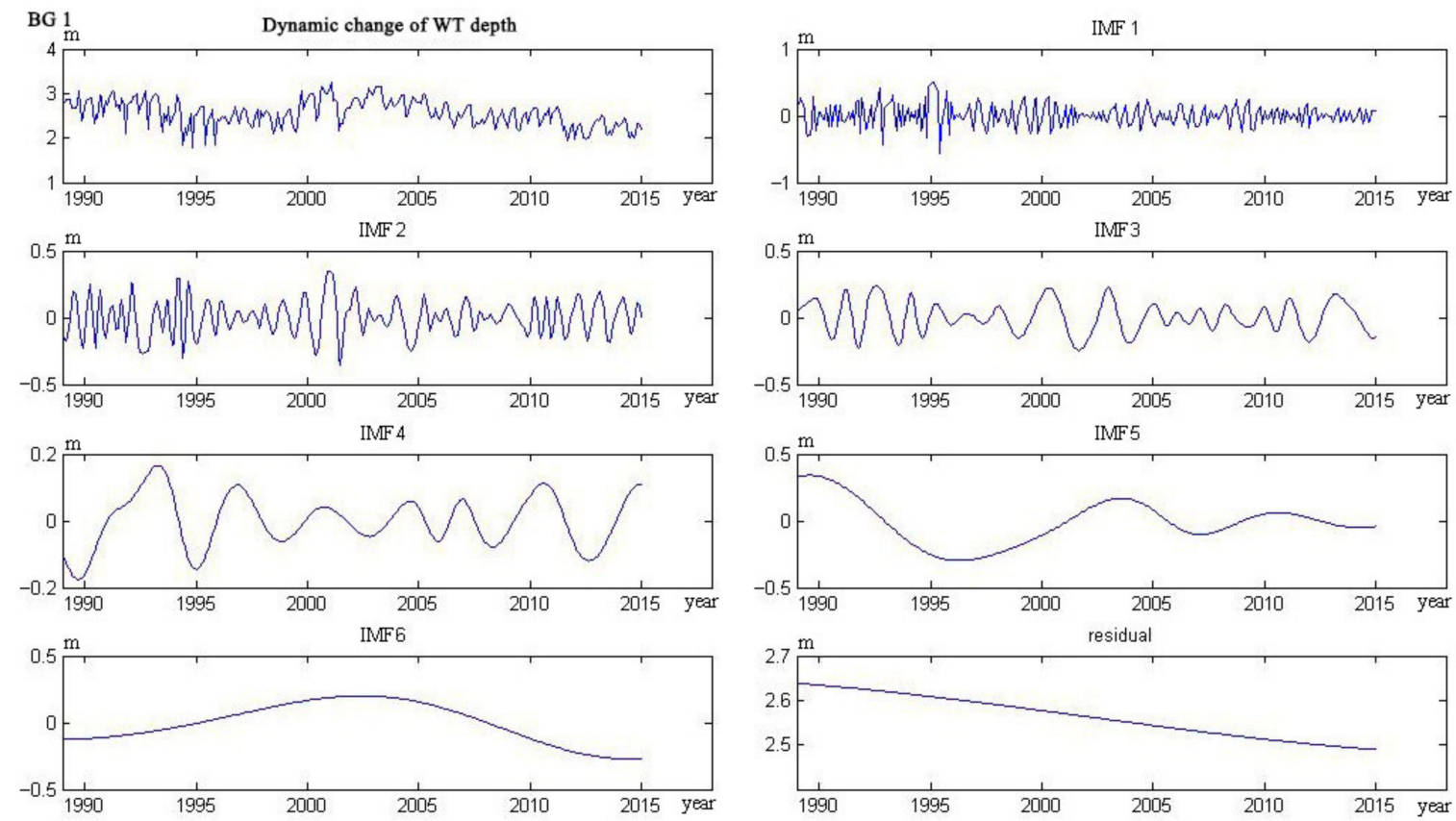

Figure A1. Decomposition of groundwater time series data of well BG1.
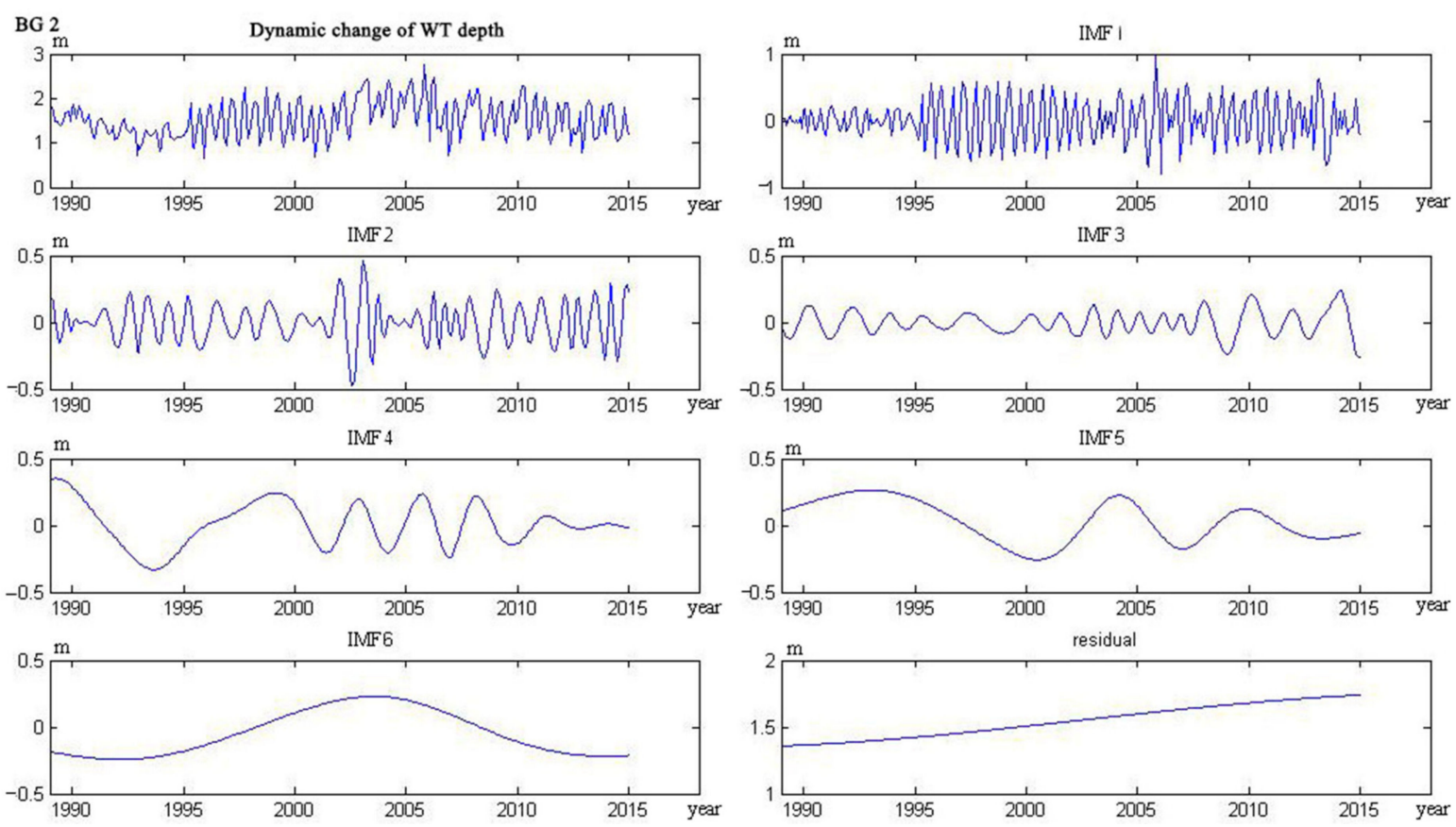

Figure A2. Decomposition of groundwater time series data of well BG2. 

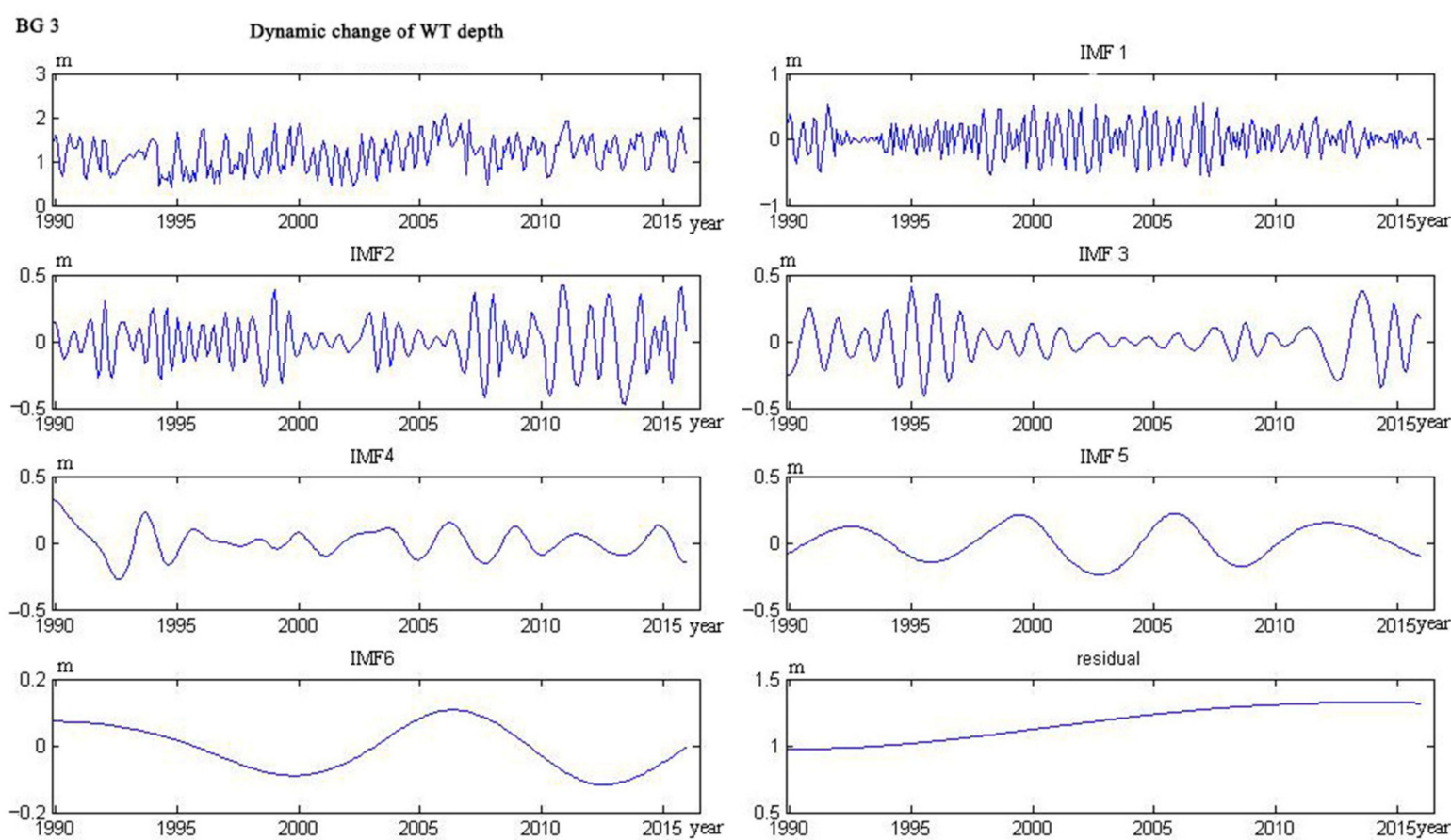

Figure A3. Decomposition of groundwater time series data of well BG3.
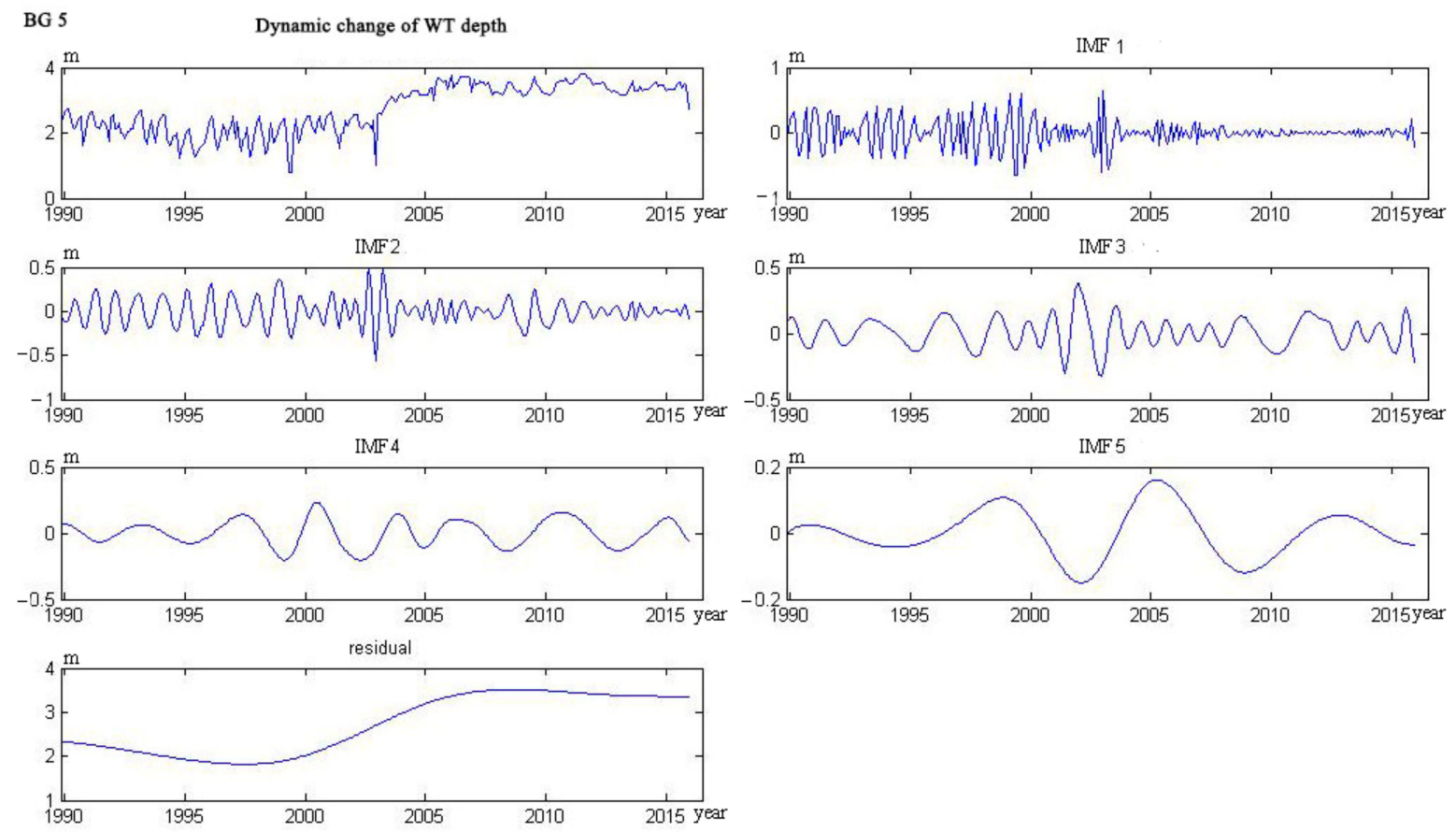

Figure A4. Decomposition of groundwater time series data of well BG5. 

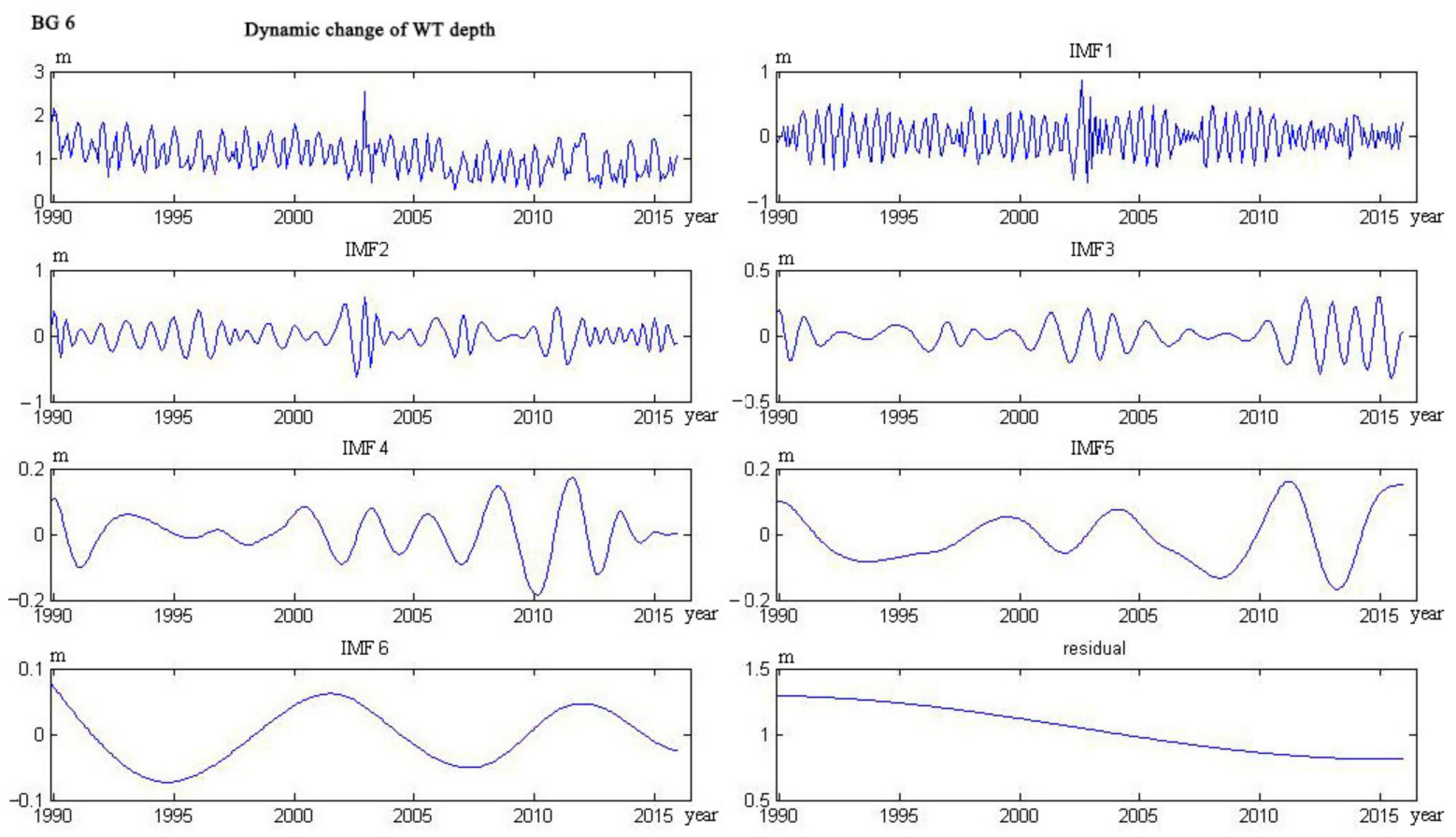

Figure A5. Decomposition of groundwater time series data of well BG6.
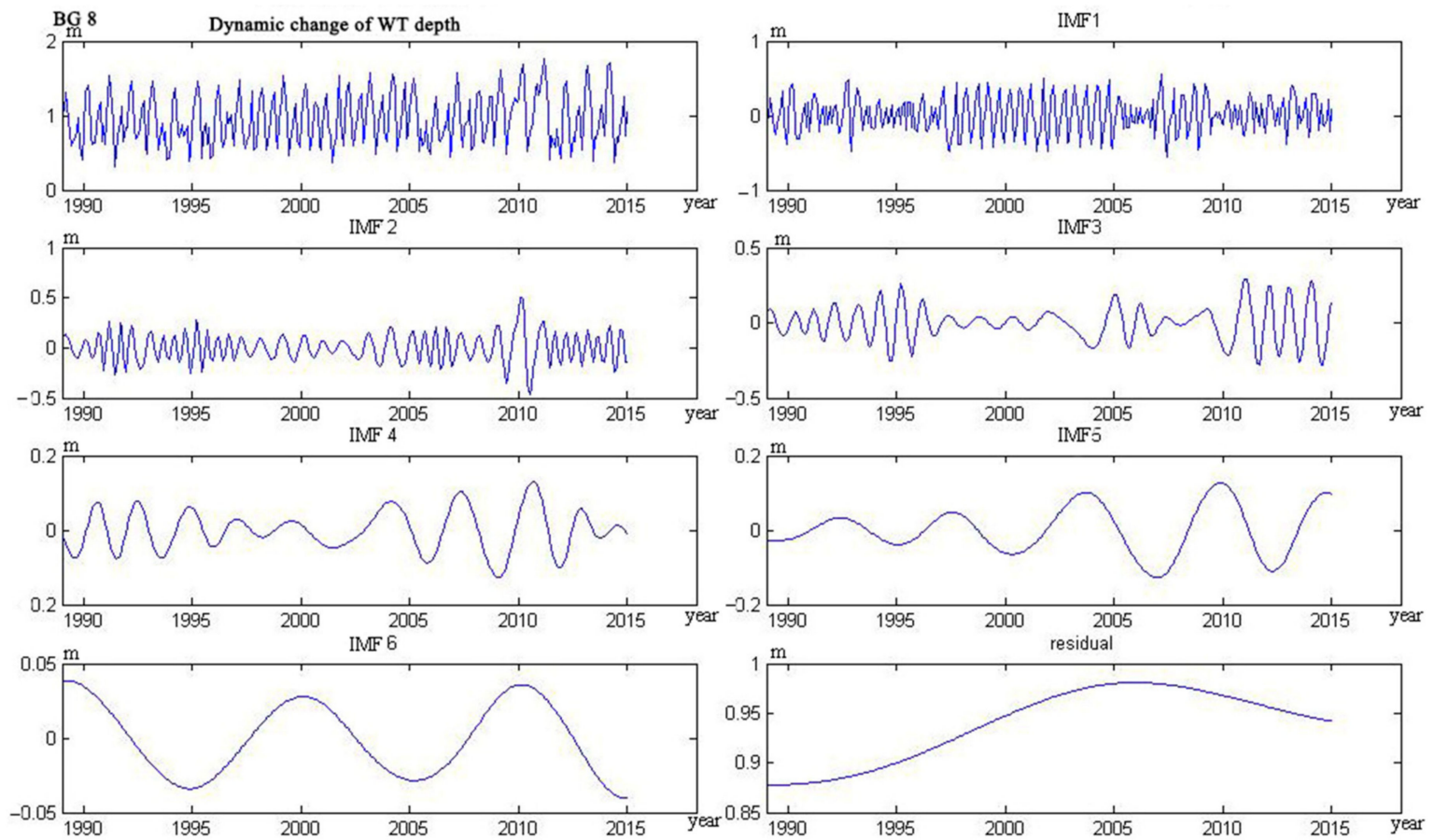

Figure A6. Decomposition of groundwater time series data of well BG8. 

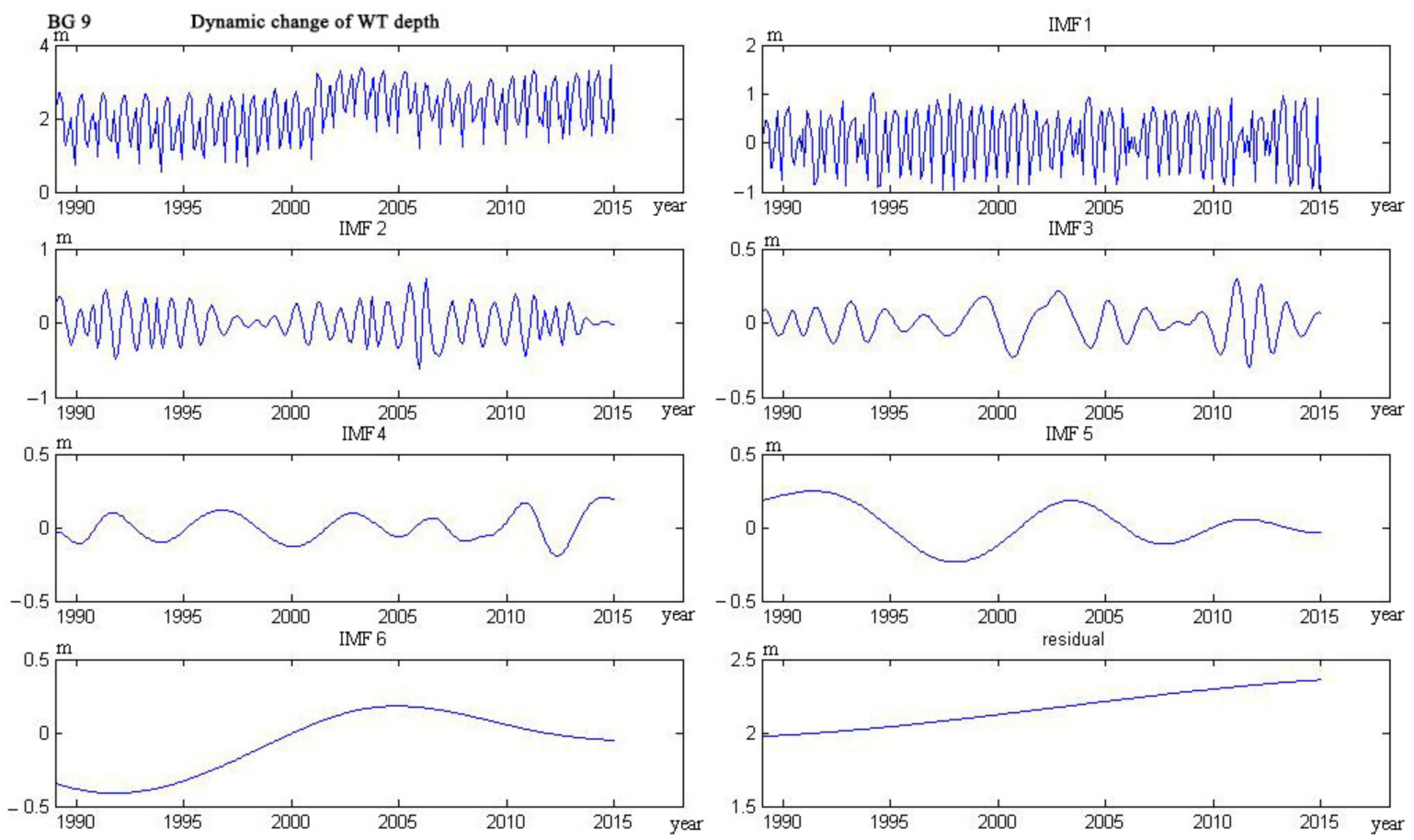

Figure A7. Decomposition of groundwater time series data of well BG9.
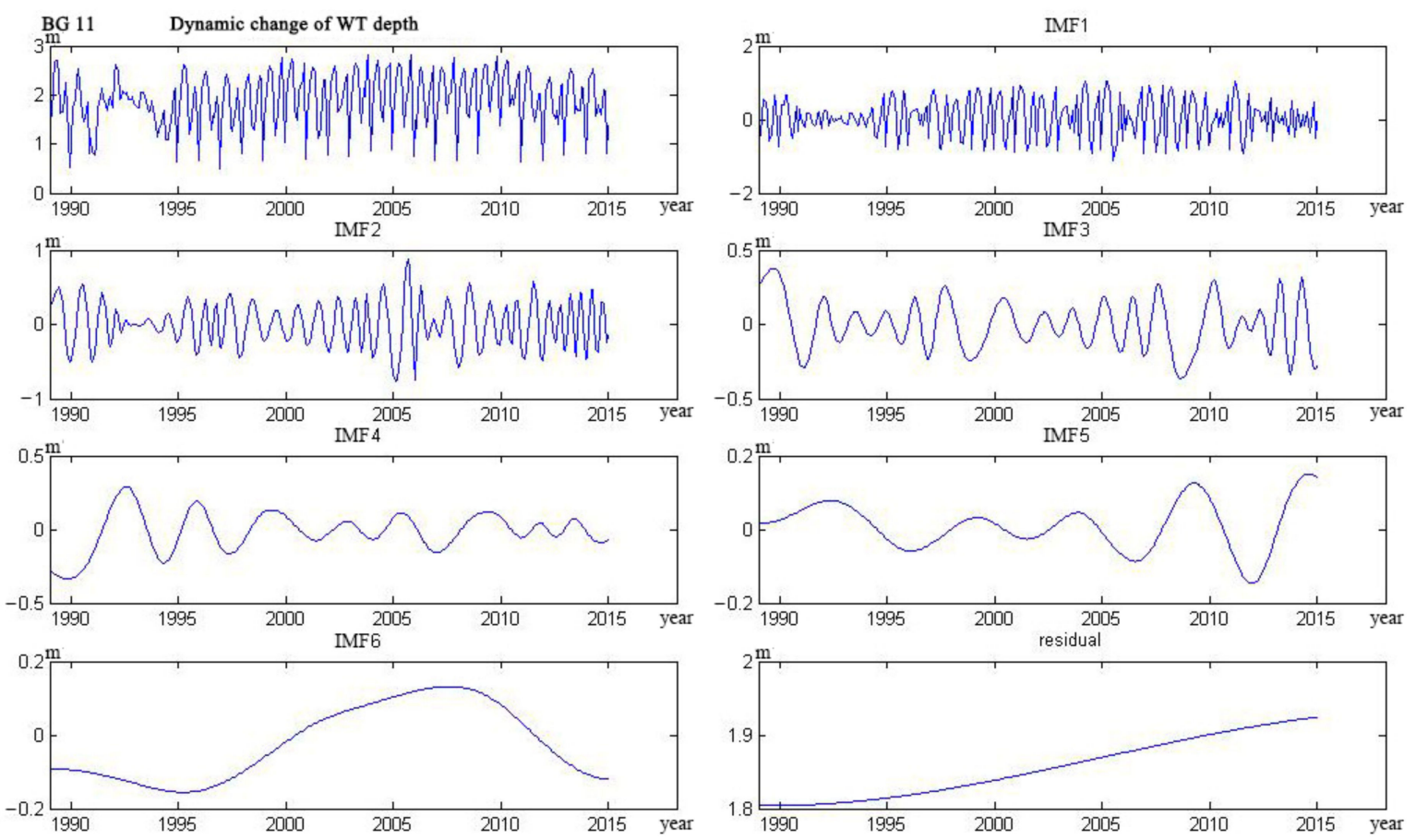

Figure A8. Decomposition of groundwater time series data of well BG11. 

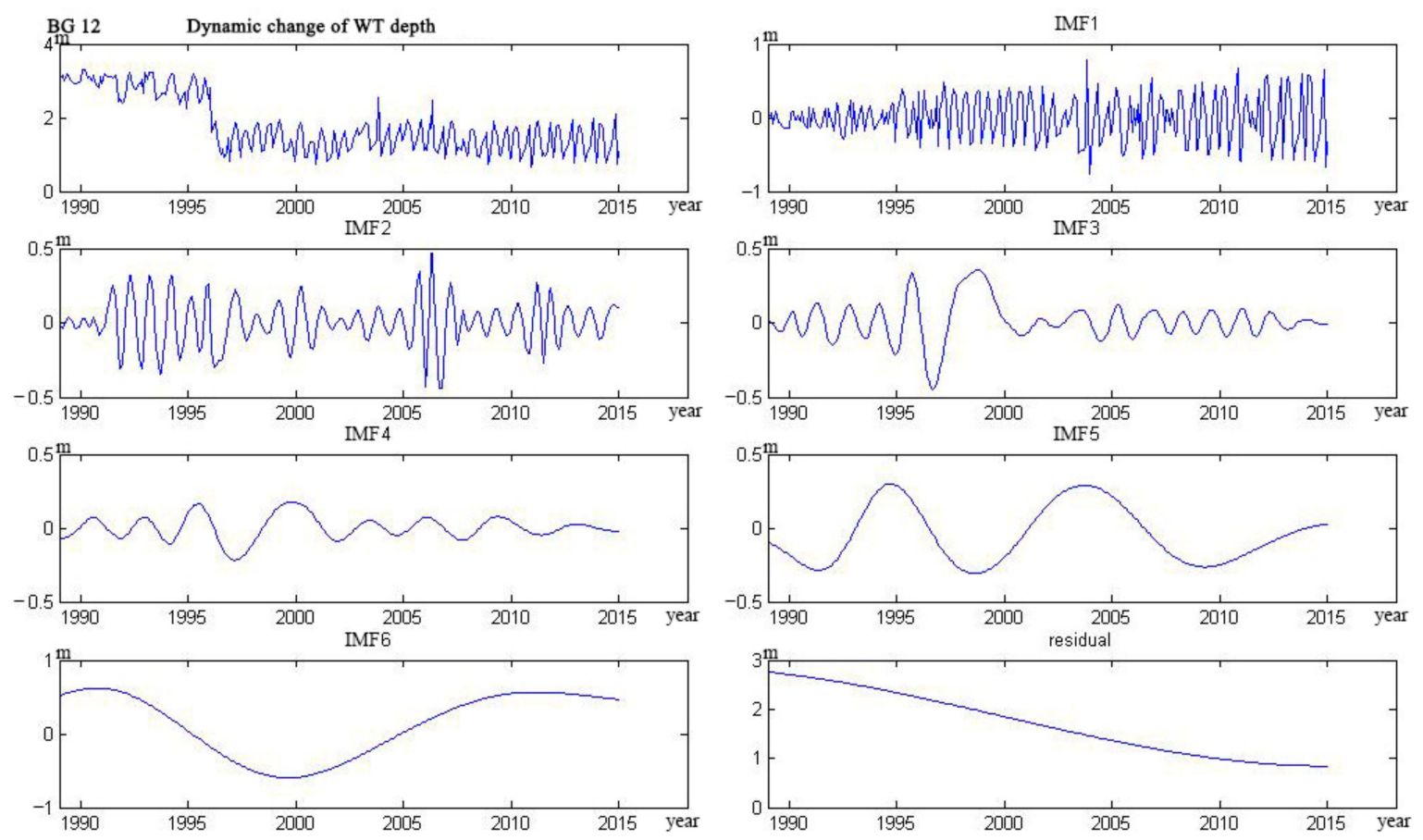

Figure A9. Decomposition of groundwater time series data of well BG12.
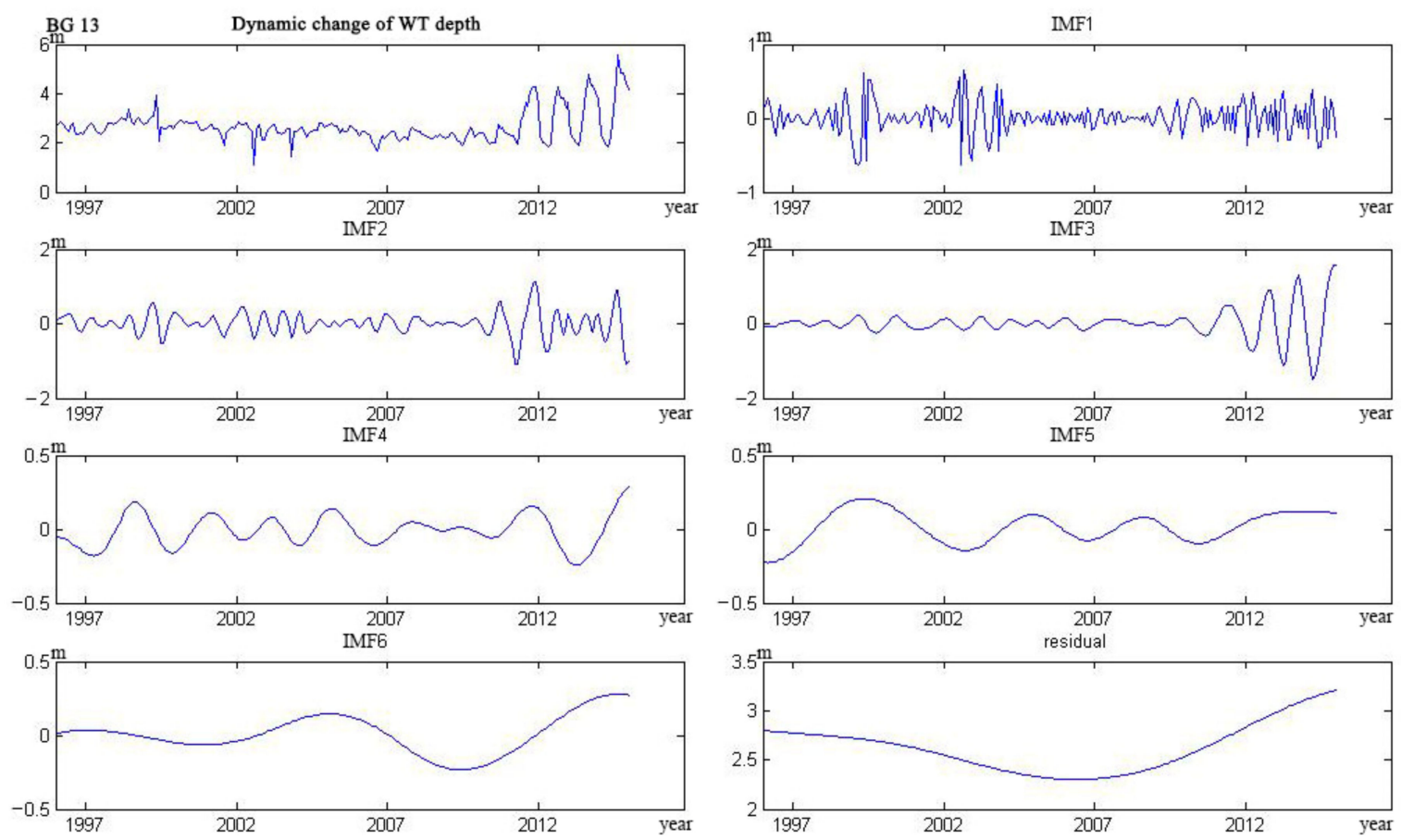

Figure A10. Decomposition of groundwater time series data of well BG13. 

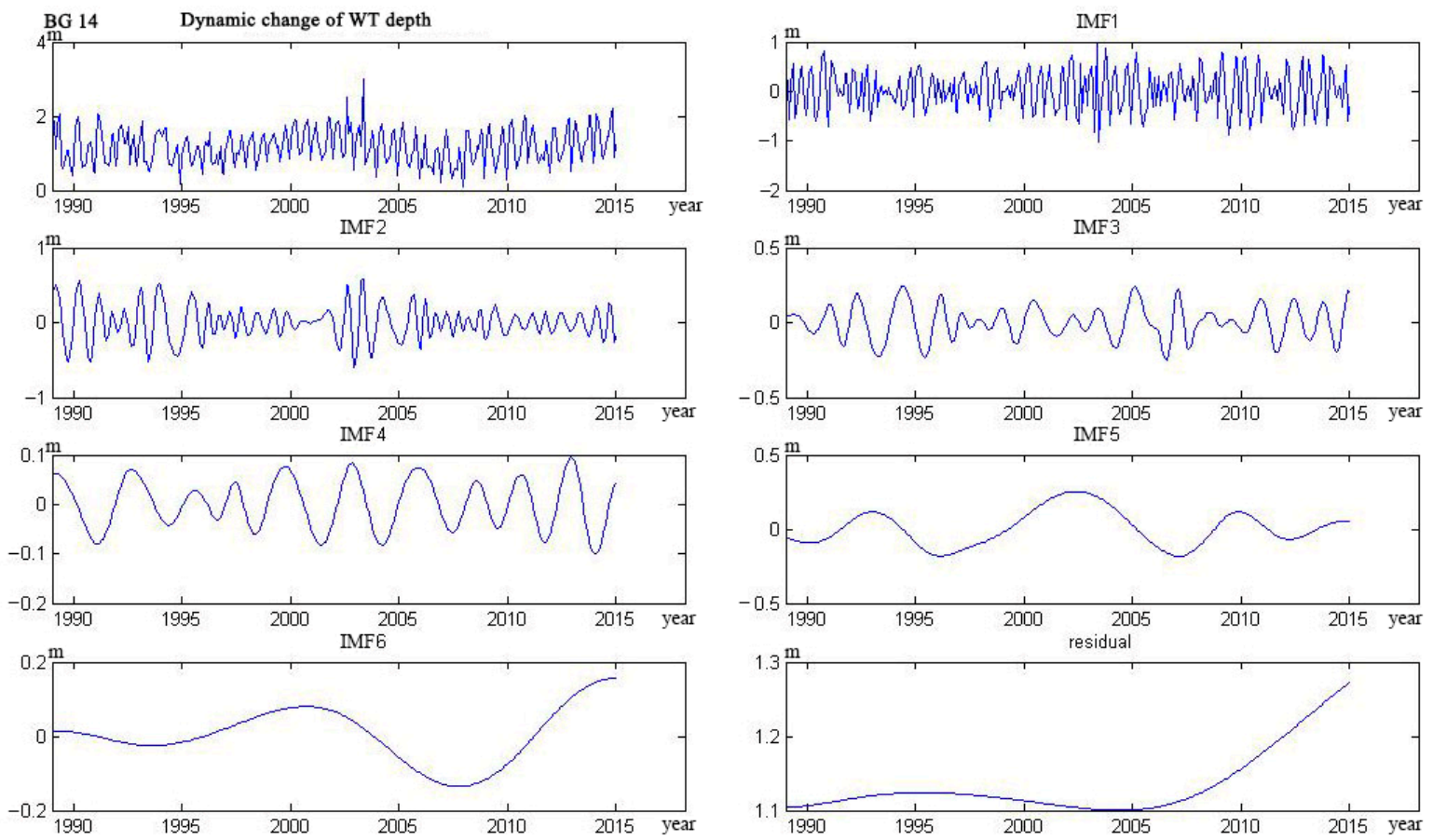

Figure A11. Decomposition of groundwater time series data of well BG14.
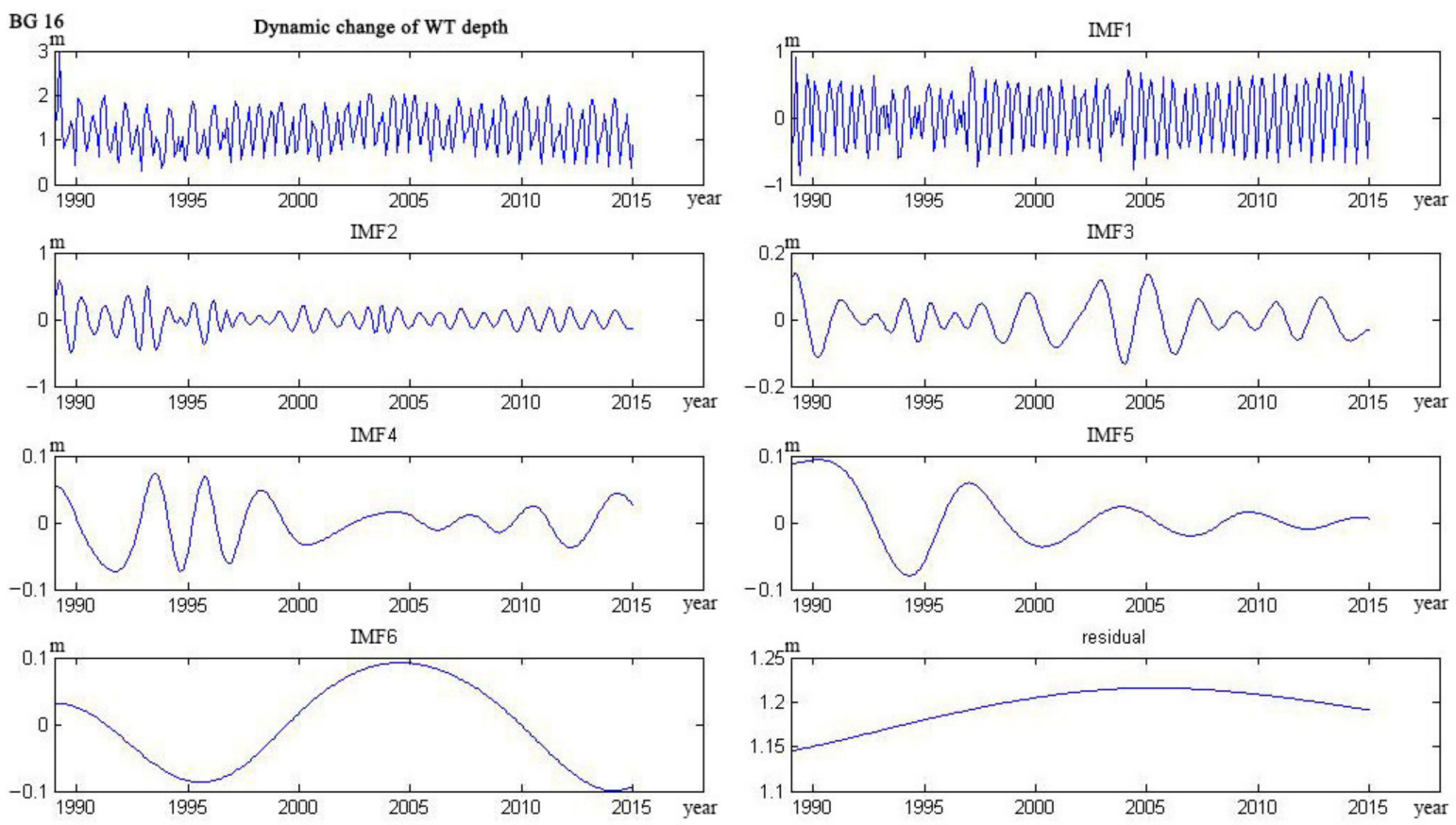

Figure A12. Decomposition of groundwater time series data of well BG16. 

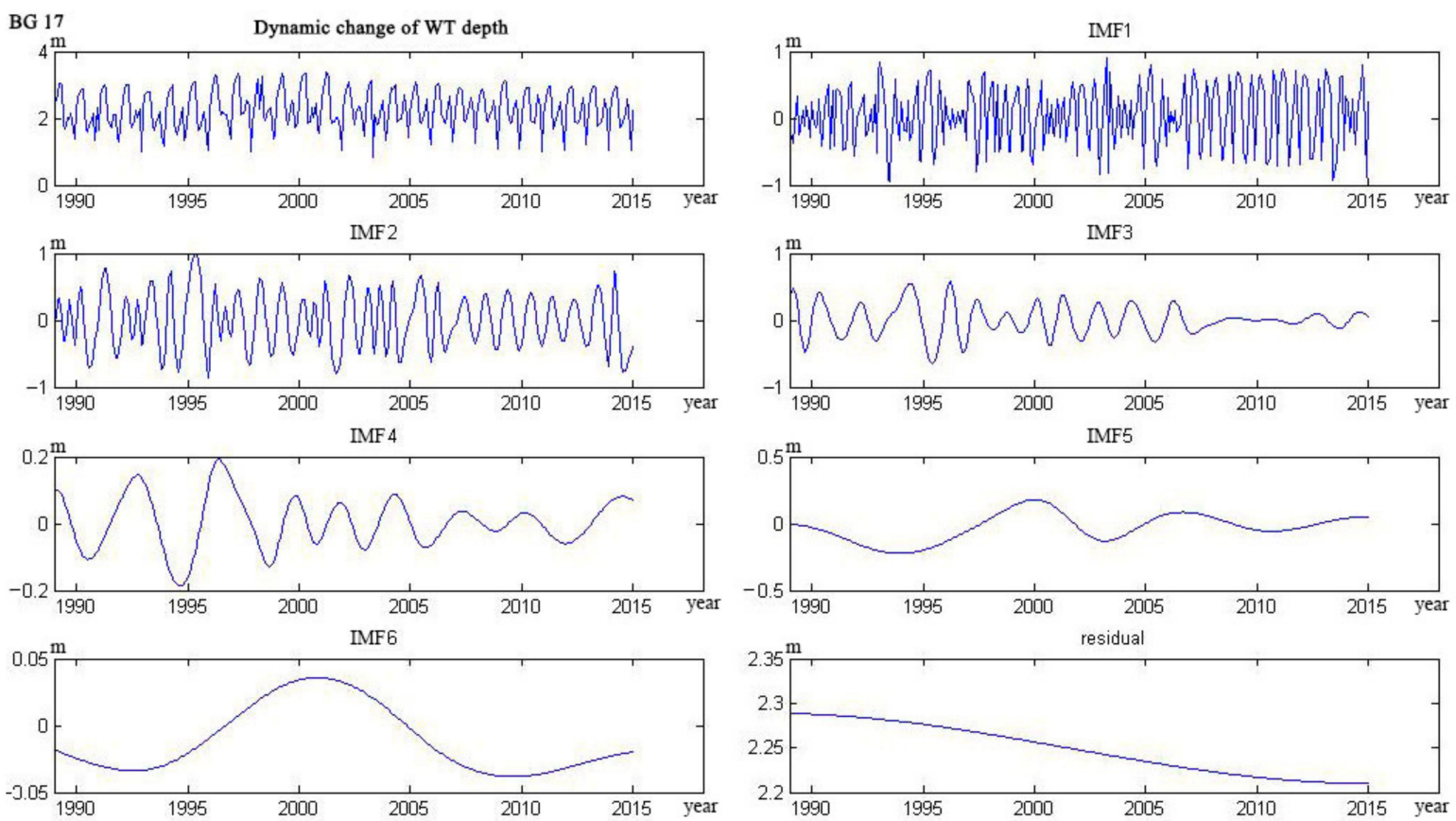

Figure A13. Decomposition of groundwater time series data of well BG17.
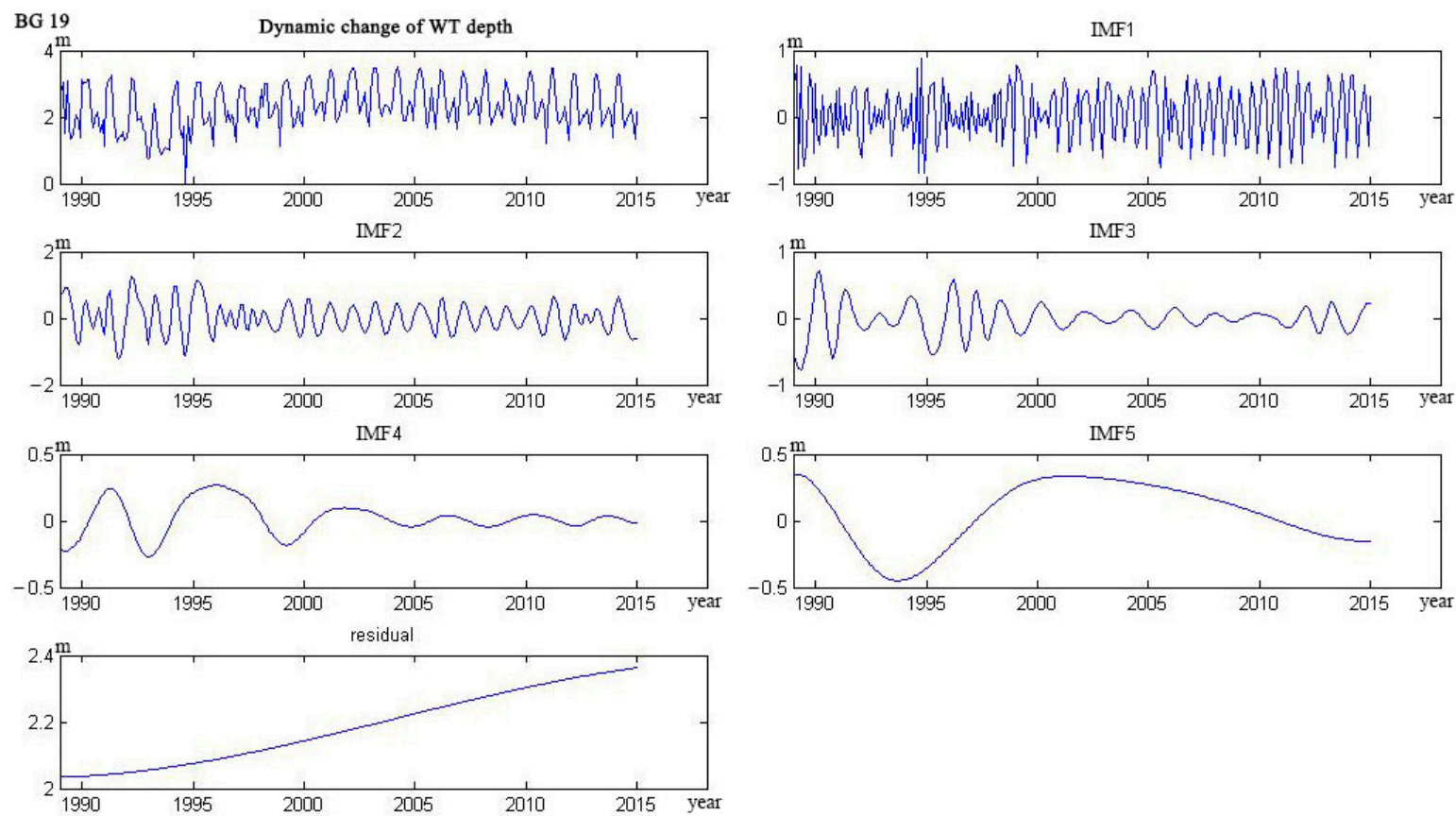

Figure A14. Decomposition of groundwater time series data of well BG19. 

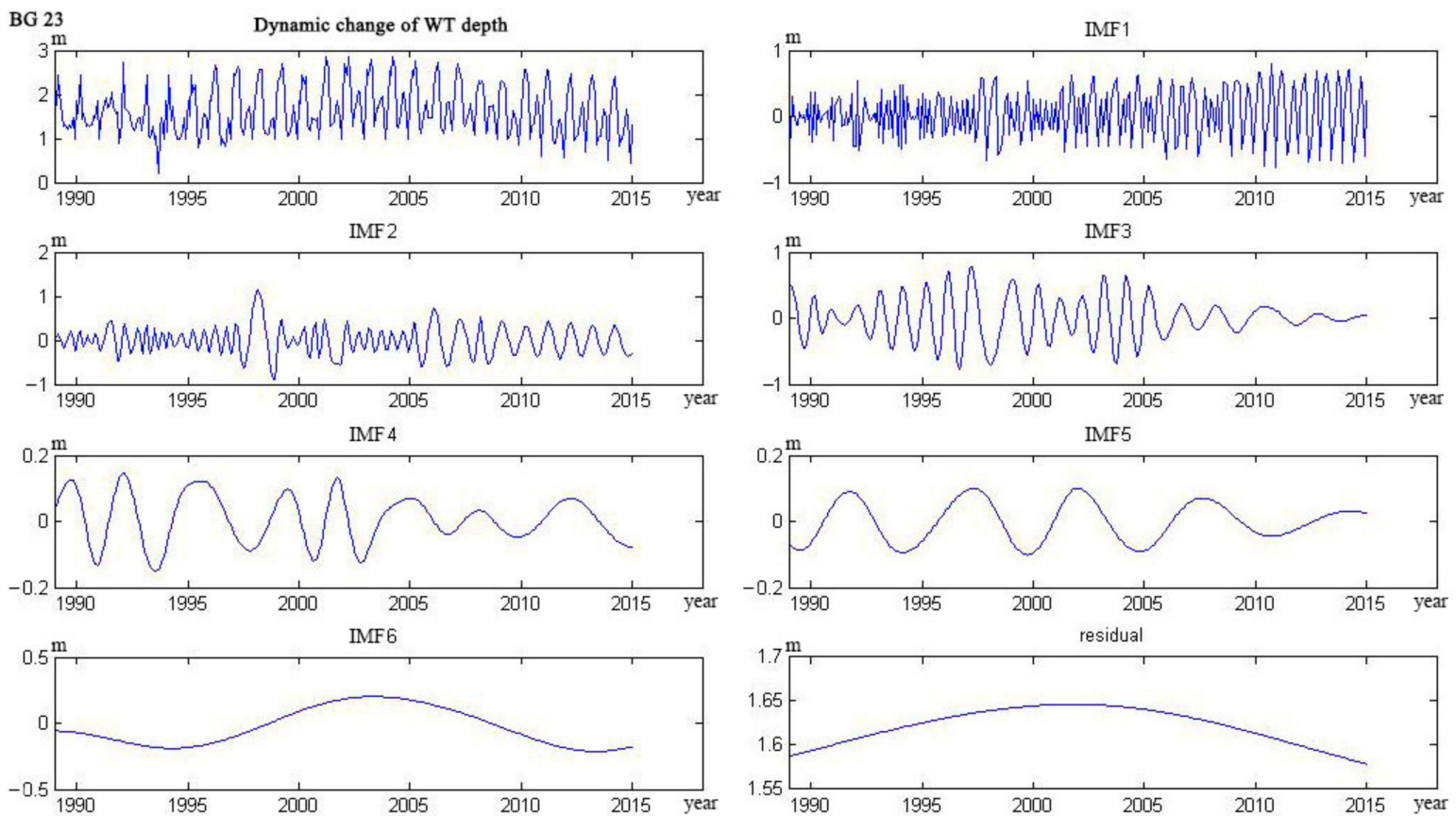

Figure A15. Decomposition of groundwater time series data of well BG23.
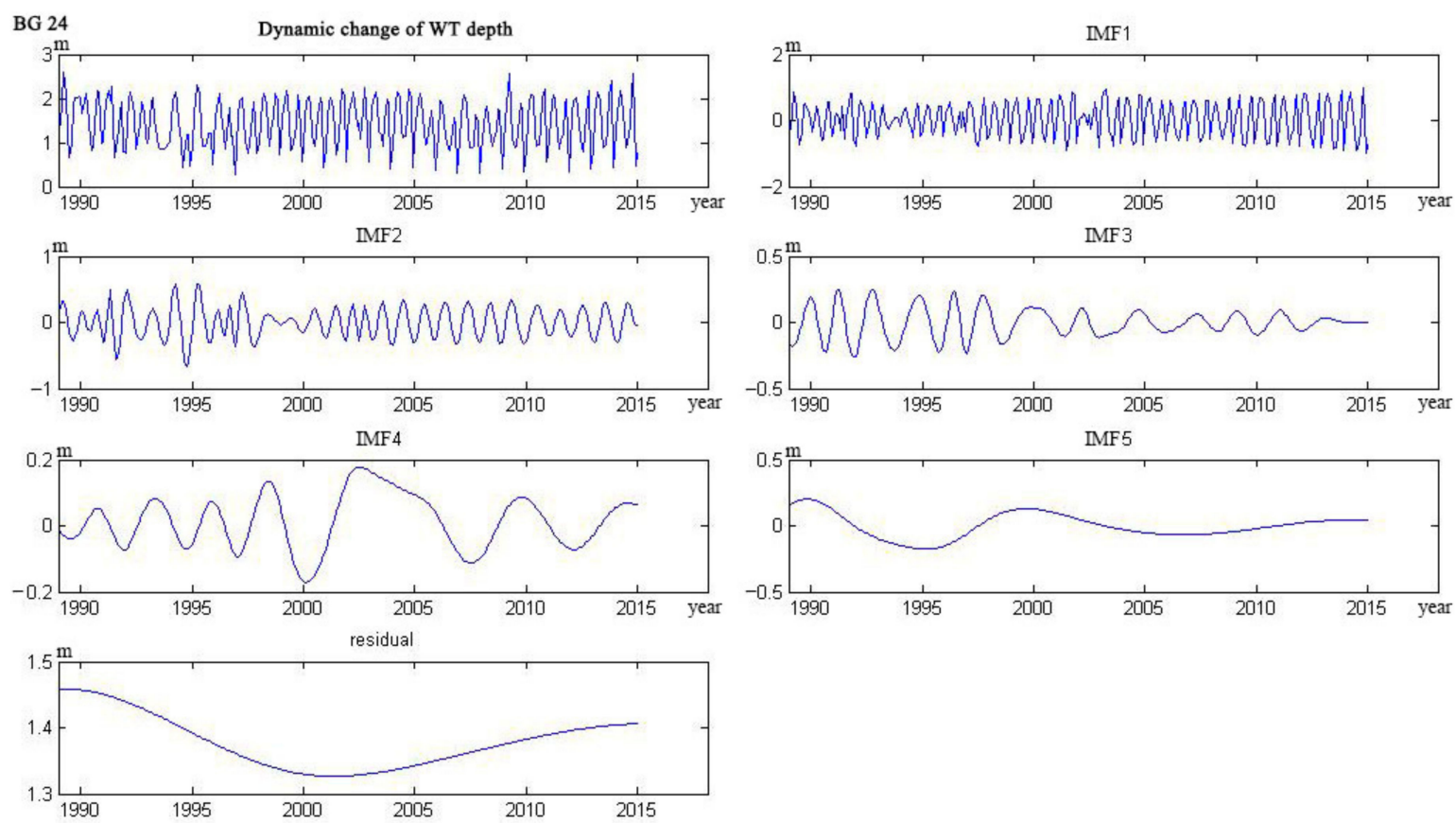

Figure A16. Decomposition of groundwater time series data of well BG24. 

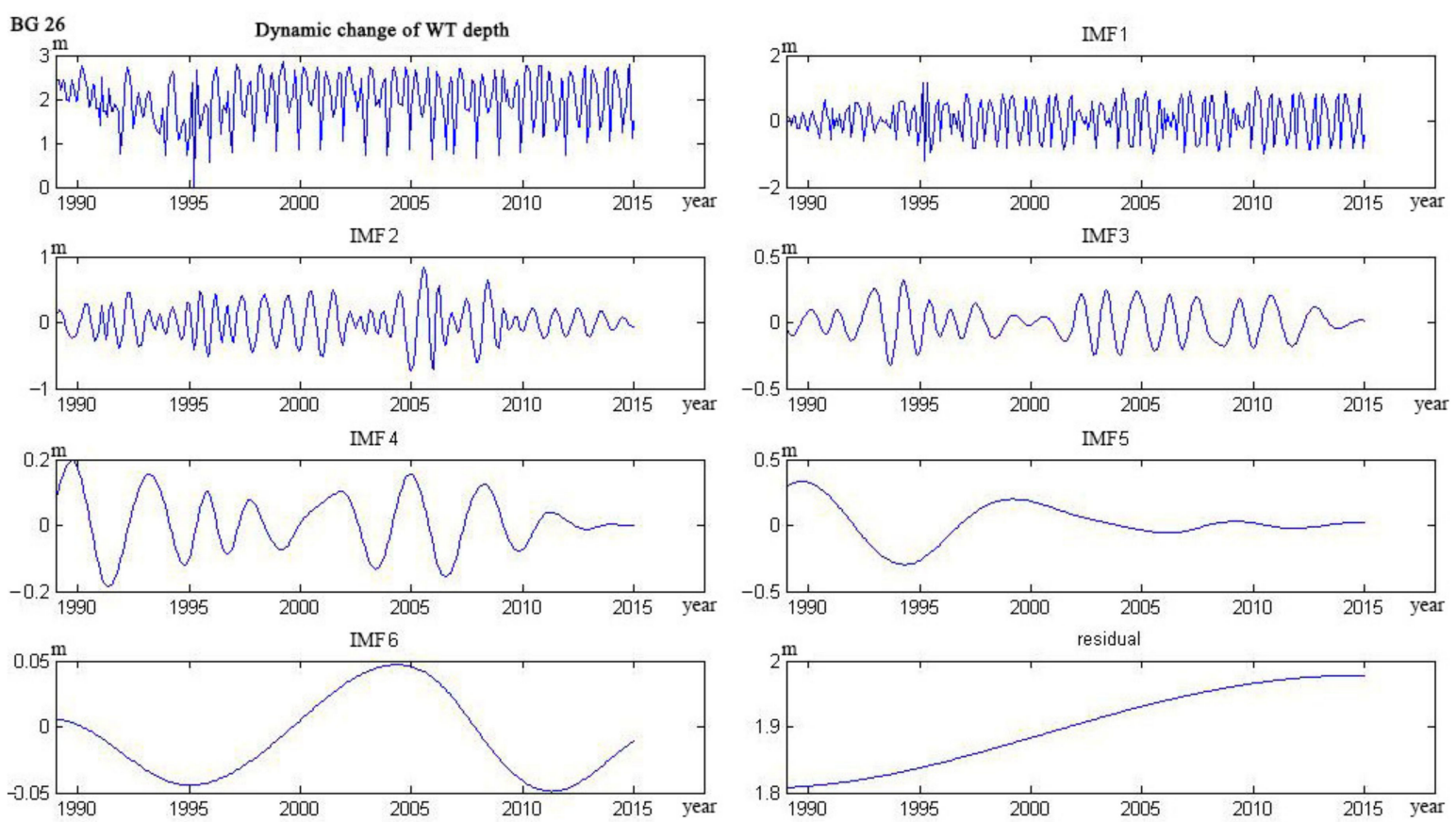

Figure A17. Decomposition of groundwater time series data of well BG26.

\section{Appendix C}

The interannual dynamics of precipitation from 1990 to 2016 are as follows. The abscissa represents the month, and the ordinate represents the precipitation.

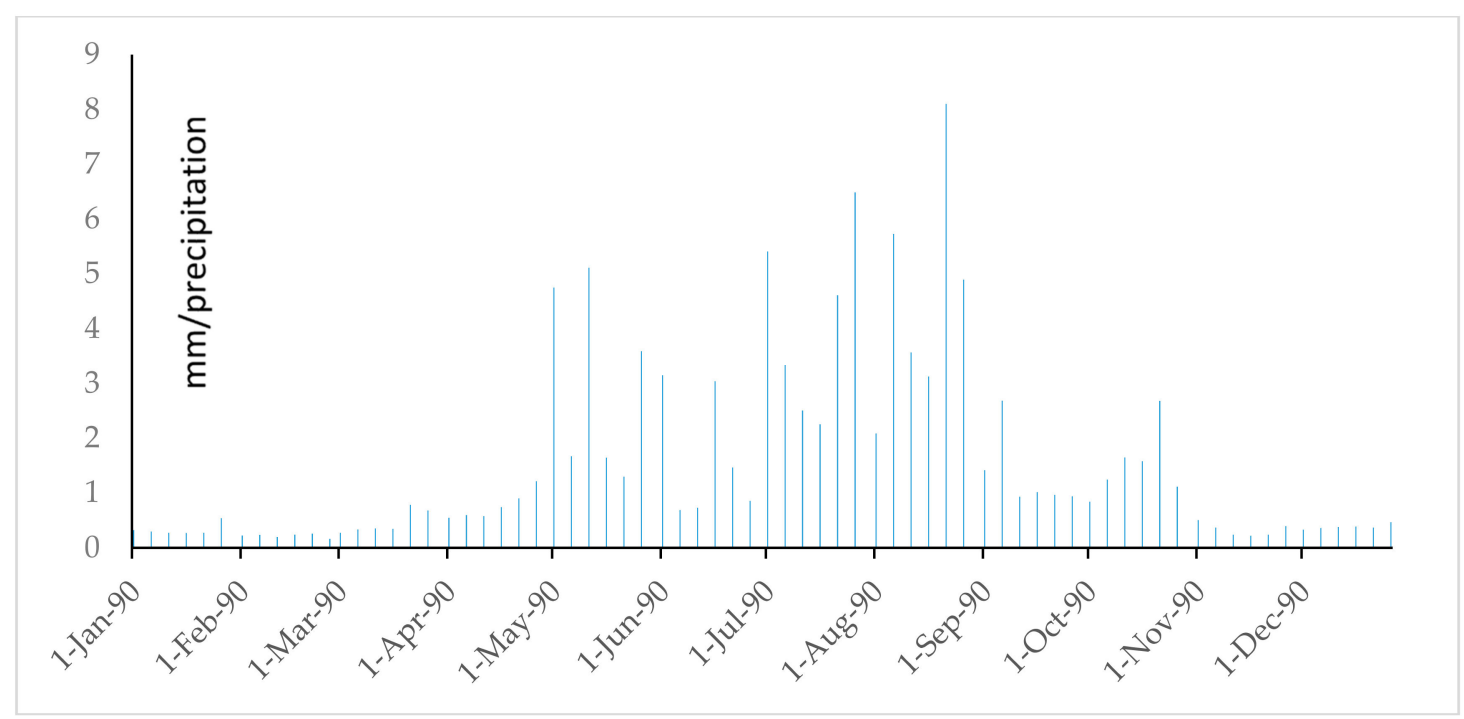

Figure A18. Precipitation of Denko County in 1990. 


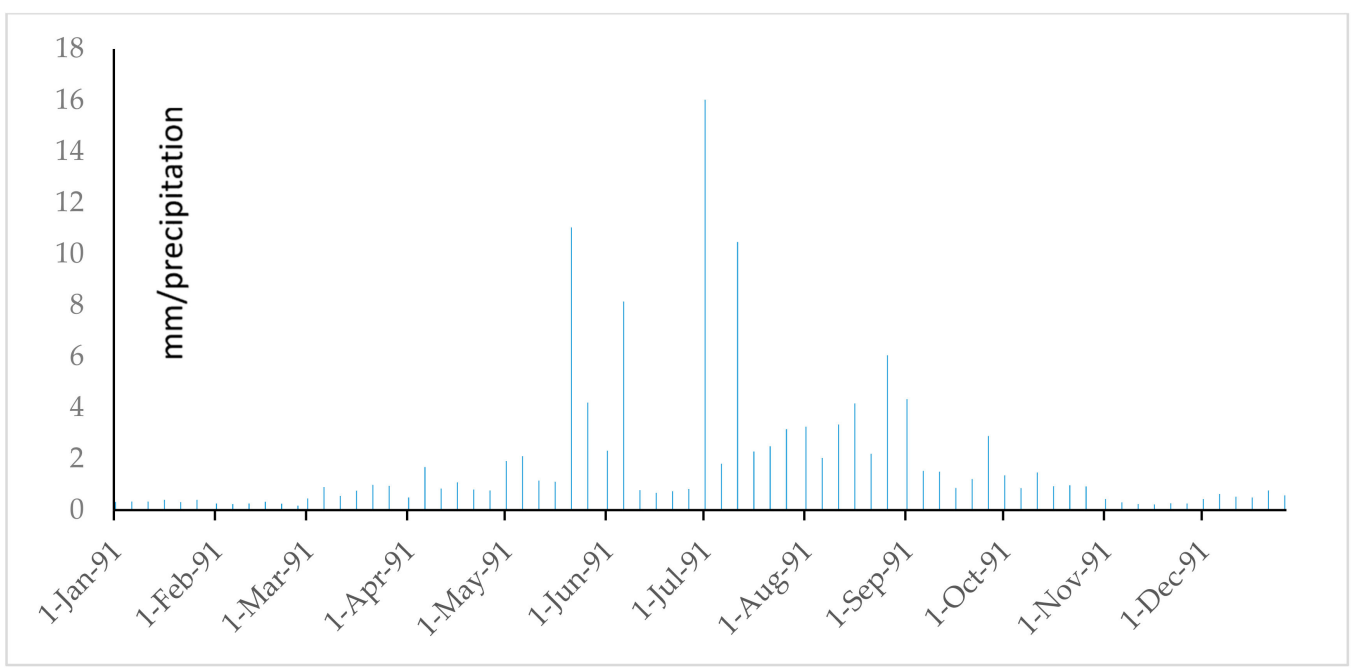

Figure A19. Precipitation of Denko County in 1991.

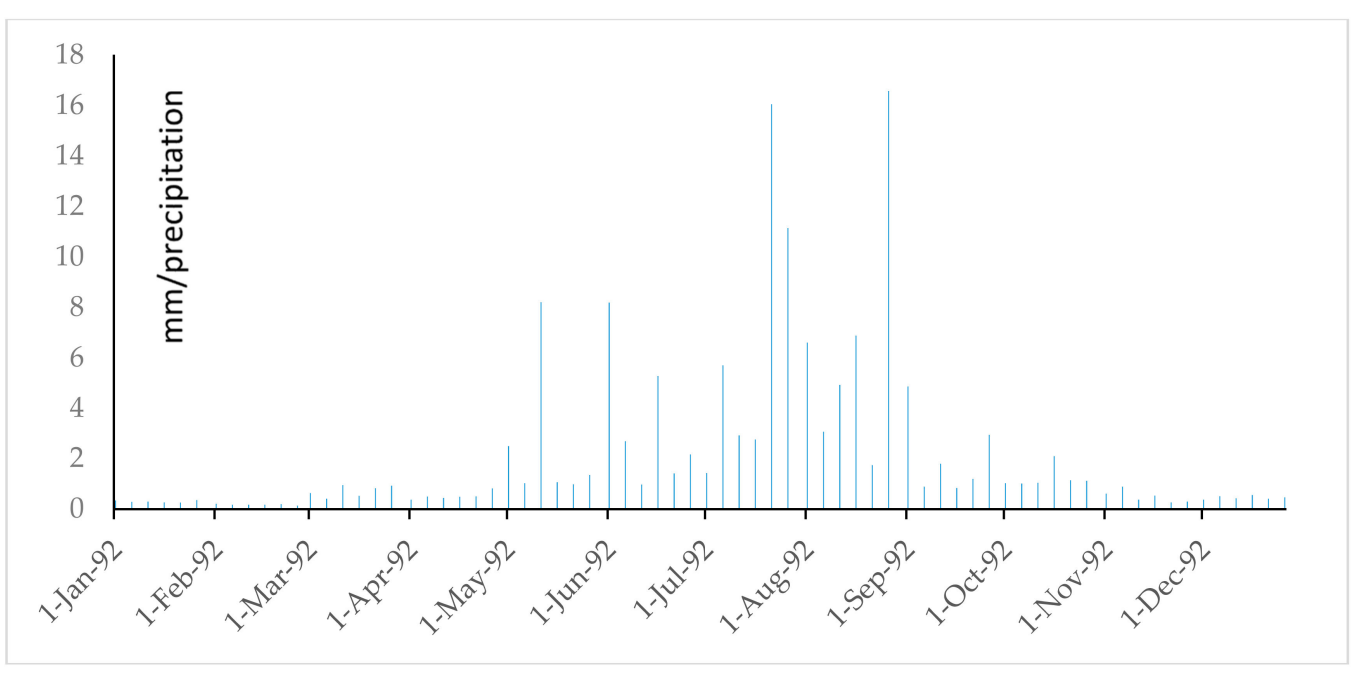

Figure A20. Precipitation of Denko County in 1992.

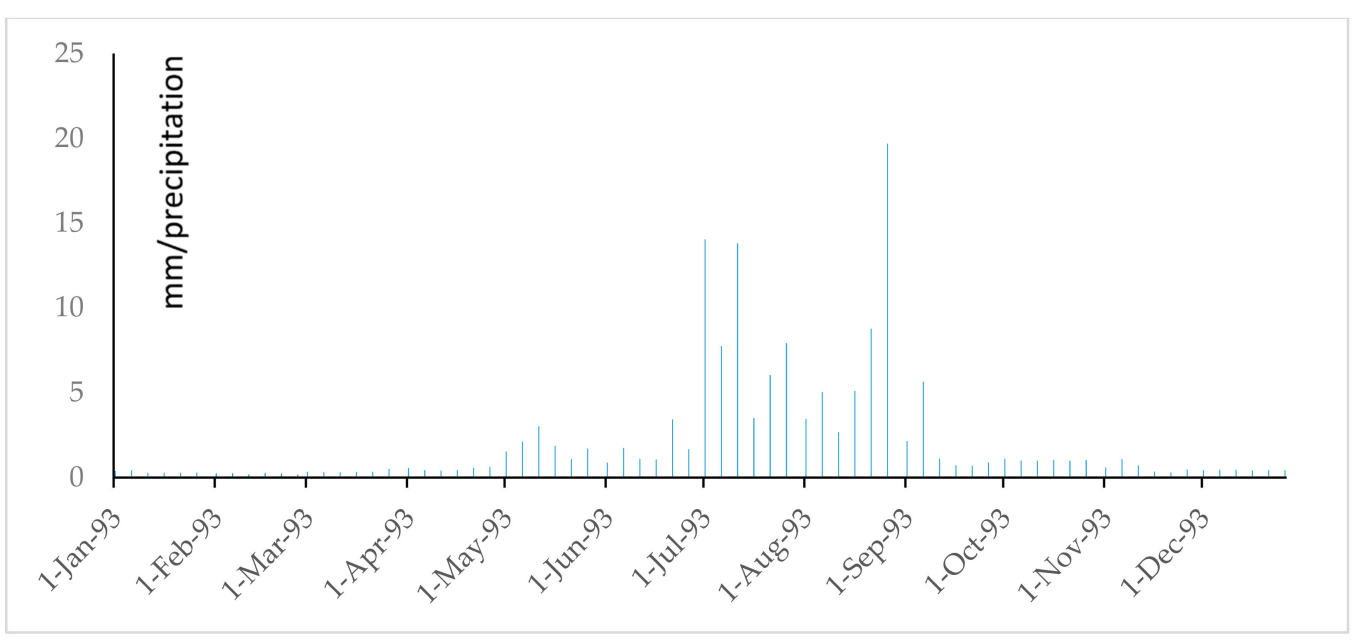

Figure A21. Precipitation of Denko County in 1993. 


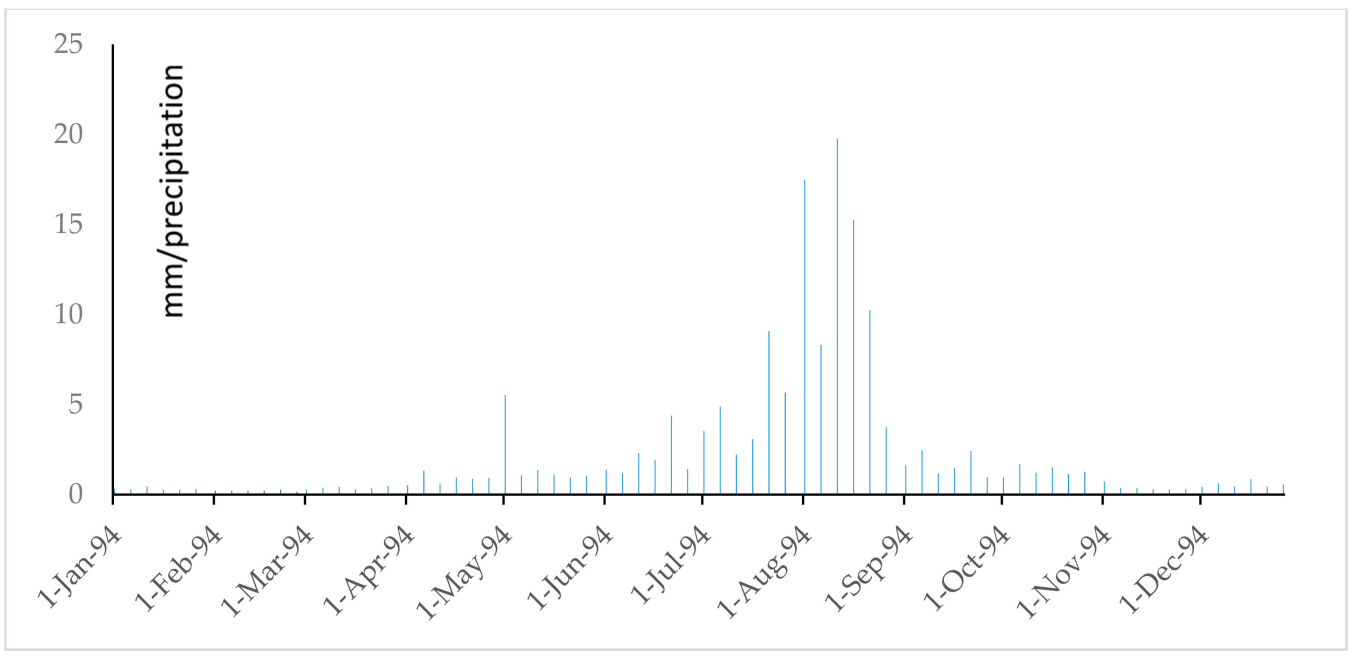

Figure A22. Precipitation of Denko County in 1994.

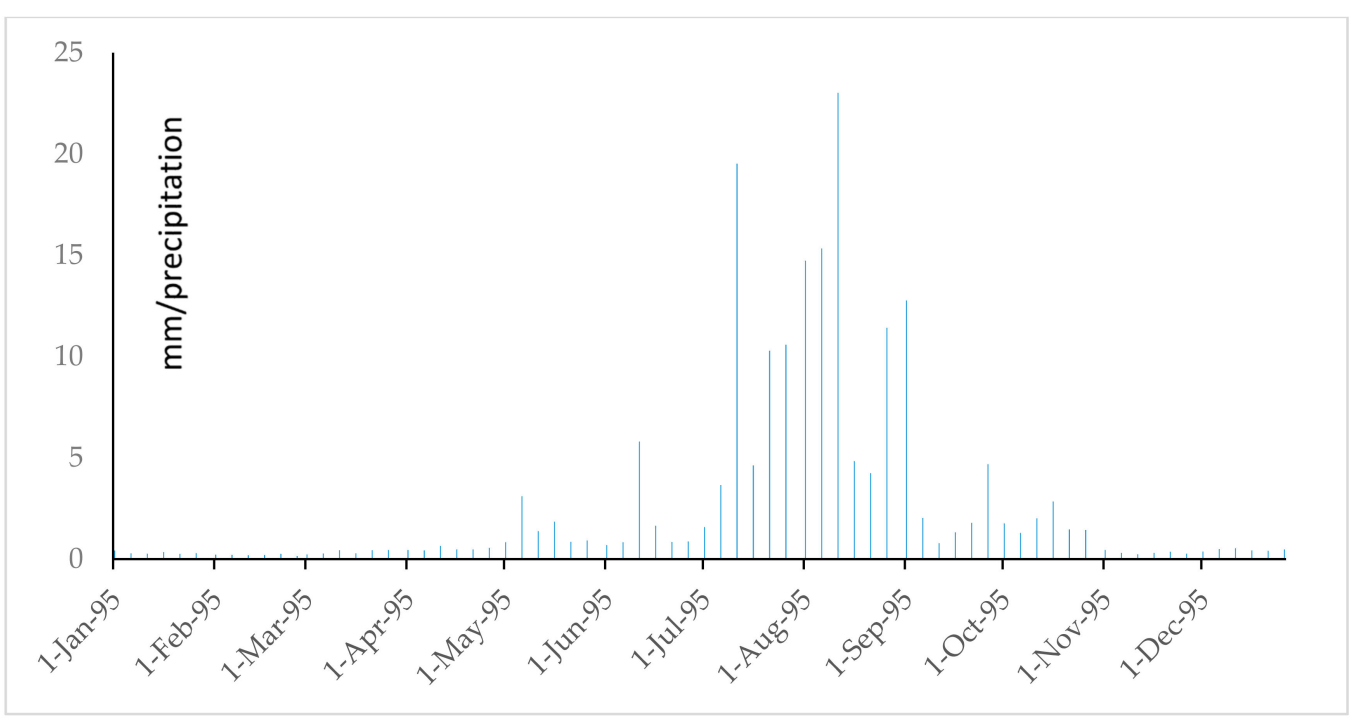

Figure A23. Precipitation of Denko County in 1995.

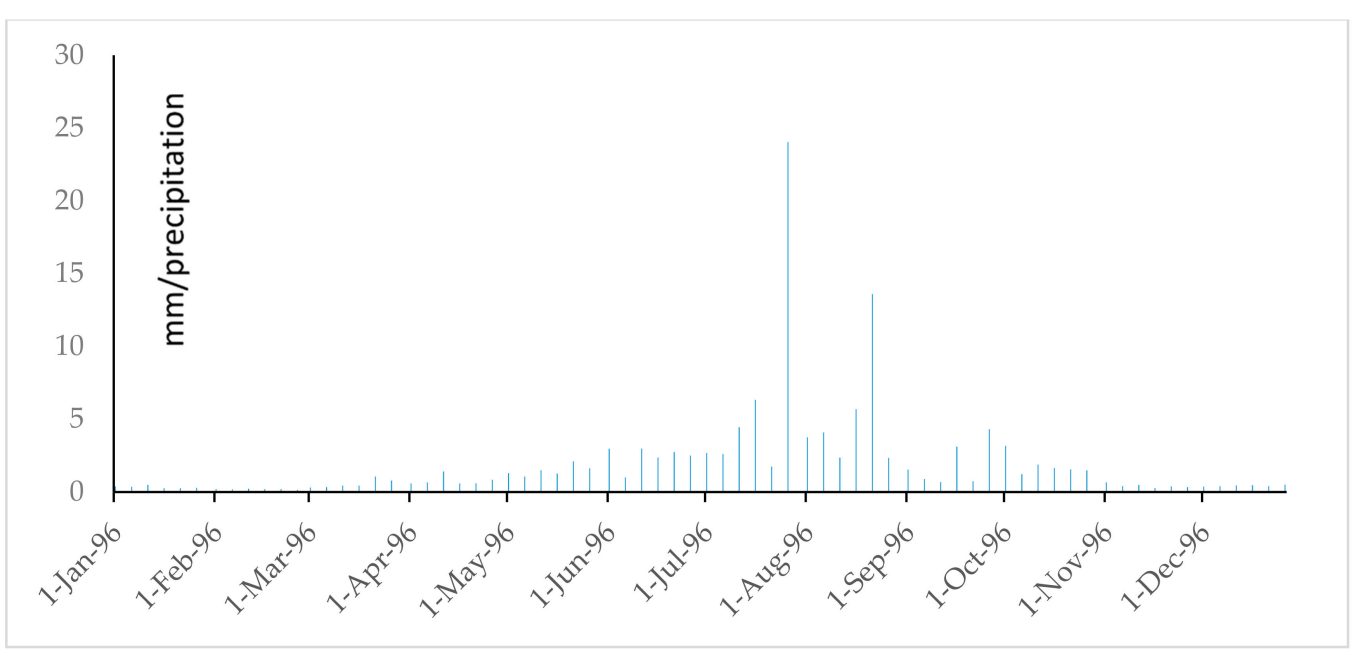

Figure A24. Precipitation of Denko County in 1996. 


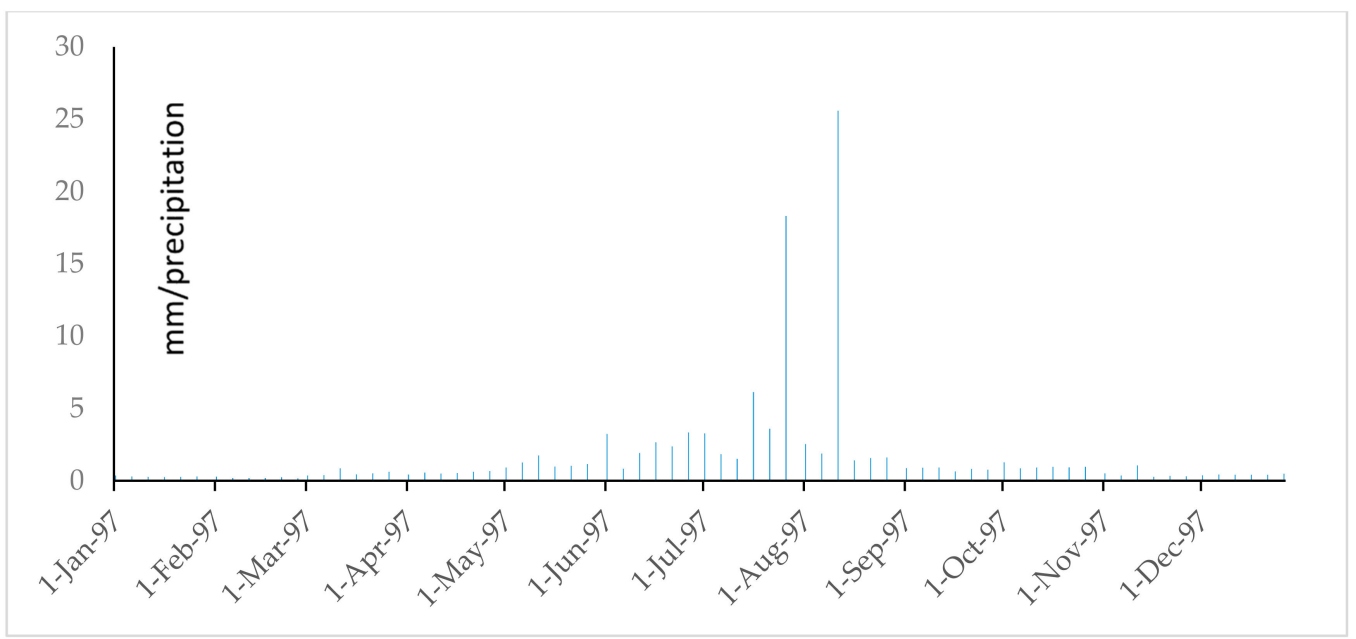

Figure A25. Precipitation of Denko County in 1997.

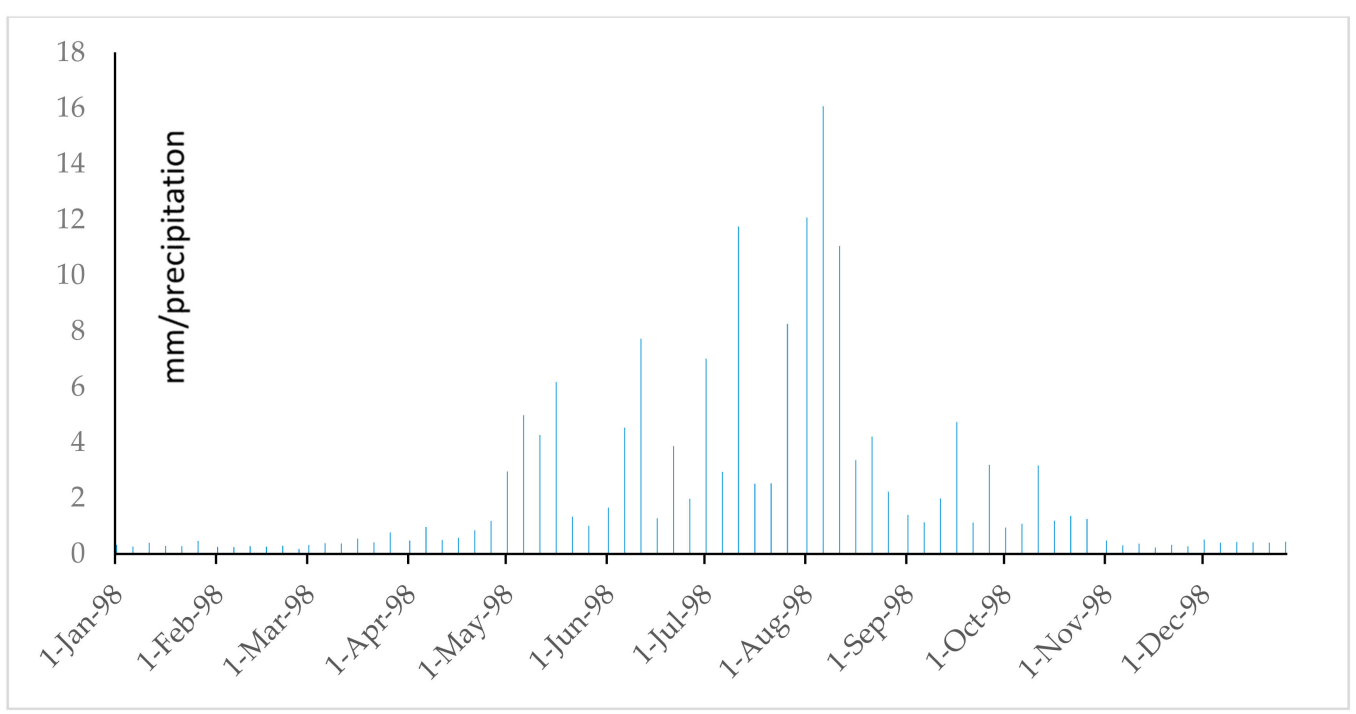

Figure A26. Precipitation of Denko County in 1998.

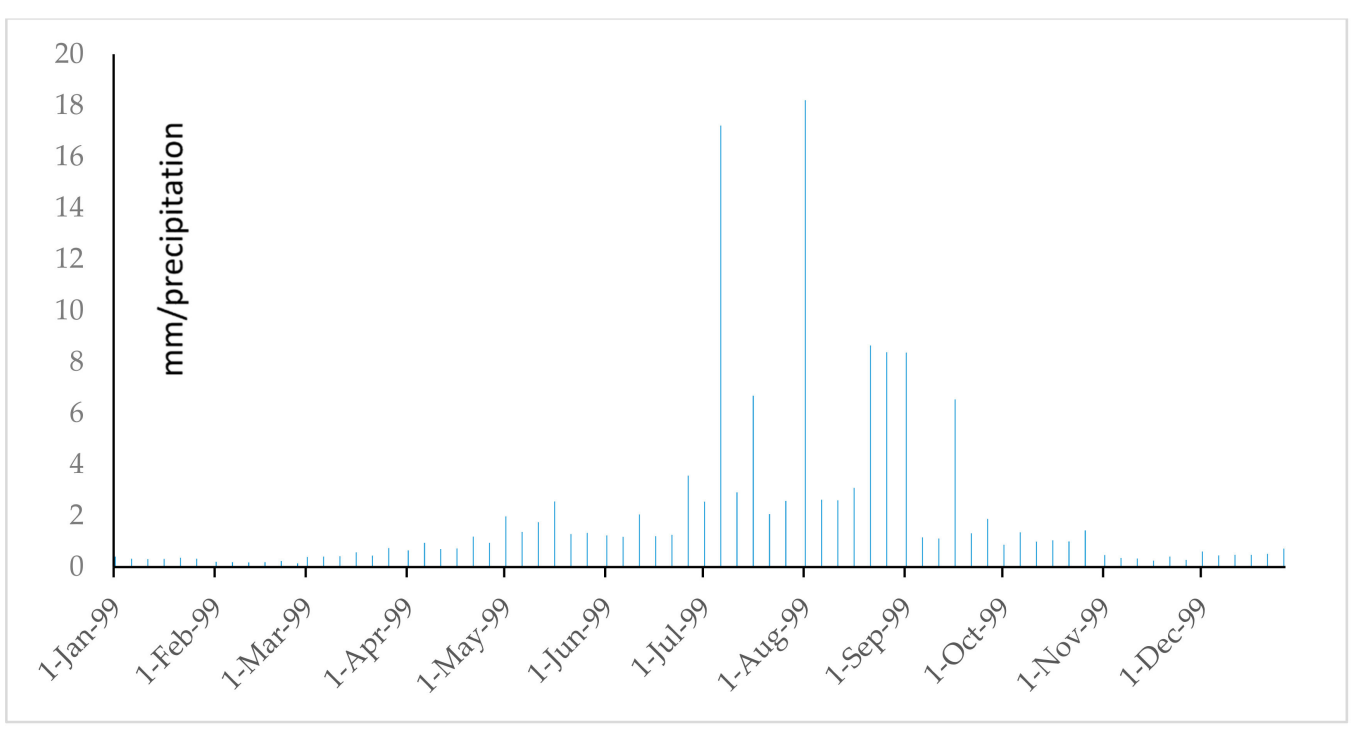

Figure A27. Precipitation of Denko County in 1999. 


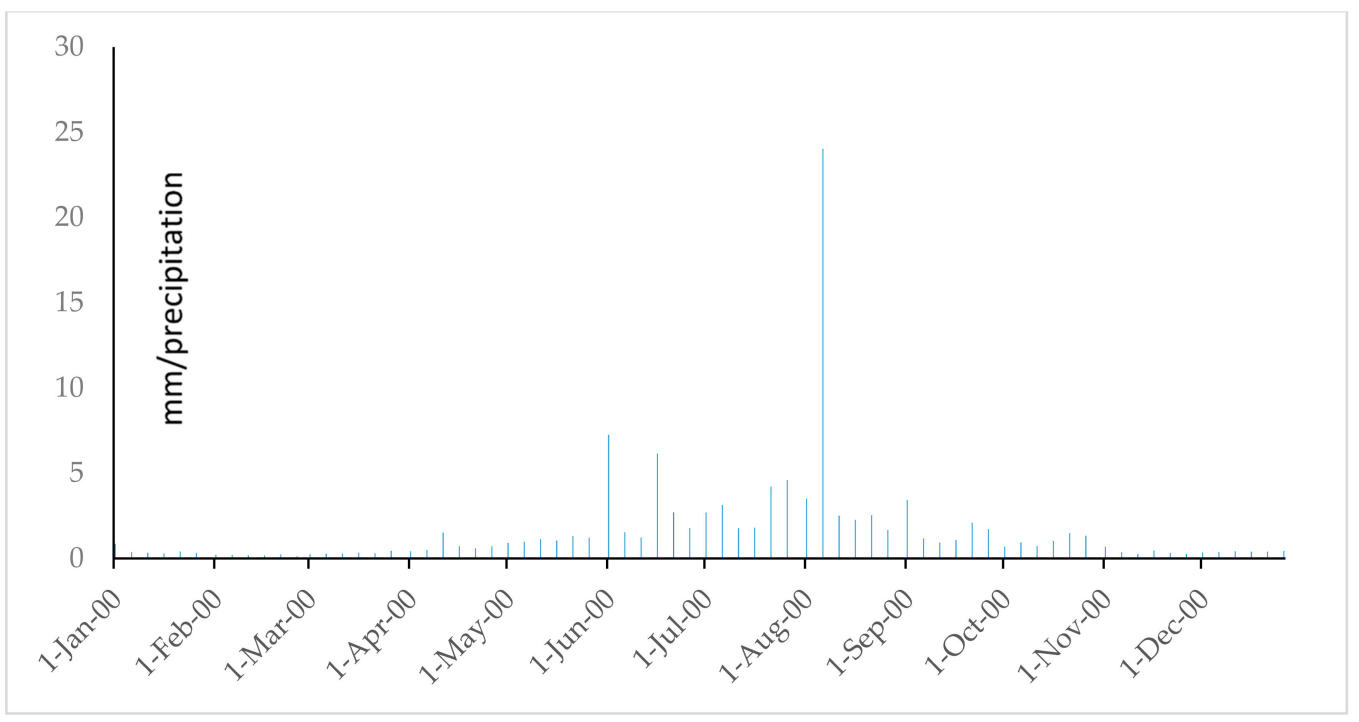

Figure A28. Precipitation of Denko County in 2000.

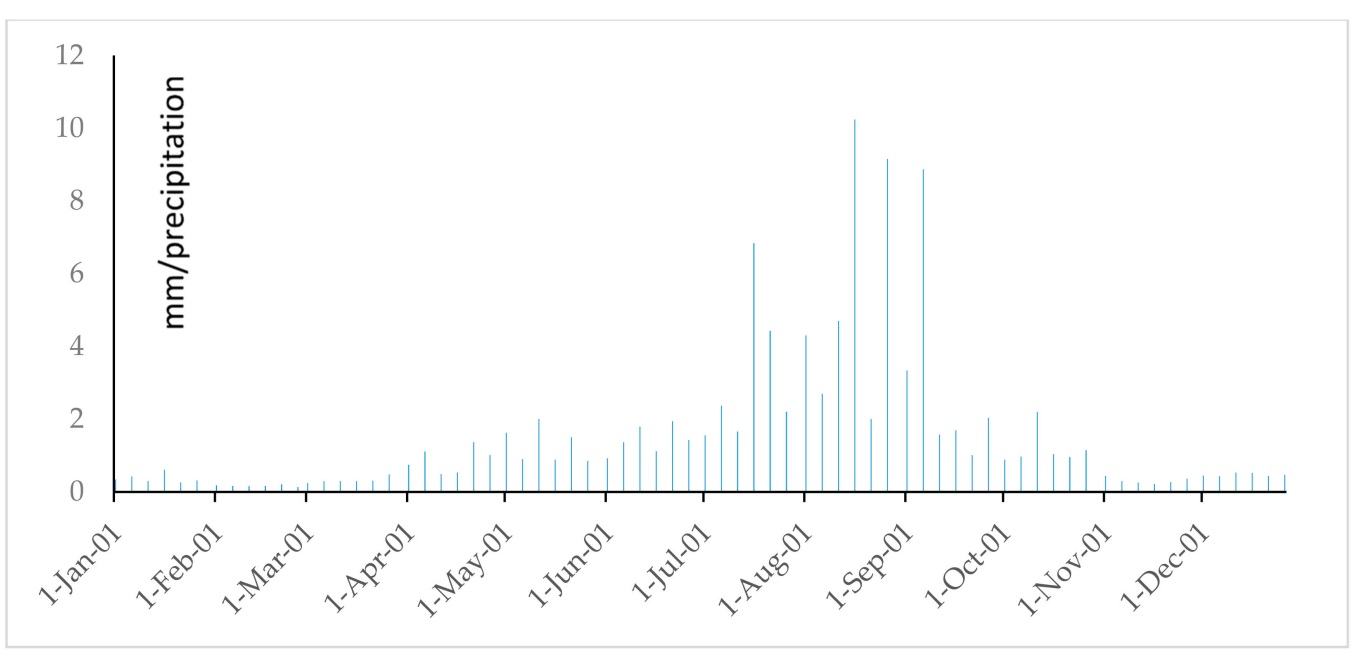

Figure A29. Precipitation of Denko County in 2001.

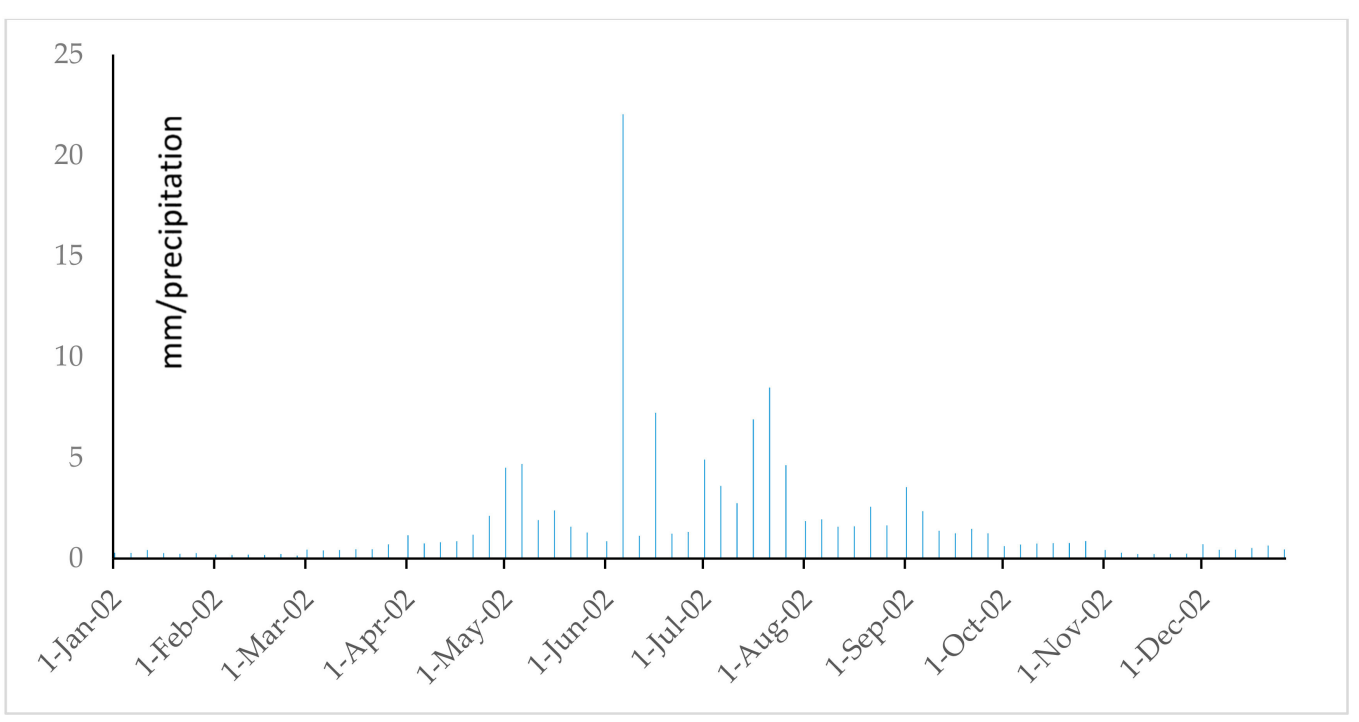

Figure A30. Precipitation of Denko County in 2002. 


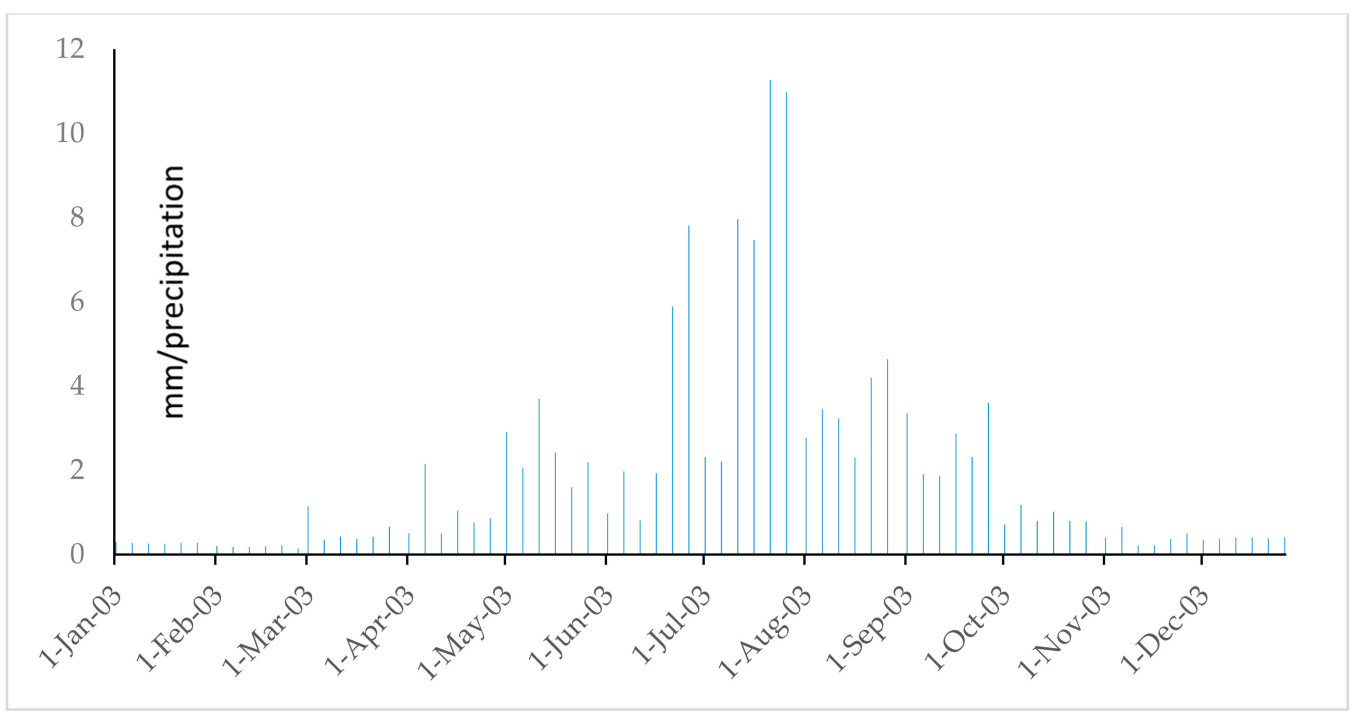

Figure A31. Precipitation of Denko County in 2003.

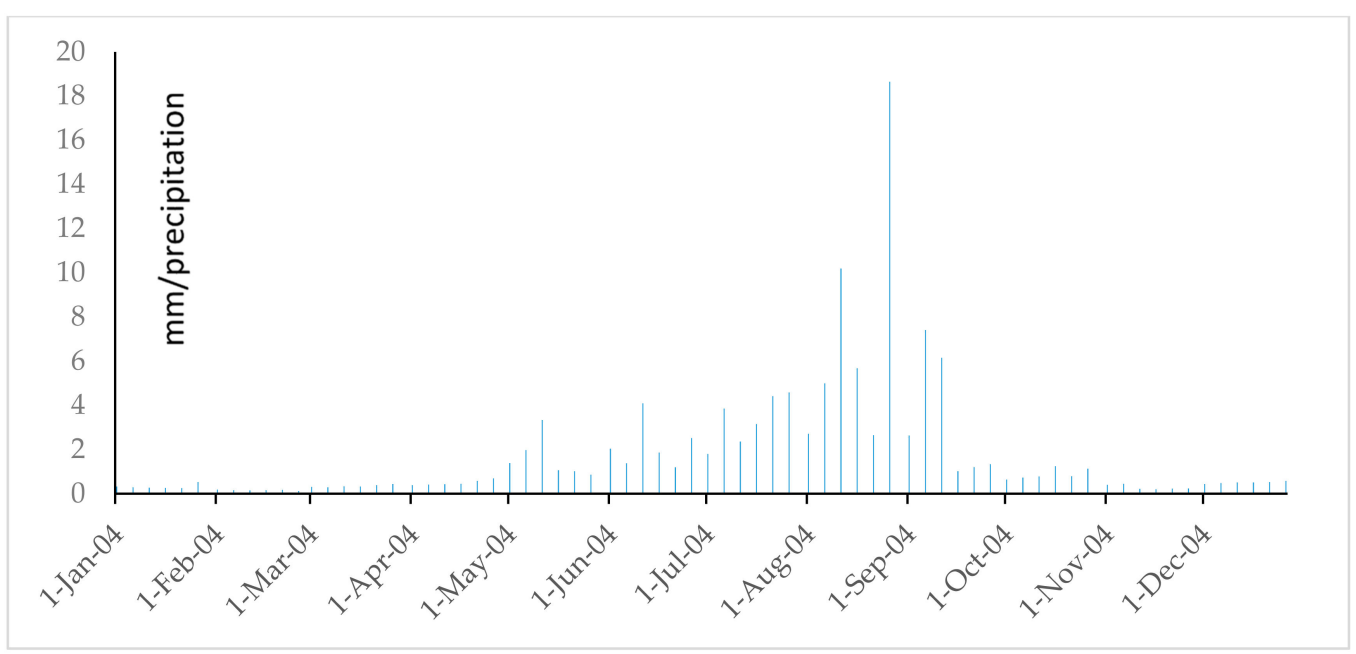

Figure A32. Precipitation of Denko County in 2004.

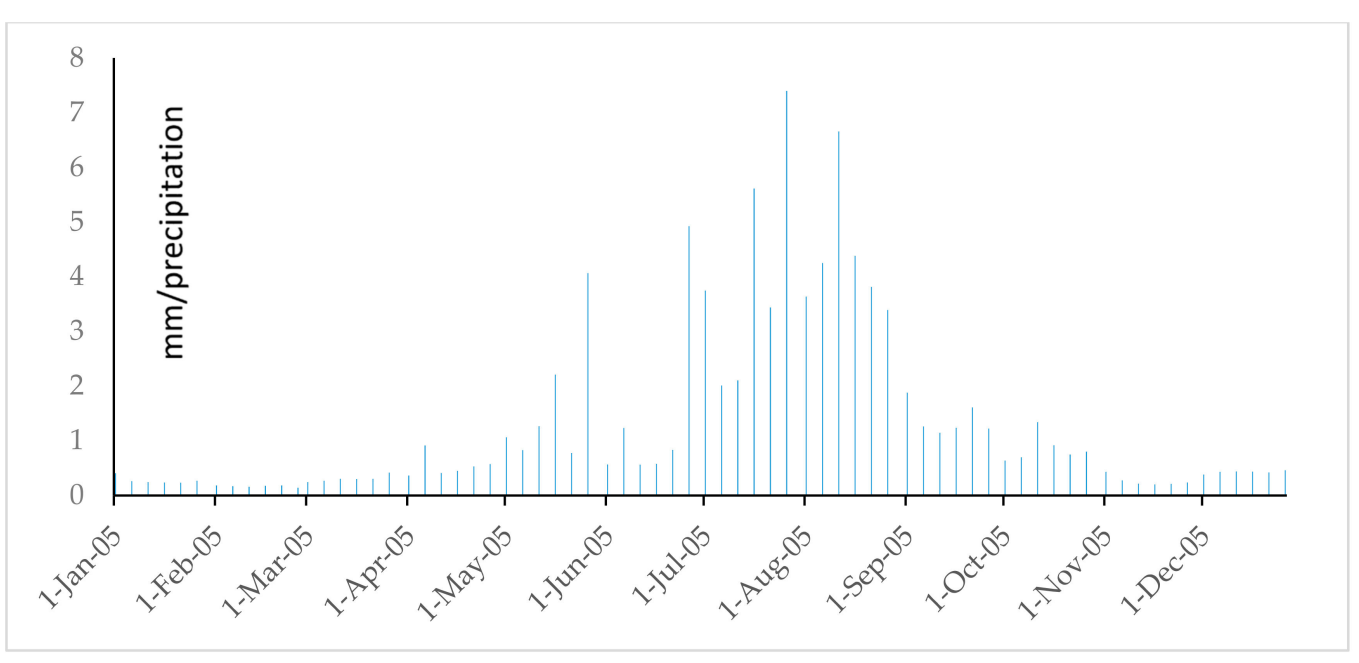

Figure A33. Precipitation of Denko County in 2005. 


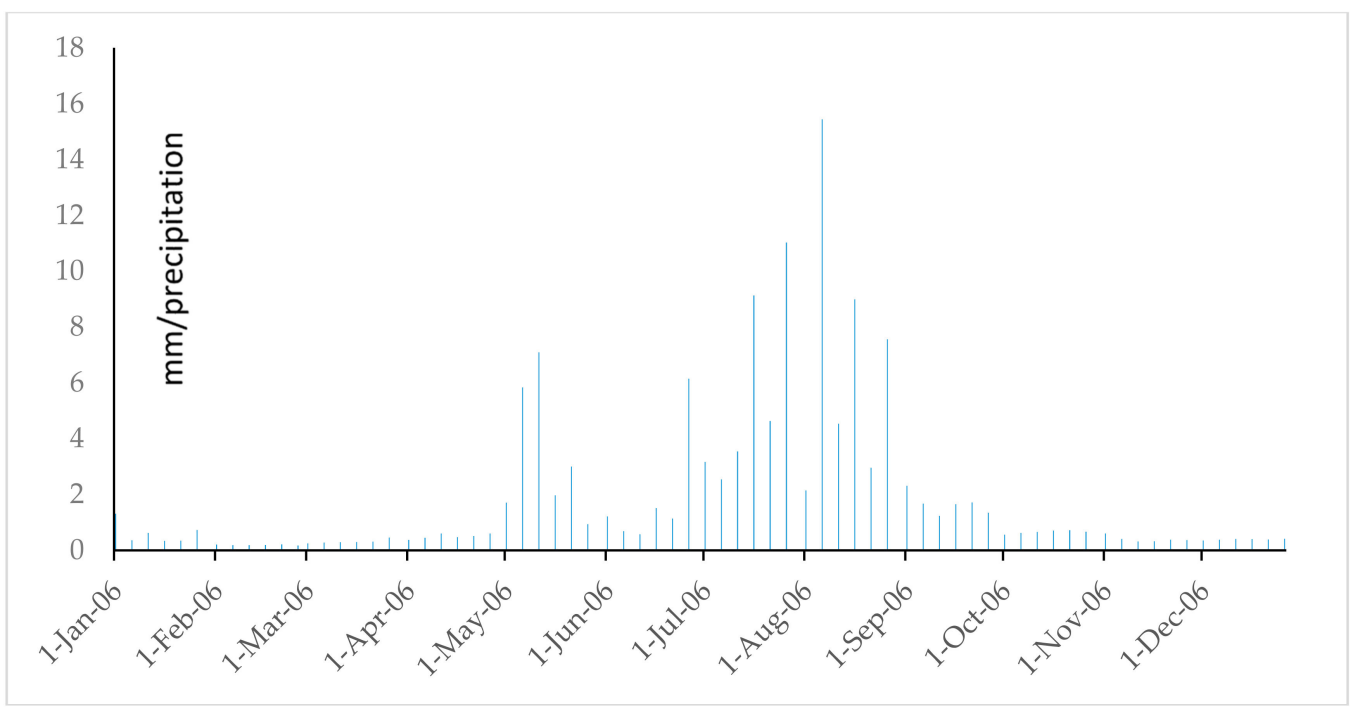

Figure A34. Precipitation of Denko County in 2006.

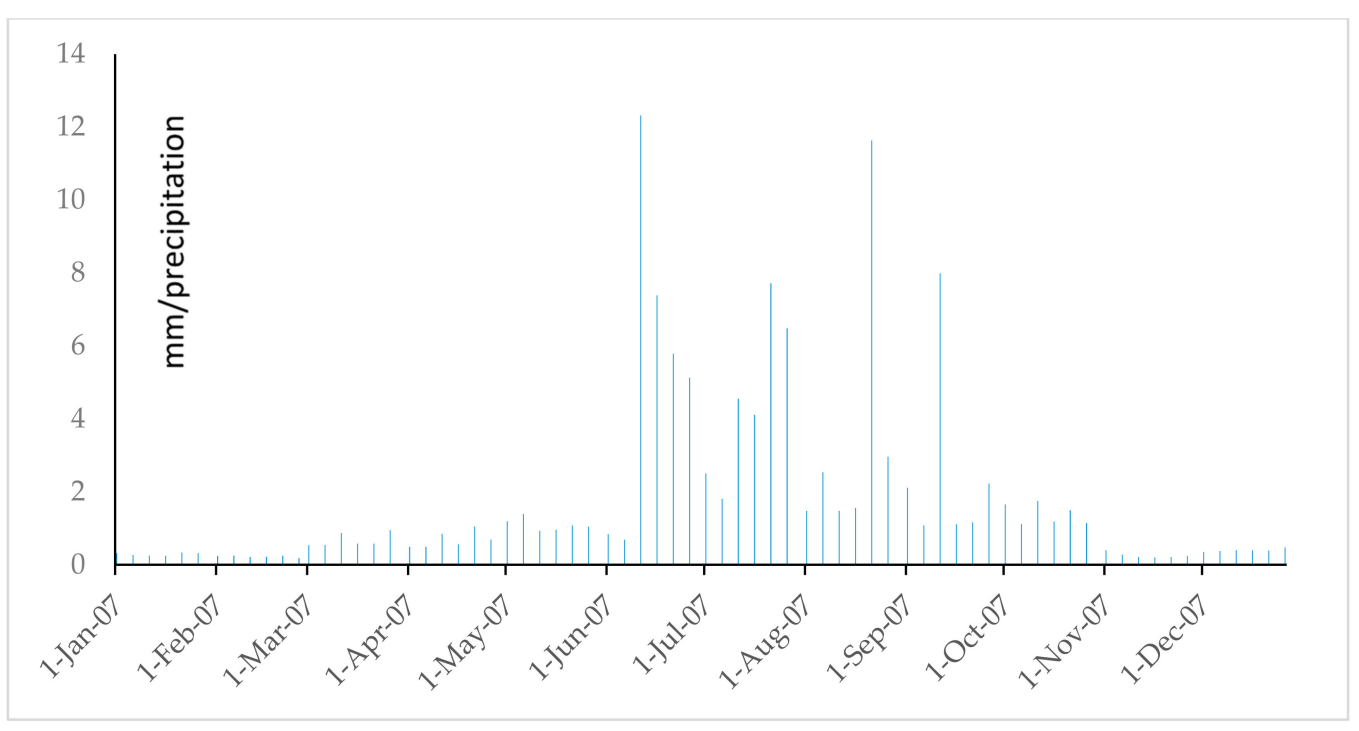

Figure A35. Precipitation of Denko County in 2007.

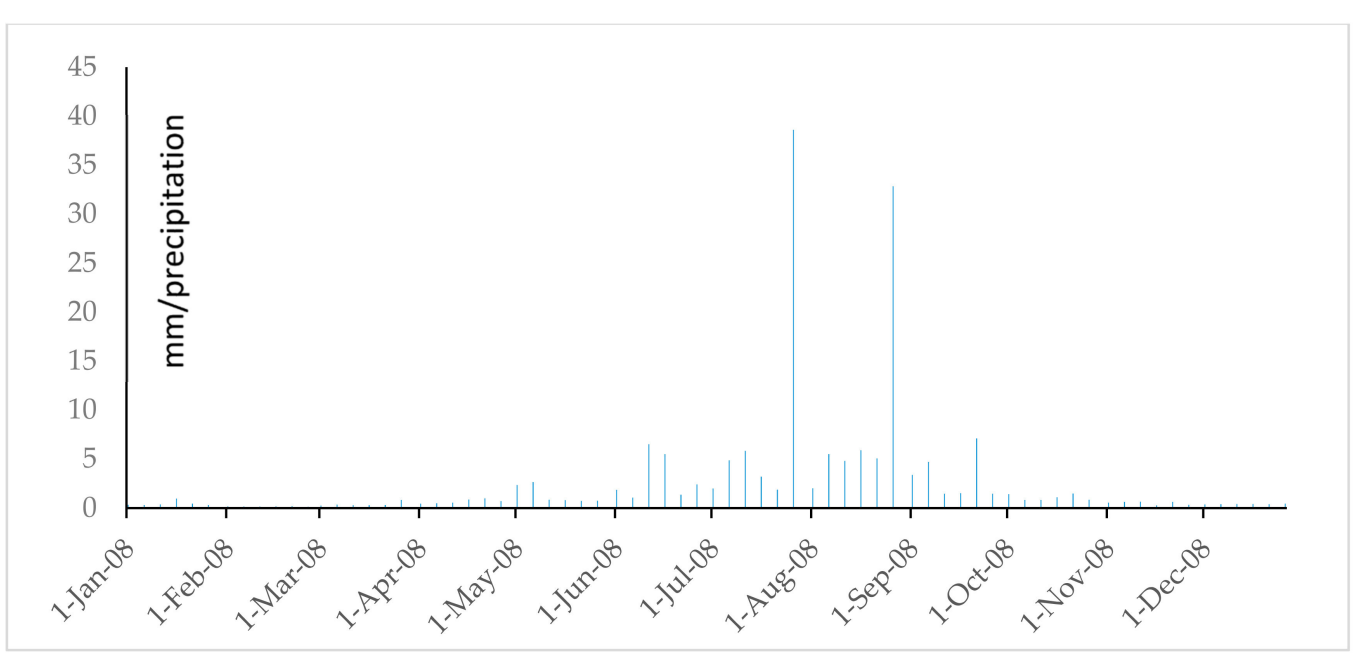

Figure A36. Precipitation of Denko County in 2008. 


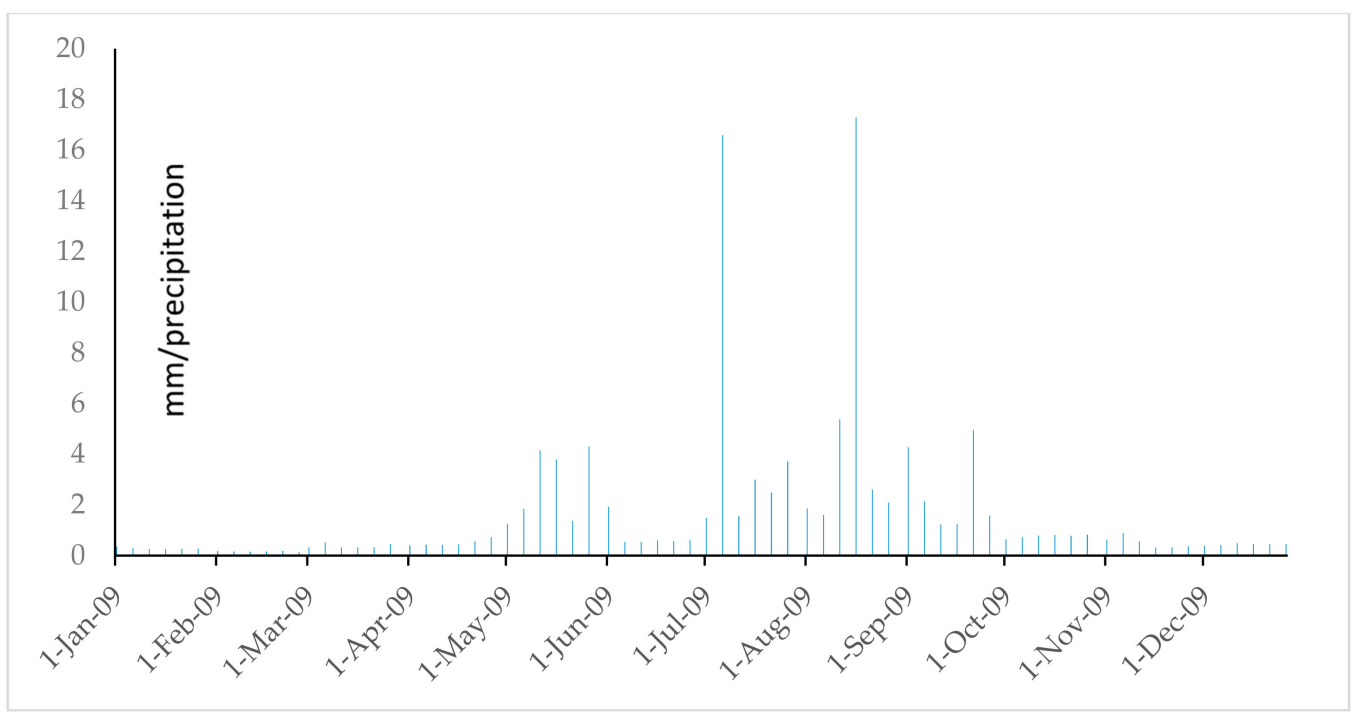

Figure A37. Precipitation of Denko County in 2009.

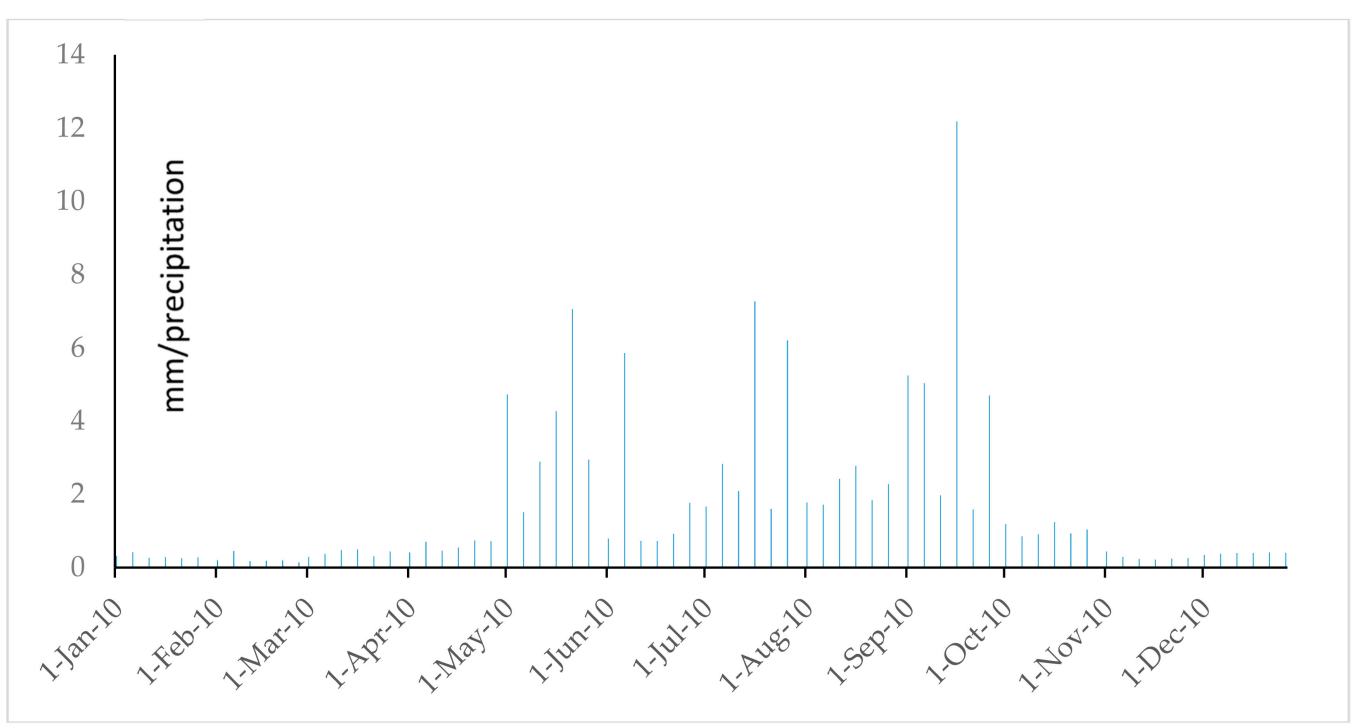

Figure A38. Precipitation of Denko County in 2010.

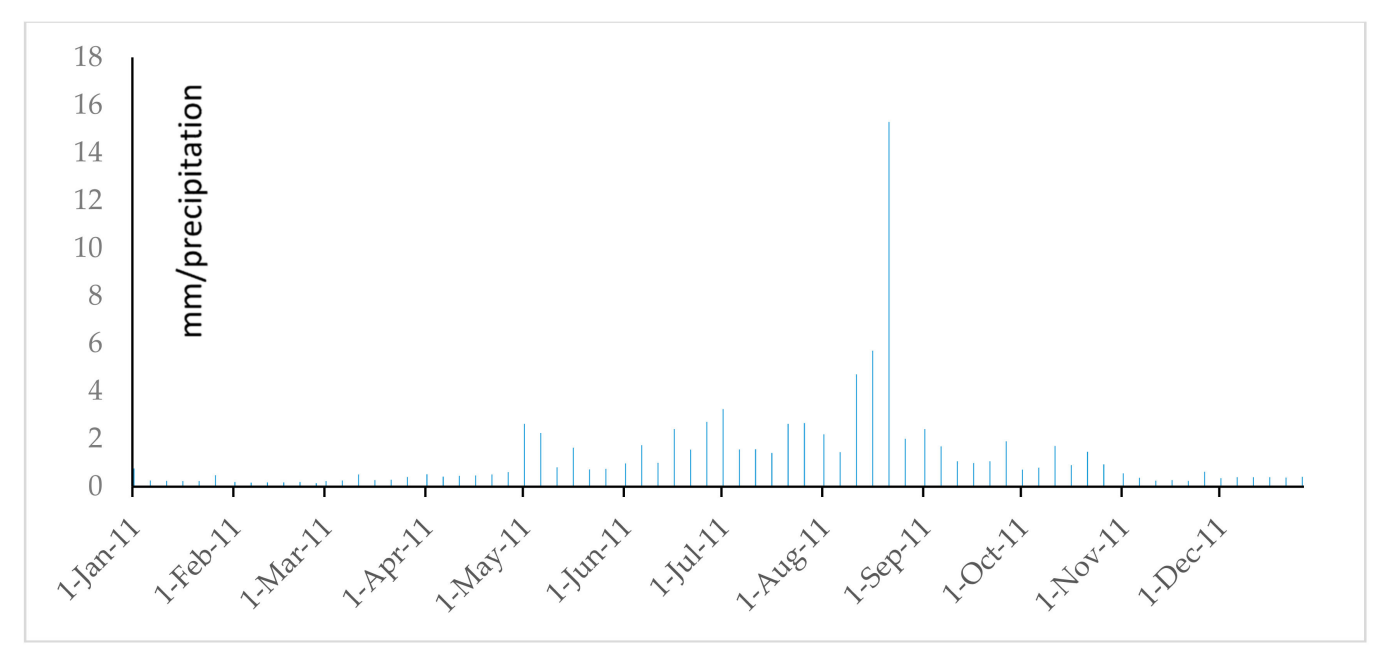

Figure A39. Precipitation of Denko County in 2011. 


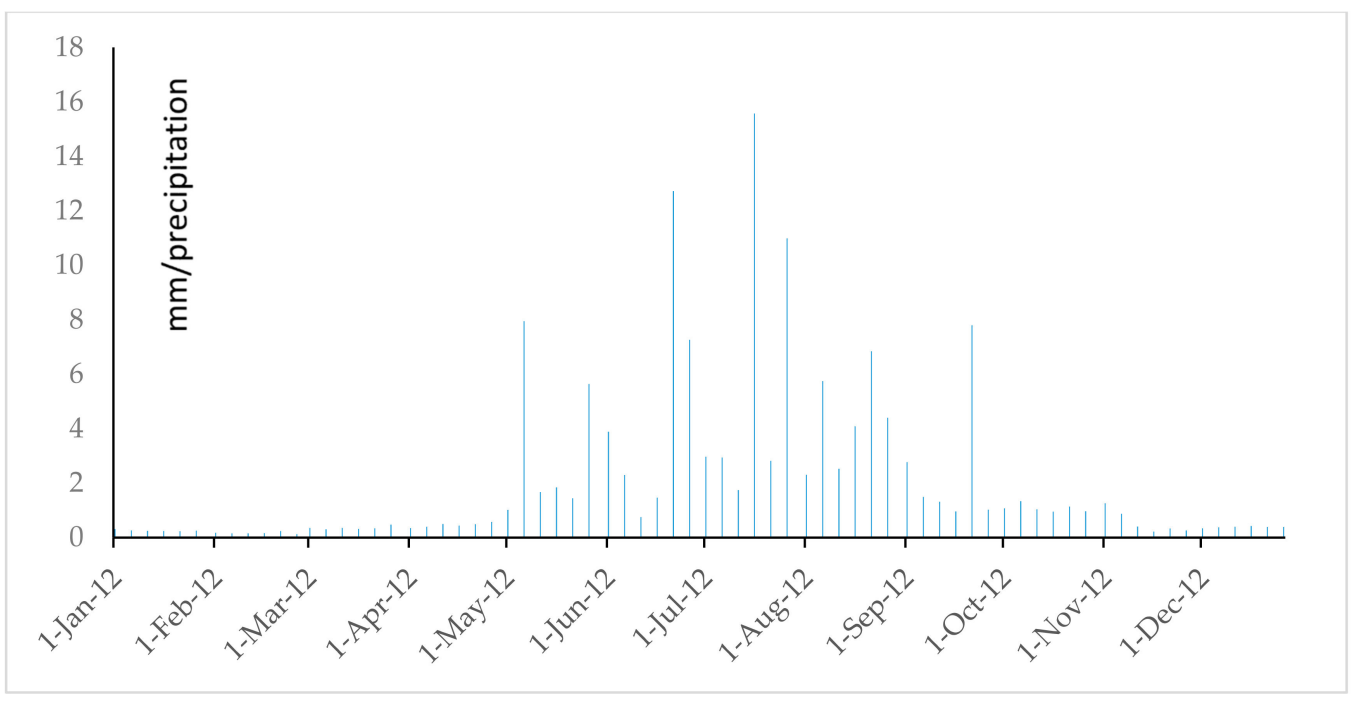

Figure A40. Precipitation of Denko County in 2012.

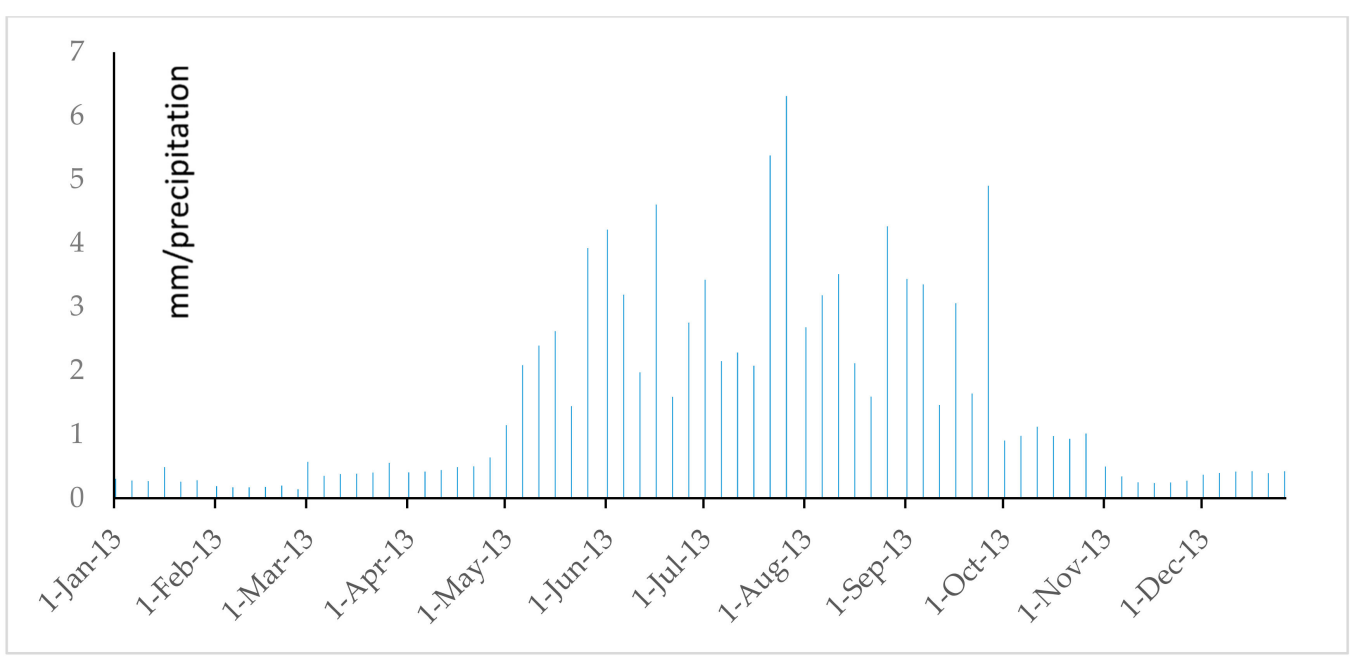

Figure A41. Precipitation of Denko County in 2013.

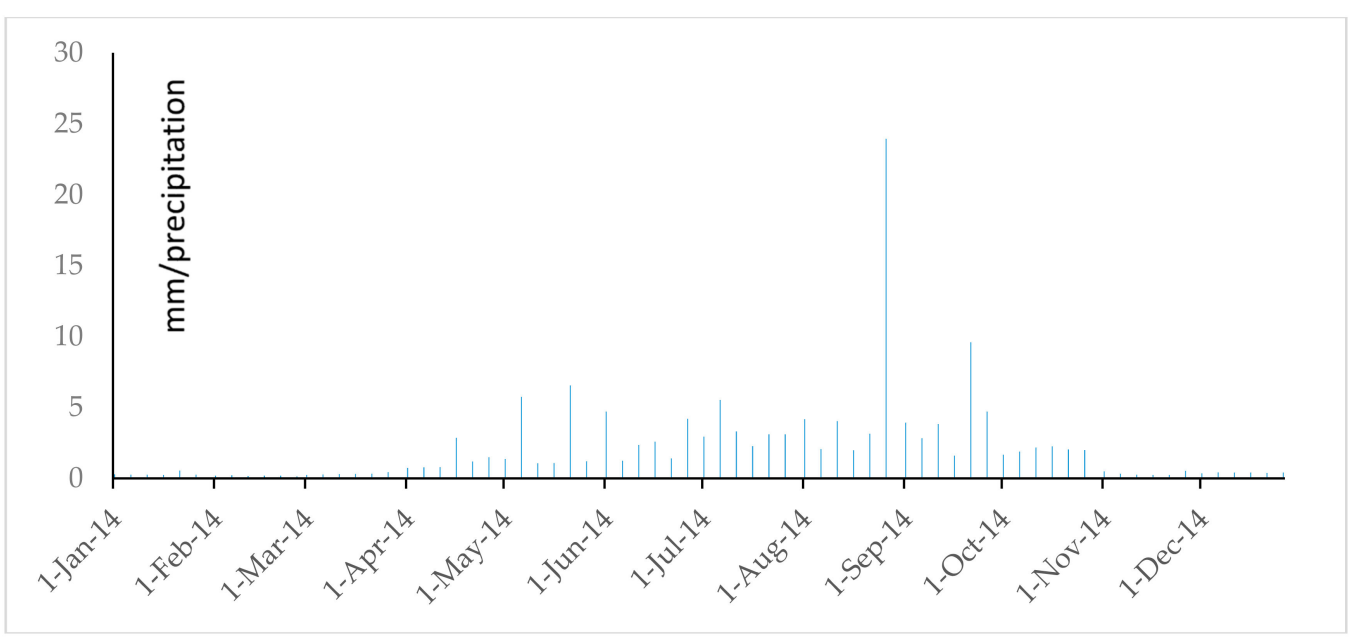

Figure A42. Precipitation of Denko County in 2014. 


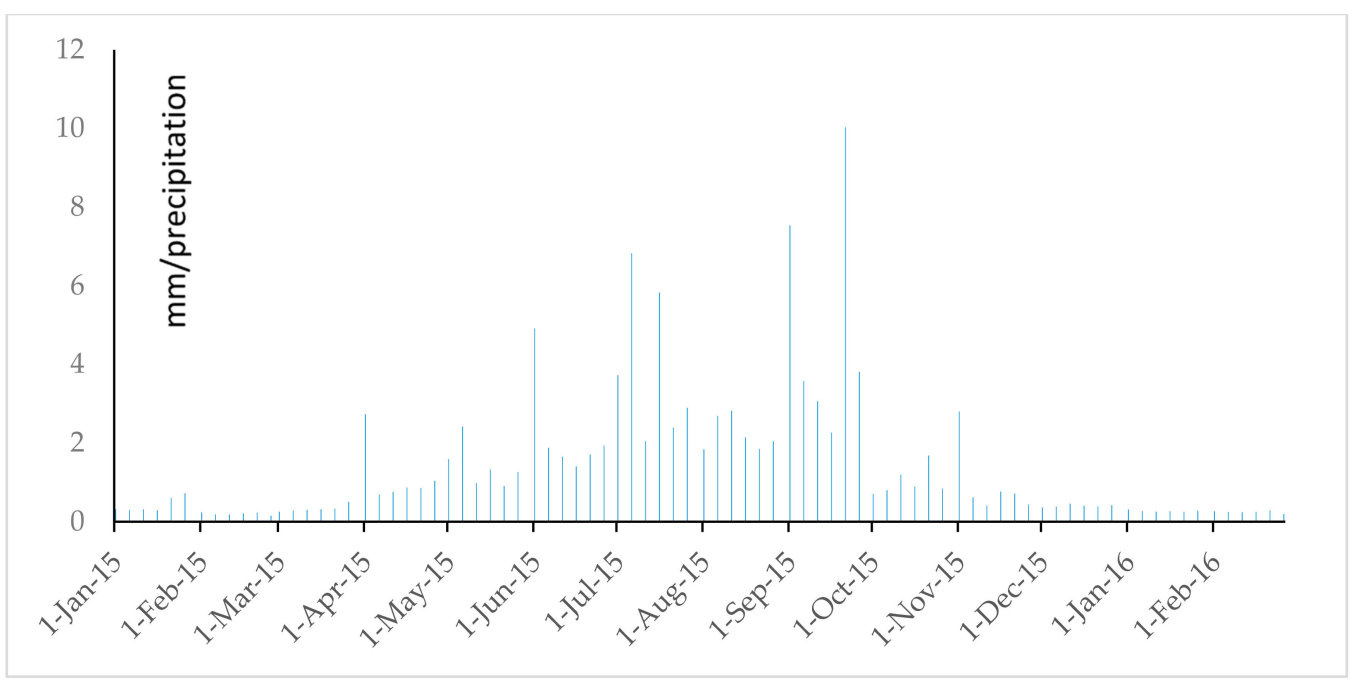

Figure A43. Precipitation of Denko County in 2015 and 2016.

\section{References}

1. Bestelmeyer, B.T.; Okin, G.S.; Duniway, M.C. Desertification, land use, and the transformation of global drylands. Front. Ecol. Environ. 2016, 13, 28-36. [CrossRef]

2. Liu, A.; Wang, J.; Liu, Z.; Wang, J. Monitoring desertification in arid and semi-arid areas of China with NOAA-AVHRR and MODIS data. In Proceedings of the 2005 IEEE International Geoscience and Remote Sensing Symposium, IGARSS '05, Seoul, Korea, 25-29 July 2005; pp. 2362-2364.

3. Varghese, N.; Singh, N.P. Linkages between land use changes, desertification and human development in the Thar Desert Region of India. Land Use Policy 2016, 51, 18-25. [CrossRef]

4. Yuan, J.; Cohen, M.J.; Kaplan, D.A. Linking metrics of landscape pattern to hydrological process in a lotic wetland. Landsc. Ecol. 2015, 30, 1893-1912. [CrossRef]

5. Fu, B.J.; Zhao, W.W.; Chen, L.D. Eco-hydrological effects of landscape pattern change. Landsc. Ecol. Eng. 2005, 1, 25-32. [CrossRef]

6. Han, M.; Zhao, C.; Feng, G. An eco-hydrological approach to predicting regional vegetation and groundwater response to ecological water conveyance in dryland riparian ecosystems. Quat. Int. 2015, 380, 224-236. [CrossRef]

7. Chen, S.; Chen, B. Urban energy consumption: Different insights from energy flow analysis, input-output analysis and ecological network analysis. Appl. Energy 2015, 138, 99-107. [CrossRef]

8. Mossman, H.L.; Panter, C.J.; Dolman, P.M. Modelling biodiversity distribution in agricultural landscapes to support ecological network planning. Landsc. Urban Plan. 2015, 141, 59-67. [CrossRef]

9. Kati, V.; Hovardas, T.; Dieterich, M.; Ibisch, P.L.; Mihok, B.; Selva, N. The challenge of implementing the European network of protected areas Natura 2000. Conserv. Biol. 2015, 29, 260-270. [CrossRef] [PubMed]

10. Schaubroeck, T.; Staelens, J.; Verheyen, K. Improved ecological network analysis for environmental sustainability assessment; a case study on a forest ecosystem. Ecol. Model. 2012, 247, 144-156. [CrossRef]

11. Fu, Q.; Song, J.; Mao, F. Evaluation and construction of wetland ecological network in Qingdao City. Acta Ecol. Sin. 2012, 32, 3670-3680.

12. Kyushik, O.; Dongwoo, L.; Changsug, P. Urban ecological network planning for sustainable landscape management. J. Urban Technol. 2011, 18, 39-59.

13. Matthew, S.D.; Travis, B.R.; Gregory, H.A.; Jocelyn, L.A. The world's largest wilderness protection network after 50 years: An assessment of ecological system representation in the U.S. National Wilderness Preservation System. Biol. Conserv. 2015, 184, 431-438.

14. Zhang, L.; Zhao, M.; Gao, Y. Estimation of vegetation ecological water requirement in arid areas based on neural network. In Proceedings of the International Symposium on Computational Intelligence and Design, Hangzhou, China, 29-31 October 2010; pp. 28-30. 
15. Liu, H.L.; Willems, P.; Bao, A.M.; Wang, L.; Chen, X. Effect of climate change on the vulnerability of a socio-ecological system in an arid area. Glob. Planet. Chang. 2016, 137, 1-9. [CrossRef]

16. Mo, W.B.; Wang, Y.; Zhang, Y.X.; Zhuang, D.F. Impacts of road network expansion on landscape ecological risk in a megacity, China: A case study of Beijing. Sci. Total Environ. 2017, 574, 1000-1011. [CrossRef] [PubMed]

17. Chen, L.; Bojie, F.U.; Zhao, W. Source-sink landscape theory and its ecological significance. Acta Ecol. Sin. 2008, 3, 131-136. [CrossRef]

18. Olagunju, T.E. Drought, desertification and the Nigerian environment: A review. J. Ecol. Natl. Environ. 2015, 7, 196-209. [CrossRef]

19. Mahamane, M.; Volker, H.; Alfred, S.; Jude, N.K. Fragmentation rate and landscape structure of the Tillabry landscape (Sahel region) with reference to desertification. J. Geogr. Reg. Plan. 2016, 9, 77-86. [CrossRef]

20. Blanco-Libreros, J.F.; Estrada-Urrea, E.A. Mangroves on the edge: Anthrome-dependent fragmentation influences ecological condition (Turbo, Colombia, Southern Caribbean). Diversity 2015, 7, 206-228. [CrossRef]

21. Haddad, N.M.; Brudvig, L.A.; Clobert, J.; Davies, K.F.; Gonzalez, A.; Holt, R.D.; Lovejoy, T.E.; Sexton, J.O.; Austin, M.P.; Collins, C.D.; et al. Habitat fragmentation and its lasting impact on earth's ecosystems. Sci. Adv. 2015, 1. [CrossRef] [PubMed]

22. Gao, Y.; Ma, L.; Liu, J.; Zhuang, Z.; Huang, Q.; Li, M. Constructing ecological networks based on habitat quality assessment: A case study of Changzhou, China. Sci. Rep. 2017, 7. [CrossRef] [PubMed]

23. Guo, Y.; Liu, Y. Connecting regional landscapes by ecological networks in the greater Pearl River Delta. Landsc. Ecol. Eng. 2016, 13, 265-278. [CrossRef]

24. Ding, W.; Tan, X.; Yuan, L. Construction of ecological network for urban green space system from the perspective of landscape ecology: A case study of Wanzhou District, Chongqing Municipality. J. Landsc. Res. 2016, 8, 41-48.

25. Chen, J.Y.; Yin, H.W.; Kong, F.H.; Yao, G.P. The complex eco-network development around Taihu Lake, China. Acta Ecol. Sin. 2015, 35, 3113-3123.

26. Zhang, X.; Guo, X.; Jing, G.; Xie, H. Research of improved shortest path algorithm in campus GIS. Open Cybern. Syst. J. 2015, 9, 1060-1063. [CrossRef]

27. Boegh, E.; Soegaard, H.; Thomsen, A. Evaluating evapotranspiration rates and surface conditions using Landsat TM to estimate atmospheric resistance and surface resistance. Remote Sens. Environ. 2002, 79, 329-343. [CrossRef]

28. Panzacchi, M.; Van, M.B.; Strand, O.; Saerens, M.; Kivimäki, I.; St Clair, C.C.; Herfindal, I.; Boitani, L. Predicting the continuum between corridors and barriers to animal movements using step selection functions and randomized shortest paths. J. Anim. Ecol. 2015, 85, 32-42. [CrossRef] [PubMed]

29. Soininen, J. Spatial structure in ecological communities-A quantitative analysis. Oikos 2015, 8, 51-60. [CrossRef]

30. Pierik, M.E.; Dell'Acqua, M.; Confalonieri, R.; Bocchi, S.; Gomarasca, S. Designing ecological corridors in a fragmented landscape: A fuzzy approach to circuit connectivity analysis. Ecol. Indic. 2016, 67, 807-820. [CrossRef]

31. Li, F.; Ye, Y.P.; Song, B.; Wang, R.S. Evaluation of urban suitable ecological land based on the minimum cumulative resistance model: A case study from Changzhou, China. Ecol. Model. 2015, 318, 194-203. [CrossRef]

32. Fath, B.D.; Scharler, U.M.; Ulanowicz, R.E. Ecological network analysis: Network construction. Ecol. Model. 2007, 208, 49-55. [CrossRef]

33. Yuyao, Y.E.; Yongxian, S.U.; Zhang, H.O. Construction of an ecological resistance surface model and its application in urban expansion simulations. J. Geogr. Sci. 2015, 25, 211-224.

34. Meng, J.; Wang, X.; Zhen, Z. Integrated landscape pattern optimization in arid region: A case study of middle reaches of Heihe River. Acta Sci. Nat. Univ. Pekin. 2017, 53, 451-461.

35. D'Alelio, D.; Libralato, S.; Wyatt, T.; Ribera, D.M. Ecological-network models link diversity, structure and function in the plankton food-web. Sci. Rep. 2016, 6. [CrossRef] [PubMed]

36. Chen, Y.F.; Yin, L.K.; Cao, Q.M.; Wang, Q. Vegetation information extraction and analysis of Xinjiang Altay two-river source nature reserve. Arid Land Geogr. 2016, 39, 843-850.

37. Ling, H.; Jia, Q.; Chao, L.; Li, Z.; Hao, X. Land use pattern simulation based on ecosystem service value and ecological security pattern. Trans. Chin. Soc. Agric. Eng. 2016, 32, 275-584. 
38. Sun, D.; Yu, X.; Liu, X.; Li, B. A new artificial oasis landscape dynamics in semi-arid Hongsipu region with decadal agricultural irrigation development in Ning Xia, China. Earth Sci. Inform. 2016, 9, 21-33. [CrossRef]

39. Echeverría, J.C.; Crowe, J.A.; Woolfson, M.S.; Hayes-Gill, B.R. Application of empirical mode decomposition to heart rate variability analysis. Med. Biol. Eng. Comput. 2001, 39, 471-479. [CrossRef] [PubMed]

40. Li, H.; Li, Z.; Mo, W. A time varying filter approach for empirical mode decomposition. Signal Process. 2017, 138, 146-158. [CrossRef]

41. Gatrell, A.C.; Bailey, T.C.; Diggle, P.J.; Rowlingson, B.S. Spatial point pattern analysis and its application in geographical epidemiology. Trans. Inst. Br. Geogr. 1996, 21, 256-274. [CrossRef]

42. Lancaster, J.; Downes, B.J. Spatial point pattern analysis of available and exploited resources. Ecography 2004, 27, 94-102. [CrossRef]

43. Funk, C.C.; Peterson, P.J.; Landsfeld, M.F.; Pedreros, D.H.; Verdin, J.P.; Rowland, J.D. A Quasi-Global Precipitation Time Series for Drought Monitoring Data Series 832; USGS Professional Paper; Data Series (832); U.S. Geological Survey: Reston, VA, USA, 2014.

44. Rilling, G.; Flandrin, P. One or two frequencies? The empirical mode decomposition answers. IEEE Trans. Signal Process. 2008, 56, 85-95. [CrossRef]

45. Haghverdi, A.; Leib, B.G.; Washington-Allen, R.A. High-resolution prediction of soil available water content within the crop root zone. J. Hydrol. 2015, 530, 167-179. [CrossRef]

46. Ma, H.; Yue, D.P.; Yang, D.; Yu, Q.; Zhang, Q.B.; Huang, Y. Interpolation of groundwater depth based on data assimilation. Trans. Chin. Soc. Agric. Mach. 2017, 48, 206-214.

47. Birtwistle, A.N.; Laituri, M.; Bledsoe, B.; Friedman, J.M. Using NDVI to measure precipitation in semi-arid landscapes. J. Arid Environ. 2016, 131, 15-24. [CrossRef]

48. Pelgrum, H.; Davids, G.; Thoreson, B.P.; Allen, R.G.; Bastiaanssen, W.G.M.; Noordman, E.J.M. SEBAL model with remotely sensed data to improve water-resources management under actual field conditions. J. Irrig. Drain. Eng. 2005, 131, 85-93.

49. Li, Z.; Liu, X.; Ma, T. Retrieval of the surface evapotranspiration patterns in the alpine grassland-wetland ecosystem applying SEBAL model in the source region of the Yellow River, China. Ecol. Model. 2013, 270, 64-75. [CrossRef]

50. Tang, W.; Feng, W.; Jia, M. Massively parallel spatial point pattern analysis: Ripley's K function accelerated using graphics processing units. Int. J. Geogr. Inf. Sci. 2015, 29, 412-439. [CrossRef]

51. Yu, Q.; Yue, D.P.; Wang, J.P.; Zhang, Q.B.; Li, Y.T.; Yu, Y.; Chen, J.X.; Li, N. The optimization of urban ecological infrastructure network based on the changes of county landscape patterns: A typical case study of ecological fragile zone located at Dengkou (Inner Mongolia). J. Clean. Prod. 2017, 163, S54-S67. [CrossRef]

52. Knaapen, J.P.; Scheffer, M.; Harms, B. Estimating habitat isolation in landscape planning. Landsc. Urban Plan. 1992, 23, 10-16. [CrossRef]

53. Shi, P.Z.; Yu, B.J.; Yang, X.Y. Research on bitter and salt water irrigation on cotton in a desert oasis area. J. Exp. Bot. 2003, 54, 54-55.

54. Nguyen, H.; Wiegand, K.; Getzin, S. Spatial patterns and demographics of Streblus macrophyllus trees in a tropical evergreen forest, Vietnam. J. Trop. For. Sci. 2014, 26, 309-319.

55. Kathleen, L.S.; Amatangelo, K.L.; Behrensmeyer, A.K. Holocene shifts in the assembly of plant and animal communities implicate human impacts. Nature 2015, 529, 80-83. [CrossRef] [PubMed]

56. Matt, M.E.; Vladimir, R.; Wei, Z. Improved particle counting and size distribution determination of aggregated virus populations by asymmetric flow field-flow fractionation and multiangle light scattering techniques. Biotechnol. Prog. 2011, 27, 547-554.

57. Cook, E.A. Landscape structure indices for assessing urban ecological networks. Landsc. Urban Plan. 2002, 58, 269-280. [CrossRef]

58. Dong, J.; Dai, W.; Shao, G. Ecological network construction based on minimum cumulative resistance for the city of Nanjing, China. ISPRS Int. J. Geo-Inf. 2015, 4, 2045-2060. [CrossRef] 
59. Hasanuzzaman, M.; Song, X.; Han, D.; Zhang, Y.; Hussain, S. Prediction of groundwater dynamics for sustainable water resource management in Bogra District, Northwest Bangladesh. Water 2017, 9, 238. [CrossRef]

60. Blazquez-Cabrera, S.; Gastón, A.; Beier, P. Influence of separating home range and dispersal movements on characterizing corridors and effective distances. Landsc. Ecol. 2016, 31, 2355-2366. [CrossRef] 